\title{
LEADERSHIP TOWARD POSITIVE WORKPLACE CULTURE IN AOTEAROA NEW ZEALAND: CLINICAL NURSE MANAGER PERSPECTIVES
}

\author{
By \\ Krystle-Lee Graham
}

\begin{abstract}
A thesis
submitted to the Victoria University of Wellington

in partial fulfilment of the requirements for Master of Nursing Science
\end{abstract}

Victoria University of Wellington 


\section{ABSTRACT}

Clinical nurse managers play a vital role in the healthcare system. They are responsible for the day to day running of departments and ensuring that patients are safely cared for. The leadership behaviour and practices of a clinical nurse manager are fundamental for establishing and maintaining positive workplace culture, which is important for nurse performance and quality patient outcomes. This research sought to understand how clinical nurse managers build positive culture in their workplace and to identify leadership attributes and actions that they perceive to be important for generating positive workplace culture. Furthermore, it aimed to identify the challenges of creating positive workplace culture in Aotearoa New Zealand.

A qualitative descriptive design was used to capture rich in-depth understanding and insight into clinical nurse manager experiences of positive workplace culture from their position in nursing leadership. Ten clinical nurse managers from one secondary hospital within the North Island of Aotearoa participated in semi structured face-to-face interviews. Data was transcribed and analysed using thematic analysis with assistance of NVIVO 12 coding software to manage the process of analysing transcripts.

Findings demonstrated that clinical nurse managers deliberately engage in strategies to build positive workplace culture and the more prepared they were for their role, the better equipped they were to do so. Three themes were identified: role preparation, achieving perspective, and intentionality. The theme of role preparation describes the actions clinical nurse managers use to cope with realities of the job, build good teams, and manage uncertainty. The second theme achieving perspective represents the internal processes clinical nurse managers use to understand situations and make decisions. The final theme intentionality describes the leadership strategies clinical nurse managers use to enhance collaborative behaviour and positive relationships within the team.

To prepare and develop nurses into leadership positions, organisations and executive leadership teams must actively invest in the preparation of this workforce. Establishing 
educational prerequisites and having structured orientation and mentoring programmes will build a clinical nurse manager workforce that is equipped to foster positive workplace culture in Aotearoa. Furthermore, conducting performance appraisals habitually will provide a foundation for training and development that is needed to keep nurses motivated and engaged in their workplace.

Keywords: Workplace Culture, Leadership, Clinical Nurse Manager 


\section{DEDICATION}

To my daughter.

Anything is possible with hard work and perseverance. 


\section{ACKNOWLEDGEMENTS}

I would like to pass on sincere thanks to my research guru, coach, counsellor, and supervisor Dr Helen Rook for supporting me with patience throughout my research journey over the past two years. You have kept me calm and motivated throughout. I appreciated you drip feeding me information bits at a time to ensure I was not overwhelmed more than I already was. Without your guidance I would not have produced a thesis like this one.

Thank you to the wonderful clinical nurse managers who participated in this research project (even if you secretly did not want too). I express my deepest appreciation to you for sharing your wonderful experiences with me so that those who read this thesis will understand the amazing leadership that you provide in creating a great place to work for frontline nurses.

I would like to thank the following people Professor Karen McBride-Henry and Manu Graham for helping me finalise my project.

I wish to convey gratitude to my daughter and husband for being on this journey with me. Thank you for allowing me to be grumpy and tired without complaining, chipping in with house chores when I needed you, and for being understanding when I needed to reschedule outings or prioritise study over precious time with you. You both are my rock and have kept me grounded and focussed in achieving my potential.

To my supportive work colleagues. Thank you for cheering me on through my journey and allowing me to moan that I had no life other than work, study, and sleep, and for inspiring me toward the many possibilities that this achievement will bring now that it is complete.

And lastly, thank you to my wonderful family and friends who have always been there for me, accepted my oddities and habits and for being that constant reminder that fun during study does exist. Without my family and friends, I would truly not be the person I am today. 


\section{TABLE OF CONTENTS}

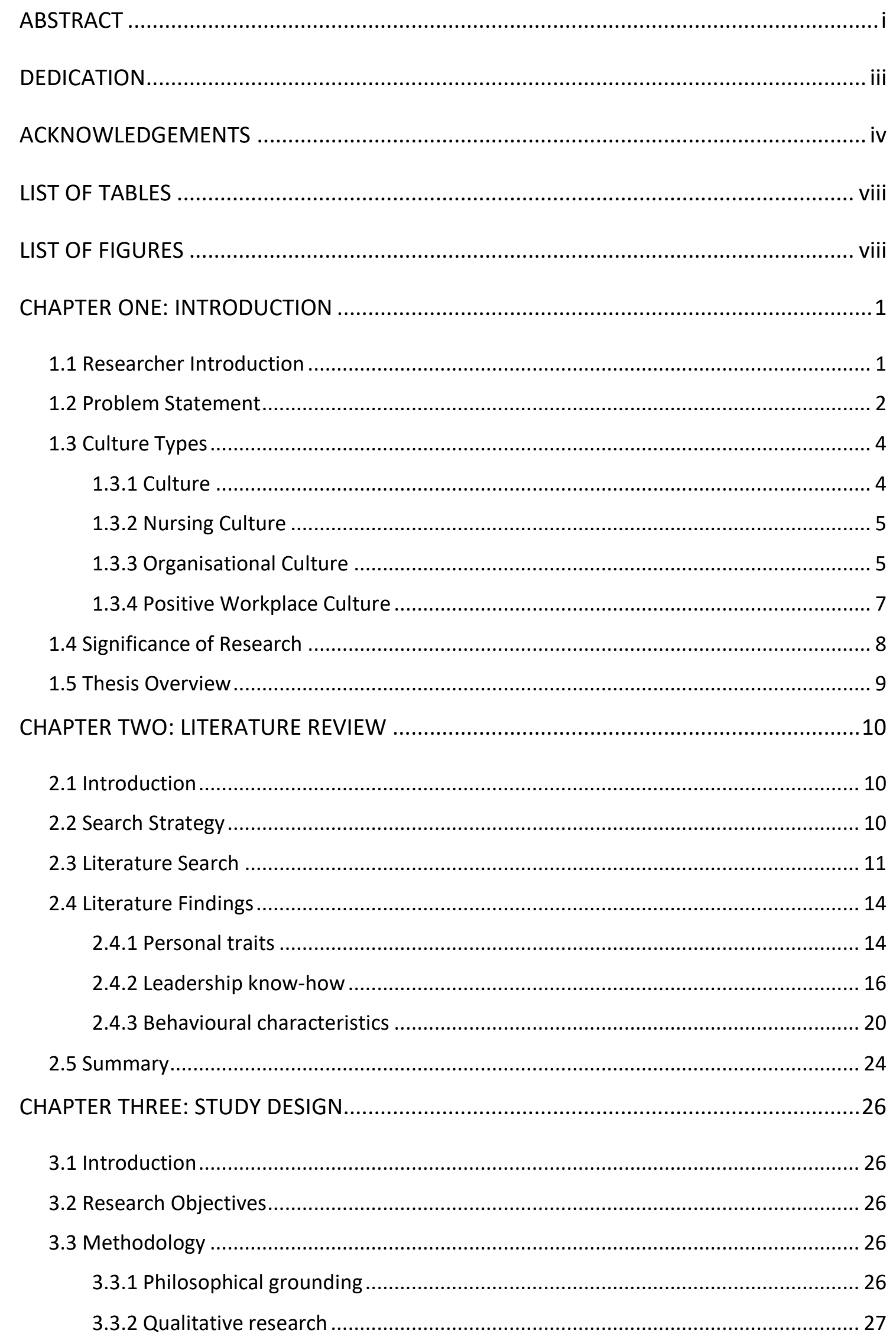




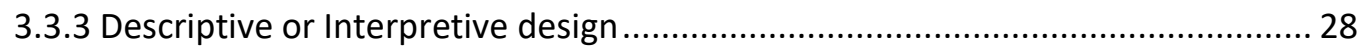

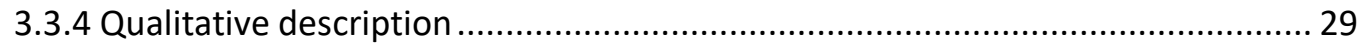

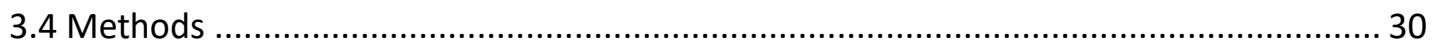

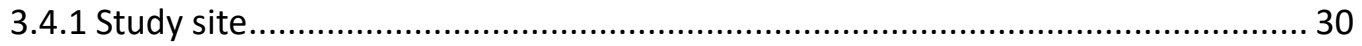

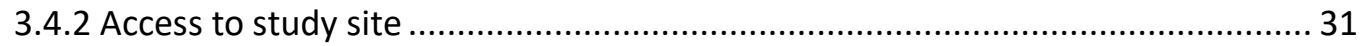

3.4.3 Participant selection, recruitment, and sampling strategy............................... 31

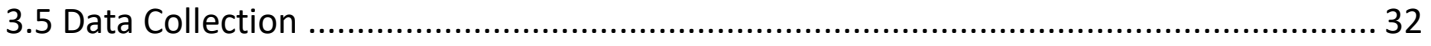

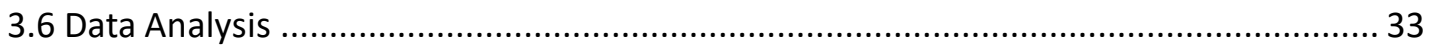

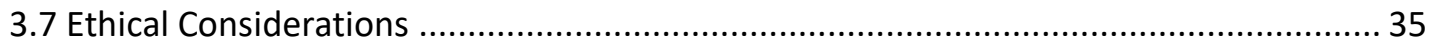

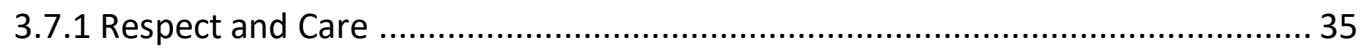

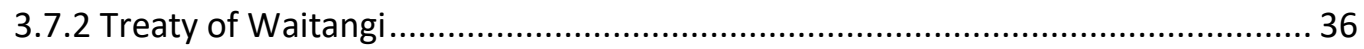

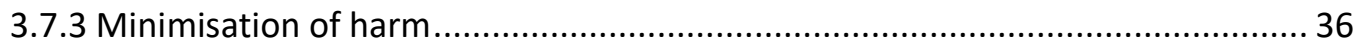

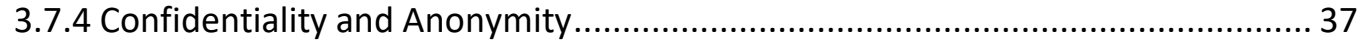

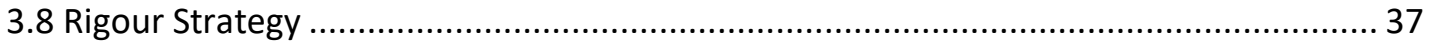

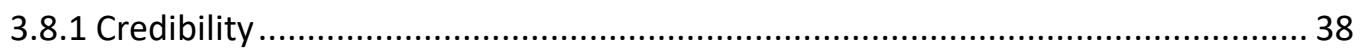

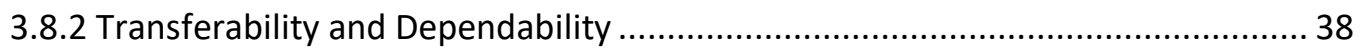

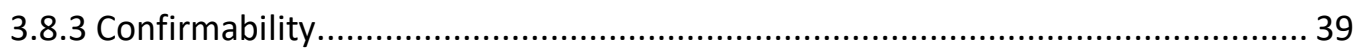

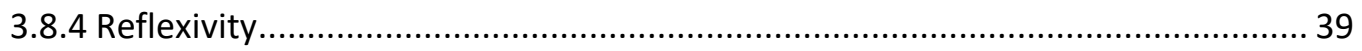

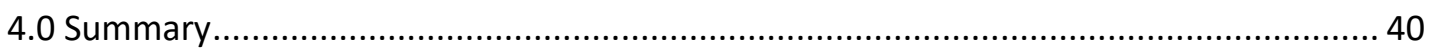

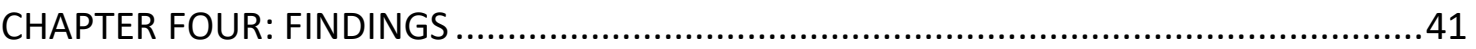

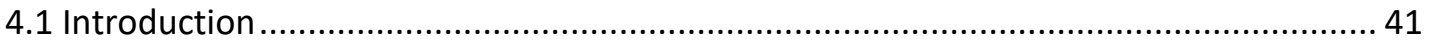

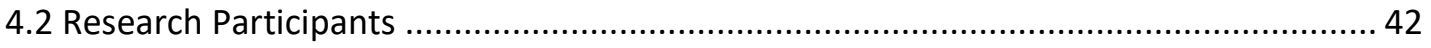

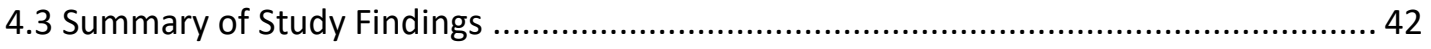

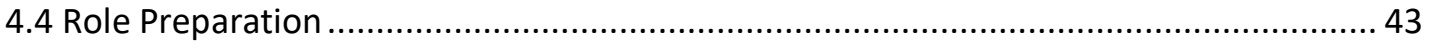

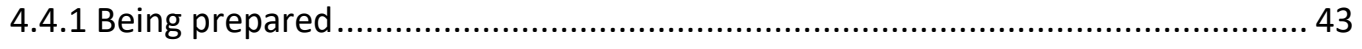

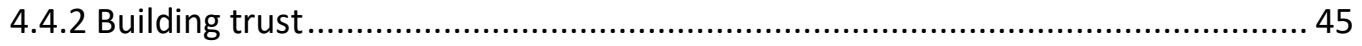

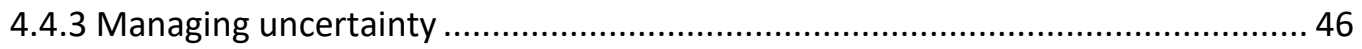

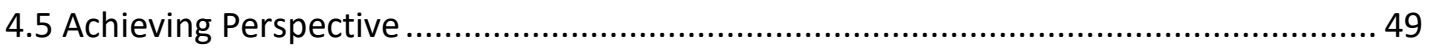

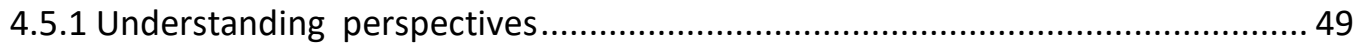

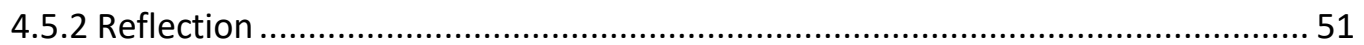

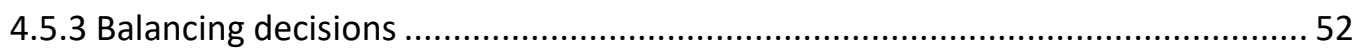

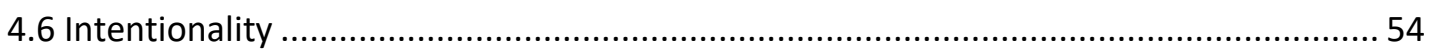

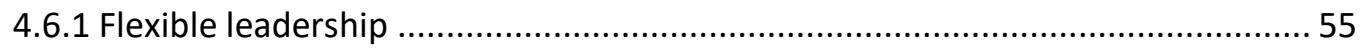

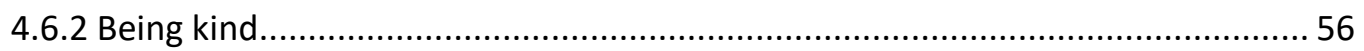

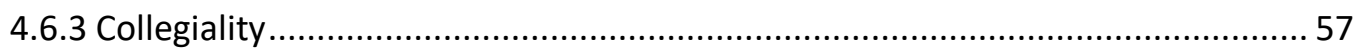




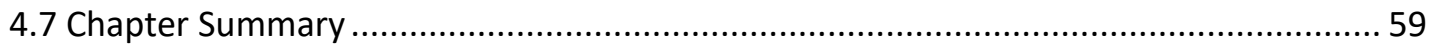

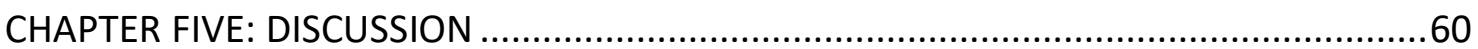

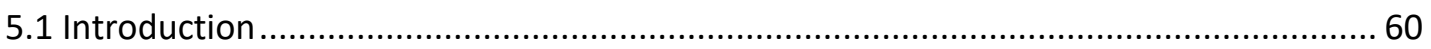

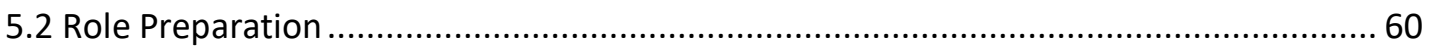

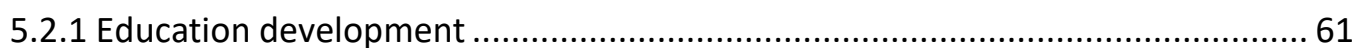

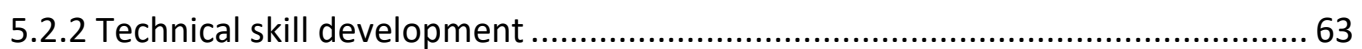

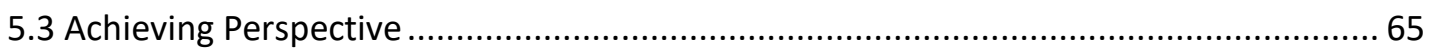

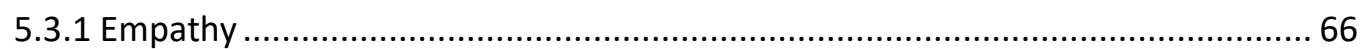

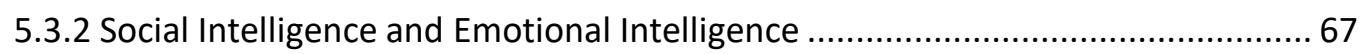

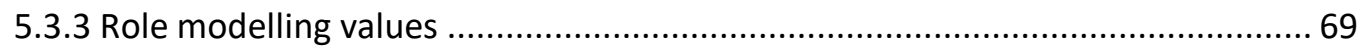

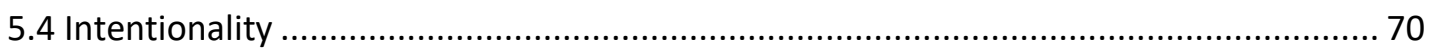

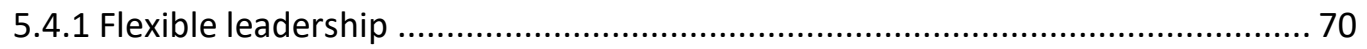

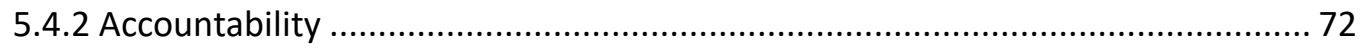

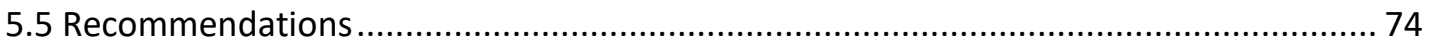

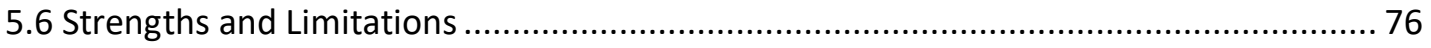

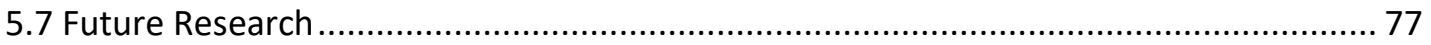

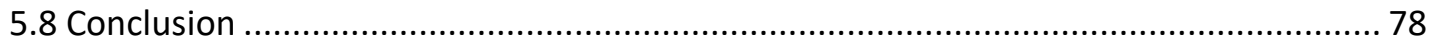

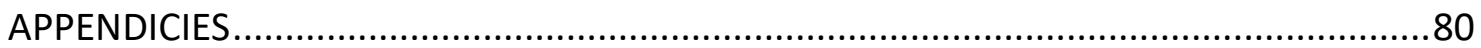

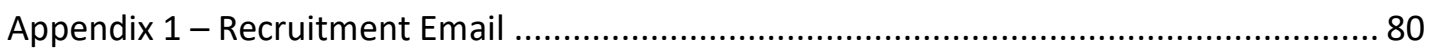

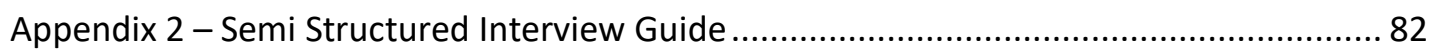

Appendix 3 - Ethics Approval from the University of Wellington ....................................... 83

Appendix 4 - Locality Consent to Conduct Research ........................................................... 84

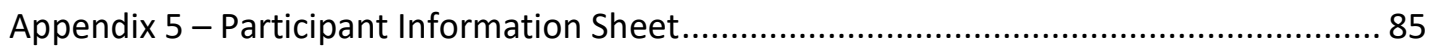

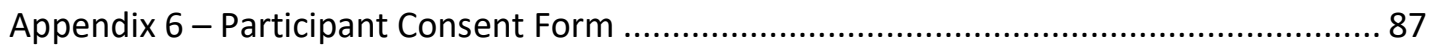

Appendix 7 - Maori Health Advisory Committee Approval ................................................. 89

Appendix 8 - Example of NVIVO 12 Thematic Codes and Raw Data.................................... 90

Appendix 9 - Mind Maps and Themes Table ..................................................................... 91

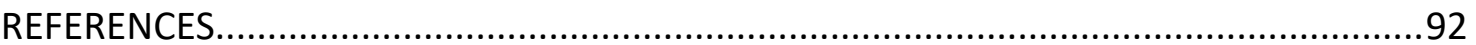




\section{LIST OF TABLES}

Table 1: Summary of literature: CNM characteristics toward positive workplace culture .13

Table 2: Professional characteristics 42

\section{LIST OF FIGURES}

Figure 1: Literature search process .12

Figure 2: CNM perspectives of leading positve workplace culture..... .40 


\section{CHAPTER ONE: INTRODUCTION}

\subsection{Researcher Introduction}

With over a decade of nursing experience in acute care settings such as intensive care, high dependency and cardiac care, the time I spend at the bedside with patients has lessened overtime. Despite having expert skills and knowledge that is needed to function well in busy healthcare environment's, growing pressures to meet the overwhelming needs of the organisation is impacting on my ability to safely function and provide what I value as a high standard of care. Given time with patient's I care for is something that I value most as a nurse, it saddens me that in reality patients and their families can be alone in their most vulnerable moments, fundamental nursing care is often missed, and care quality continues to be evaluated against measurable outcomes as opposed to what patients actually need, that being compassionate and clinically excellent care.

I know because I have experienced how easy it is to become burnt out as a result of mental and physical exhaustion in my line of work. As an intensive care nurse, we are routinely exposed to complex and demanding situations of patient care, with repeated exposure to grave illness, loss and grief, and life-threatening events. Over time you almost become desensitised to it all. This is the problem. It becomes too easy to lose touch of what is important as you are trying to meet everyone else's expectations other than your own and your patients.

In my experience, good leaders have the ability to recognise when their team are not functioning well, and they do what they can to reduce any modifiable stressors of the environment in which nurses work to allow them to optimally function. In contrast, leaders who are less effective are those that overlook what is really going on, demonstrate ignorance, and shy away from advocating for what is best for their team and patients. The opportunity to explore CNMs understanding of positive workplace culture and leadership factors that can contribute to positive workplace culture has motivated me to this research project. 


\subsection{Problem Statement}

Healthcare environments are complex and challenging. Those who work in healthcare and those who lead healthcare teams face immense pressure. These pressures stem from complex issues related to a growing population, chronic health conditions, consumer demands and public expectations, an aging workforce, new treatment modalities and technology, and escalating costs (Clendon, 2011; Ministry of Health $[\mathrm{MOH}], 2016)$. All of which are driving service providers to do more with less. Subsequently nurses worldwide and in Aotearoa New Zealand are experiencing high levels of burnout, fatigue and moral distress (Aiken et al., 2010; Frey et al., 2018; La Grow et al., 2015); retention is proving difficult leading to loss of experienced staff and revenue (Ashton et al., 2013; $\mathrm{MOH}, 2016$ ); and the ability to provide care outcomes safely and satisfactorily is being affected (Aiken et al., 2010). To address current and future problems that exist concerning these nursing workforce issues, there is a need to understand nurses' perspectives of their work and workplace culture, along with clinical leaders' perspectives who manage healthcare teams and clinical departments to rejuvenate healthcare.

The job satisfaction of nurses is highly subjective, multifaceted and influenced by the individual, their relationships, or external factors (Bonner et al., 2010). However recent literature endorses the need for effective leadership; one that supports, inspires, and motivates frontline nursing teams to achieve shared goals and expectations for rebuilding satisfaction and wellbeing to an exhausted nursing workforce (Cummings et al., 2010; Kouzes \& Posner, 2017b; New Zealand Nurses Organisation, 2018). The influence leadership has toward nursing, patient and organisational outcomes is well documented in policy (Neira, 2010; NZNO, 2018; World Health Organisation [WHO], 2016) and health literature (Cummings et al., 2008; Cummings et al., 2010; Cummings et al., 2014; Cummings \& Wong, 2007; Cummings et al., 2013; Giallonardo \& Wong, 2013). This body of evidence revealing how behaviours and practices of individual leaders are fundamental for creating workplaces that help to retain, satisfy, and empower the nursing workforce to perform better. 
Clinical nurse manager's (CNMs) play a vital role in the healthcare system. Positioned between senior management and frontline nursing teams, they are responsible for dayto-day decisions that affect nurses and patients in clinical practice, and among other things they are accountable for creating and sustaining the processes, policies, infrastructure and resources needed to facilitate safe operations and changes to their clinical service (NZNO, 2014). How they enact these responsibilities mark the general harmony of workplace culture (Catling-Paull et al., 2009). Workplace culture that is important for shaping the way patient care is delivered, as such can impact on aspects of practice (Aiken et al., 2011). It is important that CNMs understand workplace culture (positive and negative), know what an effective workplace culture looks like, and know how to develop one so that they can foster skills of their own that transform outcomes at practice level. Yet little is understood about CNMs approach to positive workplace culture, and what is practically done by them to foster positive culture. Therefore, objectives of this research sought to understand how CNMs build positive culture in their workplace and to identify leadership attributes and actions that they perceive to be important for generating positive workplace culture. Furthermore, it aimed to identify the challenges of creating positive workplace culture in Aotearoa.

The purpose of this introduction chapter is to set the context to this thesis project and stipulate research objectives. Described were some of the major healthcare challenges for frontline nurses and nurse leaders, and why clinical leadership plays a pivotal role in the development of workplace culture. Objectives to this research are stated. Theoretical underpinnings of workplace culture will now be described. This will include culture types and how clinical leadership plays a fundamental role in its development to enhance positive workplace culture. The significance of this research is presented along with an introduction to the researchers' perspective. The structure of this thesis will be outlined in the thesis overview. 


\subsection{Culture Types}

\subsubsection{Culture}

Culture is a complex term to define. Sociologists and anthropologists have described the concept of culture in a variety of ways, each with their own philosophical perspectives and understanding. Anthropologists for example generally talk about culture being grounded in beliefs and values of people that are learnt, shared, patterned, adaptive and symbolic through social interaction with one another ( $\mathrm{O}^{\prime} \mathrm{Neil}$, 2006). Cultural anthropologist Edward Tylor (1832-1917) understood culture as an acquired process defining it as "that complex whole which includes knowledge, beliefs, arts, morals, laws, customs and any other capabilities and habits acquired by man [human] as a member of society" (Tylor, 1871, p.1). In contrast, sociologists talk about culture as symbolic in nature, made up of materially observable factors such as buildings, clothing, class, gender or race, and non-material factors like values, beliefs and morals. Collectively material and non-material factors form a system in which all parts function together to create societies of human behaviour that shape cultural norms (Jenks, 2005).

Within a naturalist paradigm of inquiry this study is guided by a social science perspective that views culture as a way of life for people through common sharing of beliefs, values, practices, and behaviour (Jenks, 2005). In my own attempt to define it, culture is artefactual, observable, and psychological. Artefactual means to have symbolic representation such as the clothes we wear and how we wear them. Observable through actions of behaviour such as the way we communicate and how we act in social situations. Psychological as it shapes a particular way of thinking and how we feel in sense of being in the world. Aotearoa has many diverse cultures that build our nation and kiwi character. We have bicultural groups such as European, Polynesian, and Asian populations; and Māori are the Indigenous peoples. We have various team squads such as sport and leisure groups, youth groups, music, and performance groups. We have multiple religious and spiritual groups who share different faith and belief systems. Every group is unique in their own purposeful way, but all share culture. 
Nursing as a discipline also creates its own culture and is identified typically within healthcare environments.

\subsubsection{Nursing Culture}

Nursing culture is centred around shared values and person-centred care for the common purpose of caring for others (Clendon, 2010). Their practice is directed by official guidelines and standards established by the Nursing Council of New Zealand [NCNZ] (2019) including the Code of Conduct, practice competencies, and guidelines that describe and provide direction for nursing practice. Nursing culture practices within a larger organisational culture with its own expectations, philosophy as well as values that guide the behaviour of members within it. Organisational culture too is based on shared attitudes, beliefs and customs that are developed over time (Davies \& Mannion, 2018). So essentially there are cultures working within cultures.

\subsubsection{Organisational Culture}

Cameron and Quinn (1999) describe four unique culture types in their 'competing values framework of organisational culture' (p.33-35). These are Hierarchy, Market, Adhocracy, and Clan culture. Each culture type typically represents basic assumptions, orientations, and values that are associated with different forms of organisations. Hierarchy culture for example values clear lines of decision making, authority, standardized rules and procedures, control, and accountability as key to success. Organisations compatible with this form of culture can be present in large corporation's such as fast-food restaurants, where work is formalised and structured, policies hold the organisation together and procedures govern what people do to maintain efficient, reliable, fast, smooth-flowing production. Market culture has some similar elements to Hierarchy culture, but more emphasis is placed on values of profitability, competitiveness, and productivity. Relationships with other constituencies (exchanges, sales, contracts) are formed to create competitive advantage and profitability. Organisations compatible with this form of culture can be present in sales organisations 
such as car dealerships where productivity, bottom line results, strength in market, targets, and secure customer bases are primary objectives to organisational success.

Adhocracy culture values adaptability, flexibility, and creativity. Organisations compatible with this form of culture can be present in technological organisations such as Microsoft where employees are encouraged to formulate innovative solutions to problems and find new ways of providing services. Characterised by dynamic, entrepreneurial, and creativeness, people within Adhocracy culture are not afraid to take risks. Lastly there is Clan culture characterised by shared values and goals, strong cohesion, participation, individuality, and sense of 'we-ness' that permeates the environment. Clan culture is an organisational culture desired most by nurses (Gu et al., 2020; Jambrović et al., 2019). Largely because nurses are able to connect professionally and personally within the values, norms and customs that govern the relationships of clan culture such as teamwork and development, partnership, and humane working conditions (Cameron \& Quinn, 1999).

The main purpose for creating desirable organisational culture within healthcare is to achieve high-quality, safe, and efficient care (Hartnell et al., 2011). But the issue is, nurses are being asked to perform the highest quality of care under immense pressures, managed by organisational culture that promotes too much focus on hierarchy and market type firms to reach health and performance targets (Pagon \& Skela Savič, 2008), without better balance toward quality care values and professional standards. Values of clan culture that are critical to serving the attitudes and actions of nurses that directly impact on patient experiences (Rook, 2017). So, in a culture where it is an expectation that nurses be subservient to organisational values of authority, control, profitability, and productivity, with disregard for cooperation and team building; less likely will those who value clan-type firms be productive or sustainable in the workplace. On the opposite spectrum, creating workplace culture that nurses perceive to be in their best interest can shape work enjoyment, working relationships, and working processes, and furthermore play a deciding factor of whether or not they choose to work or continue with an organisation. 


\subsubsection{Positive Workplace Culture}

At its core workplace culture describes the overall character of 'how things are done' within the immediate work environment of patients and of staff, which overtime is shaped by elements such as goals and values, behaviours, attitudes, and workplace practices (Cardiff et al., 2011). The intention of positive workplace culture is to keep nurses satisfied in their work to enhance patient and organisational outcomes. Age, education and coping strategies have been reported as individual factors that can influence how nurses perceive their workplace culture, along with interpersonal connectedness by factors such as relationships with patients, colleagues and leaders; and wider institutional and governmental factors, such as pay, policies and resources (Bonner et al., 2010; Hahtela et al., 2015).

In an effort to restore gratification and commitment back into the nursing workforce, Wood (2018) suggests clinical leaders invest time and genuine commitment into nurturing nurse's health and well-being so that they can physically and mentally engage and be satisfied in their work, so that in return, they nurture their patients. Kouzes and Posner (2017b) say employees need to clearly understand organisational goals and how their personal goals can contribute to the overall success of those goals. How leaders enact these visions are unclear. Although for a start, the American Association of Critical Care Nurses [AACN] (2019) recommend that clinical leadership practise skilled communication, true collaboration, effective decision-making, appropriate staffing, meaningful recognition and authenticity to enhance healthy and therefore positive workplace culture. Furthermore, Hunt and Pavlish (2012) propose that nurse leaders take advantage of opportunities for nurses to find meaning in their work, by inspiring them through various forms of recognition so that they feel as if they are a part of something important. Like any relationship, when our needs are met by those around us, we feel comfortable, confident and motivated to stay in the relationship, and we do what we can for our relationship counterparts.

Attributes of positive workplace culture include decreased levels of emotional and physical exhaustion and increased levels of job satisfaction by nurses (Cummings et al., 
2010; De Witte et al., 2008), higher engagement (Dempsey \& Reilly, 2016; Lamont, 2015; Tillott, 2013; Giallonardo \& Wong, 2013), empowerment (Laschinger \& Wong, 2013), retention (Wong, 2015), performance (Eun Ji et al., 2018), and workplace civility (Cummings et al., 2014). The essence of these findings means that when frontline nurses have positive experiences, they are more inclined to be satisfied at work, develop higher commitment to their organisation, and feel as if they want to contribute toward better outcomes and organisational goals. This is because most people would prefer to be surrounded in workplace culture that encourages pleasurable rather than toxic qualities to function mentally and grow. In contrast, when nurses endure negative experiences of workplace culture, less likely are they going to feel satisfied, increasing the likelihood of burnout, stress, fatigue (Bressler et al., 2011; De Witte et al., 2008; Dyrbye et al., 2018; Todaro-Franceschi, 2019) and poor job performance (Aiken et al., 2010). Understandably then a clinical leader's ability to create positive workplace culture is highly desirable for the healthcare climate.

\subsection{Significance of Research}

Exploring what keeps nurses satisfied and engaged in their line of work is fundamental for good patient and organisational outcomes. Working conditions in hospitals of Aotearoa are challenging as a consequence of wider issues as described earlier in this chapter. Spending time and money on attracting, retaining, and developing clinical leaders with the right values, cultural fit and attitude toward positive workplace culture are essential to keeping nurses motivated in their roles and workplace. Therefore, understanding how CNMs build positive culture in their workplace and to identify leadership attributes and actions that they perceive to be important for generating and maintaining positive workplace culture will add value to nurses and nursing leadership in Aotearoa. 


\subsection{Thesis Overview}

There are four further chapters to this thesis. The second chapter that follows will present a review of literature about what is already known about practices of nurses in leadership establishing positive workplace culture, and where further research may be useful to extend the current body of knowledge. Research objectives, methodological principles, study design, ethical considerations and research approval processes are detailed in chapter three. Findings of this research are presented in the fourth chapter which outlines key themes and subthemes that emerged from the analysis of raw data. Significance of research findings will be discussed in the fifth chapter which also addresses potential strengths and limitations identified throughout the research process. The thesis is concluded with recommendations drawn from the findings and offers suggestions for further research initiatives. 


\section{CHAPTER TWO: LITERATURE REVIEW}

\subsection{Introduction}

The leadership behaviour and practices of CNMs are fundamental for establishing and maintaining positive workplace culture that is vitally important for nurse performance and quality patient outcomes. The focus of this chapter is to explore the literature that examines how CNMs build positive culture in their workplace and to identify leadership attributes and actions that they perceive to be important for generating positive workplace culture. Furthermore, identify the challenges of creating positive workplace culture in Aotearoa. An overview of the evidence related to the leadership practices of CNMs will be presented. Literature pertaining to personal traits, leadership know-how and behavioural characteristics will be critically discussed.

\subsection{Search Strategy}

There were a series of steps involved in this literature review. The first was to keep a well-defined research focus at forefront to avoid deviating from information relevant to understanding research objectives (Coughlan \& Cronin, 2017). Maintaining a defined research focus involved establishment of a key research question, not too broad or too narrow (Emerson, 2005). The question posed of the literature was how do clinical nurse managers build positive culture and what leadership attributes and actions do they perceive important for generating positive workplace culture? Literature was then searched in a planned and organised manner.

Key words for the literature search and any combinations of these words were established. Key terms with use of Boolean operators AND/OR included nurse, charge nurse, nurse leader, nurse manager; leadership, management; workplace, hospital, culture. Bibliographic databases and search engines CINAHL, ProQuest Nursing Allied and Health, Scopus, and Google Scholar were accessed based on their collection of known nursing-based evidence (Galvin \& Holloway, 2017). Reference lists were screened for relevance. Use of databases and search engines as only literature search sources is common for even the experienced researcher because literature of most 
interests are stored in these online collections with the advantage of material being organised derivatives from journals, books, dissertations and reviews (Coughlan \& Cronin, 2017). Literature on nursing related topics is comprehensive, although how workplace culture is established by nurse leaders to a lesser extent. A 10-year date range (2009 to 2019) was set to capture early and recent publications. Search limitations were confined to the English language and primary research. Coughlan and Cronin (2017) recommend confining to primary research studies for a literature review given the methodological processes used to generate the information. Systematic reviews although not primary research was included in this review, given they provide an overview of what information already exists, and are useful for identifying gaps and main methodologies and research techniques that have been used in the exploration of a particular topic. Major subject headings pinpointed the main focus of a database article for more effective searching. Nurse leaders, quality of healthcare, nursing practice, nurses, managers, organisational culture, work environment, nurse attitudes, bullying, leadership, nurse administrators, retention and nursing management were integrated as major subject headings when searching CINAHL, Scopus and ProQuest databases.

\subsection{Literature Search}

The literature search process is illustrated (Figure 1). Literature was selected if the report was directly relevant to the preliminary question. Abstract and conclusions were screened once an applicable title was identified. Prospective papers were read in full once relevance was established. Reports were rejected immediately if not matched to inclusion criteria. When in doubt, rather than excluding reports too early they were reviewed in full to prevent discarding relevant papers (Coughlan \& Cronin, 2017). Literature was categorically stored and managed using 'Zotero' bibliographic software referencing system.

Appraisal tools were utilised to critique literature, offering a systematic way of evaluating the quality of studies for trustworthiness and relevance (Coughlan \& Cronin, 2017). CASP (2018) critical appraisal tool for qualitative research and Coughlan et al. 
(2015) adapted guidelines for critically appraising a research study (as cited in Coughlan \& Cronin, 2017) were useful for deciding if interpretations of study findings were grounded in the data and conclusions warranted given the methods researchers chose to adopt.

Figure 1: Literature search process

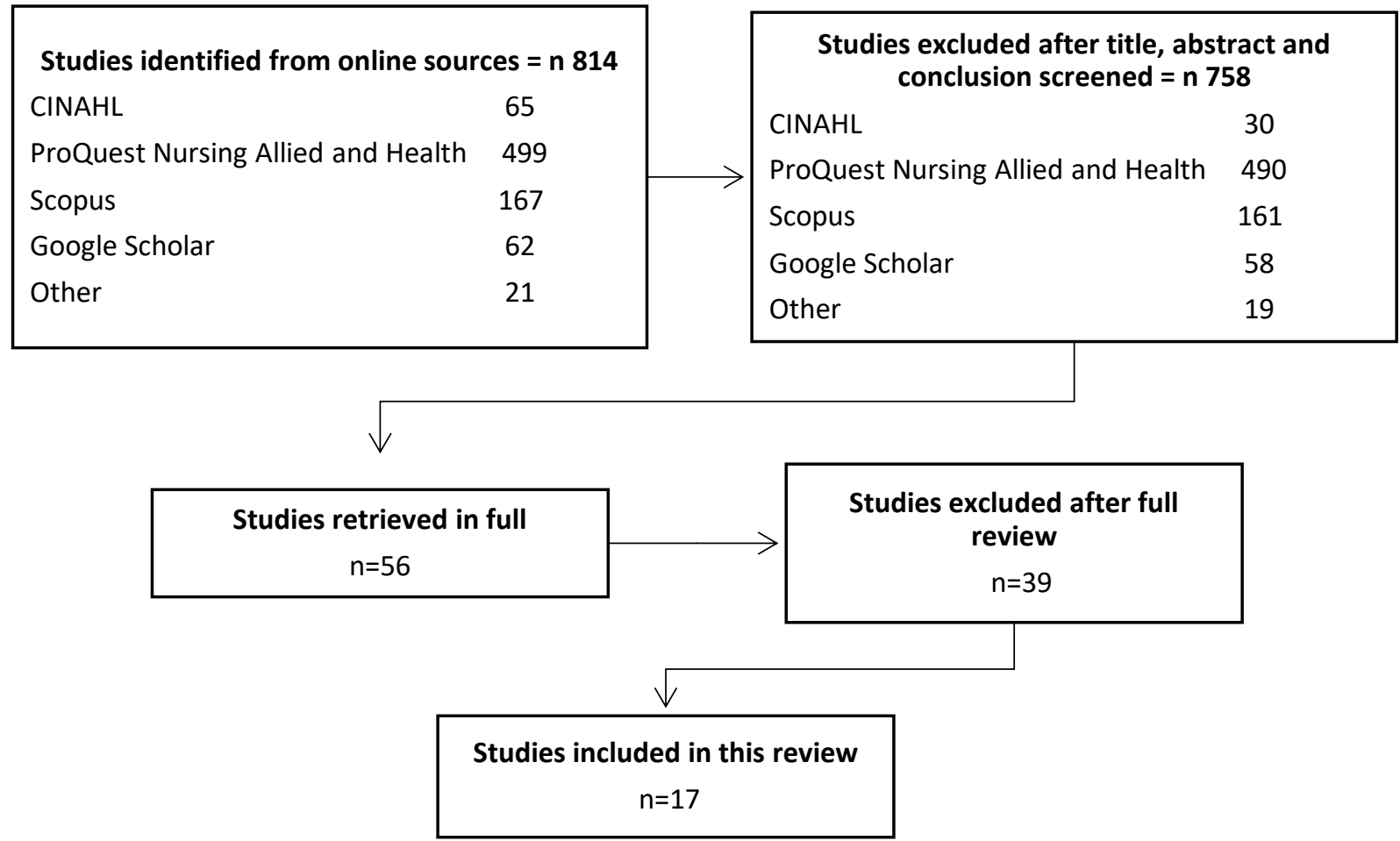

Thematic analysis by Braun and Clarke (2006) was the approach used to methodically organise information to be described. Three major themes were identified from literature that met inclusion criteria to explain what was said in relation to how CNMs build positive workplace culture. For clarity nurse leader (NL) or CNM will be terms used to define study populations. This is to help distinguish if CNMs were a single population used within a study or not. While CNMs have been introduced as middle managers who are responsible for frontline nursing teams, NLs will describe other nurse leader roles used within a study population, for example nurse executive, nurse director, nurse manager, nurse faculty member, or nurse specialist which may or may not include CNMs. 
The first key theme personal traits describe studies that report distinguishing qualities that make nurses in leadership who they are and how this can influence behaviour during situations and social interaction. The second theme leadership know-how describes studies in relation to practical attributes understood to equip nurses in leadership for the challenging healthcare climate. And the last theme behavioural characteristics refers to studies that describe behaviour of nurses in leadership and how particular personalities prove more effective than others for fostering positive culture. A summary of key themes and subthemes identified from the literature are illustrated (Table 1).

Table 1: Summary of literature: CNM characteristics toward positive workplace culture

\begin{tabular}{|c|c|c|}
\hline Personal traits & Leadership know-how & Behavioural characteristics \\
\hline $\begin{array}{l}\text { Integrity } \\
\text { Authentic } \\
\text { Executive } \\
\text { Powerful } \\
\text { Active } \\
\text { Supportive } \\
\text { Thoughtful } \\
\text { Caring } \\
\text { Practical } \\
\text { Open-minded } \\
\text { Emotional intelligence } \\
\quad \text { Inner satisfaction; } \\
\text { respect; empathy; } \\
\text { justice (being fair); } \\
\text { honesty }\end{array}$ & $\begin{array}{l}\text { Skills } \\
\text { Building Interpersonal relationships } \\
\text { Conflict resolution } \\
\text { Decision making } \\
\text { Effective communication } \\
\text { Skilled communication } \\
\text { Listening } \\
\text { Speak and write clearly Face-to-face } \\
\text { Avoid offensive communication } \\
\text { Knowledge and learning } \\
\text { Pertinent technical knowledge } \\
\text { General knowledge } \\
\text { Acquisition of knowledge } \\
\text { Cultural responsiveness } \\
\text { Convey trust and confidence } \\
\text { Encouragement } \\
\text { Giving individual consideration } \\
\text { Demonstrate leadership characteristics } \\
\text { Role model idealised behaviour } \\
\text { Fair treatment } \\
\text { Management of workplace bullying } \\
\text { One-to-one interventions } \\
\text { Establishes a culture of care } \\
\text { Communicates workplace bullying will } \\
\text { not be tolerated } \\
\text { Critical thinking; analyticity; systematicity; } \\
\text { open-mindedness; critical thinking } \\
\text { confidence } \\
\text { Meaningful recognition: ^salary; create } \\
\text { opportunities for growth; private } \\
\text { feedback; public recognition } \\
\text { Practice own beliefs and values } \\
\text { Advocacy } \\
\text { Valuing the welfare of employees }\end{array}$ & $\begin{array}{l}\text { Transformational/Collaborative } \\
\text { Resolves conflict } \\
\text { Negotiation } \\
\text { Diplomatic } \\
\text { Visionary } \\
\text { Forms interpersonal relationships. } \\
\text { Caring: collaborative; respectful; } \\
\text { collegiality } \\
\text { Exemplary leadership: models the } \\
\text { way; inspires shared vision; } \\
\text { challenges the process; enables } \\
\text { others to act; encourages the heart } \\
\text { Transactional } \\
\text { Planning and evaluation } \\
\text { Organisation } \\
\text { Conducts meetings } \\
\text { Decisive } \\
\text { Problem solves. } \\
\text { Changes behaviour to suit situation } \\
\text { Relations-orientated: consultation; } \\
\text { support; recognition; development; } \\
\text { empowerment } \\
\text { Change-orientated: risk taking, } \\
\text { encouraging; innovative thinking; } \\
\text { leads by example } \\
\text { Task-orientated: clarification of } \\
\text { roles; monitoring of operations; } \\
\text { planning } \\
\text { Resonant: visionary; coach; affiliate; } \\
\text { democratic } \\
\text { Visible } \\
\text { Accessible } \\
\text { Approachable/Safe to talk to } \\
\text { Professional } \\
\text { Cooperative } \\
\text { Flexible }\end{array}$ \\
\hline
\end{tabular}




\subsection{Literature Findings}

\subsubsection{Personal traits}

Theme of personal traits refers to things that occur exclusively in the minds of nurses and their innate ability to intelligently function as a leader. What personal traits are required for effective leadership were identified from literature investigating topics in relation to characteristics and practices understood to provide healthy and positive workplaces. Leadership traits of effectiveness, emotional intelligence, and ethical leadership, and how these attributes foster positive workplace culture will be described.

In a quantitative study conducted by Black-Arias (2015), integrity was reported a measurable competency of leadership effectiveness among NLS $(N=114)$. Black-Arias explains that integrity as a leadership characteristic means NLs can be trusted by their team to do what they promise to do, and by this inspire positive workplace culture through transformational qualities. Qualities that achieve organisational goals through "integrating creative insight, having persistence and energy, using intuition and being sensitive to the needs of others" (Avolio \& Bass, 1993, p.112). Other transformational leadership traits measured for in this population included intelligence, credibility, and honesty. However, with no statistical significance among NLs, these traits were reported as least important as a measurement of leadership competency.

In a meta-analysis conducted by Kramer et al., (2010) publications from professional agencies (health organisations) and healthy workplace experts (nurses, nurse managers and physicians) were analysed and aggregated to a single synthesized list to describe best leadership practices that enable positive workplace culture. Traits of top leaders included authentic, executive, powerful, and active. The authors argue that although literature has reported authentic, executive, powerful, and active as effective traits, executive leaders of organisations need to provide the right structure and support that will enable nurses in leadership to apply these qualities.

Two quantitative studies (Boldy et al., 2018; Boldy et al., 2013) that replicated the same research methods report that NLs from four different countries consider supportive and 
thoughtful as most important for achieving managerial effectiveness of 30 personal characteristics, followed by caring, practical and open minded. Personal characteristics are considered a subtheme of traits in this review because the list of personal characteristics within both studies correlate with concepts that define individuality as a human being. NLs $(\mathrm{N}=211)$ from Australia, Singapore, and Tanzania were recruited in the first study (Boldy et al., 2013) and NLs ( $n=149)$ from Aotearoa in the second (Boldy et al., 2018). Interestingly NLs from Singapore differed in their responses as they ranked thoughtful most important, while supportive was most important by Aotearoa, Australian and Tanzania NLs. Preference of ranking personal characteristics could be explained by the different contexts of NLs (hospital vs community), variation in role responsibilities (being different in each country), and cultural background of NLS (country, upbringing). Quantitative research methods used within these studies naturally placed limitations on the researcher's ability to ask the how and why questions which are better suited to qualitative exploration.

In their literature review Akerjordet and Severinsson (2008) reported emotional intelligence (EI) important in nurse leadership for contributing toward nurse empowerment and positive organisational outcomes. To analyse El further, Crowne et al. (2017) used quantitative methods to investigate if El could be improved for NLs $(\mathrm{N}=20)$ following a three year education programme, and to explore the relationship between El and transformational leadership, which encourages, inspires, and motivates employees toward positive practice outcomes (Bass \& Riggio, 2006). The authors define $\mathrm{El}$ as "an ability to focus on the accurate perception and expression of emotion; understand emotional knowledge; use feelings to facilitate thought; and regulate emotions in oneself and others" (p.219). Before and after evaluation techniques were employed using the Multifactor Leadership Questionnaire (MLQ) to measure transformational leadership qualities (idealized influence, inspirational motivation, intellectual stimulation and individual consideration) (Avolio \& Bass, 2004) and EQ-I to measure El qualities (intrapersonal, interpersonal, adaptability, stress management, and general mood) (Bar-On, 2004). Validity of instruments were not investigated for the purpose of this review, however Crowne et al. (2017) stipulate their own evidence- 
based rationale for use of MLQ and EQ-I (p.223). Before and after survey findings reported El could be improved following education, the study further advocating that organisation's use a long-term El programme to improve leadership of NLs and foster positive workplace culture. No connections between El and transformational leadership were reported.

Qualitative methods adopted by Atashzadeh-Shoorideh and Barkhordari-Sharifabad (2018) reported NLs $(\mathrm{N}=14)$ to experience inner satisfaction within themselves by developing and demonstrating ethical principles of respect, empathy, justice, and honesty. Ethical leadership was reported to evoke higher nurse satisfaction which in turn fostered positive workplace outcomes such as patient satisfaction and better productivity. Ethical acts stem from ones morals, beliefs and values that can be learned overtime through social interaction (Brown et al., 2005). Based on the findings of this study, leaders who demonstrate ethical behaviour reflect an image that motivates nursing staff to achieve same moral values and standards. Even though the study was conducted in Iran West Asia, the findings have relevance to healthcare contexts globally particularly Aotearoa where diverse ethnicities and cultural understandings exist.

From the studies reviewed, personal traits have been identified as important toward effective nurse leadership. In particular traits of integrity, authenticity, executive, powerful, active, supportive, thoughtfulness, emotional intelligence, empathy, respect, justice, and honesty have been described from the literature. The next theme is leadership know how and describes in what way knowing how to do something enhances workplace culture.

\subsubsection{Leadership know-how}

Leadership know-how illustrates practical attributes understood to effectively equipped nurses in leadership for the challenging healthcare climate. Topics within the research found in relation to this theme included managerial effectiveness, cultural competence, leadership qualities, critical thinking, communication, workplace bullying and meaningful recognition. 
Quantitative studies by Boldy et al. $(2013 ; 2018)$ as discussed in theme 2.4 .1 personal traits, report that NLs view particular skills important for managerial effectiveness followed by knowledge and learning. Skills deemed most important for NLs were interpersonal relations, conflict resolution, and decision making. Within the knowledge and learning domain attributes found to be most important by NLs were pertinent technical knowledge and general knowledge. Based on these findings, it is understood that NLs depend most on their practical skills to function best in their role, particularly relational and communication skills. The order of preferred attributes that were ranked by NLs in both studies fluctuated between theoretical and practical skills with in each domain. However, this is not surprising given they complement each other as knowledge is information acquired through observation and study (learning) and skill is developed through practice and ability of NLs to apply their knowledge in situations.

In a large quantitative study El Amouri and O'Neill (2014) proposed to identify leadership styles of NLs $(\mathrm{N}=153)$ that facilitate cultural competence. The study was conducted in Iran where there is a large immigrant population such that many languages are spoken, and a multicultural mix of people exist. Attributes of listening, skilled communication, and encouragement were reported by NLs in this study which helped them to convey a sense of trust and confidence between them and their nursing teams. To convey cultural competence, NLs reported giving individual consideration, demonstrating leadership characteristics, communicating well, role modelling idealised behaviour, and giving fair treatment as culturally responsive leadership qualities. Being culturally responsive is particularly important in Aotearoa where there is various linguistic and cultural diversity among the population that sets challenges for cultural understanding and effective communication among health care providers.

Knowing how to connect with people on a personal and professional level was found to be important in various studies within the review of literature. D'Souza and D'Souza (2013) in their small systematic review reported listening, resolving conflict, and ability to speak and write effectively effective leadership communication, and face to face communication an effective strategy for relationship building, particularly through 
transitions of change or when overcoming communication barriers. In the United States (US) qualitative descriptive methods were used to better understand communication patterns of $\mathrm{CNMs}(\mathrm{N}=6)$ (Hartung \& Miller, 2013). Knowing how to communicate in the least offensive way was reported by CNMs as an integral part of fostering healthy workplace communication, and they did this by making rounds, touching base with staff, discussing the current functioning of the unit, following up with issues, and redirecting negativity. CNMs in this study identified generational differences as a barrier toward (good/purposeful/meaningful) communication. Formal and continuing education in communication techniques was a proposed strategy to resolving generational communication challenges.

In a qualitative study about effective and ineffective interventions related to workplace bullying (Dawson et al., 2015), CNMs ( $n=6$ ) reported bully behaviour problematic for negatively impacting on workplace culture. While approaches to address workplace bullying varied among CNMs, common leadership know-hows they used and considered most effective to address it included effectively articulating to staff that such behaviour would not be tolerated, initiating one-to-one interventions with support from senior management, and establishing a culture of care. Social characteristics of a caring culture included respect, collaboration, and collegiality. Workplace bullying is prevalent in Aotearoa and is problematic because those that have been bullied experience lower levels of job satisfaction, higher levels of anxiety and depression, and are more likely to leave their place of work (Crimp, 2017). Knowing how to identify and intervene negative behaviour therefore is just as important for encouraging positive workplace experiences.

Critical thinking $(C T)$ and meaningful recognition $(M R)$ have been reported as important leadership know-how's of nursing leadership and workplace culture (Cherian, 2016; Musil et al., 2010). The concept of CT is essentially NLs ability to skilfully process a large amount of information, adopt creativity when solving problems, and make complex leadership decisions (Facione, 1994). Identified as one of five leadership attributes necessary for influencing organisational success (Lemire, 2001 as cited in Musil et al., 
2010), CT of CNMs ( $N=12$ ) were measured to compare with job satisfaction of their respective nursing staff $(\mathrm{N}=132)$. The hypothesis being when $\mathrm{CNMs}$ practice strong $\mathrm{CT}$ abilities, the practice environment improves for staff. Quantitative findings from this study reported that when CNMs had higher CT dispositions of analyticity, systematicity, open-mindedness, and critical thinking confidence they too created higher job satisfaction for their nurses. This means decision making and problem solving of CNMs can establish workflow and structure for patient care, which overall influences the practice environment and job satisfaction of nurses.

Cherian (2016) adopted mixed method research methods to determine what meaningful recognition (MR) meant to critical care nursing staff $(n=16)$ and NLs $(n=10)$ in the US. Identified as one of six essential standards of a healthy workplace (AACN, 2020), MR involves manager's having systems in place to recognise members within their team in a way that is individualised and meaningful to that person to enhance a sense of value and greater fulfilment when at work. NLs and nurses in this study reported to value most increased salary, opportunities for growth, private feedback, and public recognition as effective MR strategies. Barriers to providing MR to nursing staff by NLs included limited knowledge about what MR was and how to implement it, formal recognitions being less of a priority over day-to-day operations, and the size and diversity of the nursing workforce where rationing of formal awards took place.

A final leadership know-how pertained to how NLs applied their own beliefs and values into leadership practice. From studies already described, Dawson et al. (2015) qualitative study about interventions related to workplace bullying provides an example where CNMs reported role modelling and communicating their values to try and mitigate bully behaviour. NLs in the review by D'Souza and D'Souza (2013) on effective communication reported optimizing their interpersonal communication skills and advocating for quality and safe evidence-based care in order to achieve positive outcomes. In both studies by Boldy et al. $(2013,2018)$, NLs ranked what they considered to be most important beliefs and values to achieve managerial effectiveness. Statements reported as most important included happy employees are productive 
employees by Aotearoa, Australian, and Singapore NLs, and information is power by Tanzania NLs. Two statements on different spectrums of the leadership scale as one describes valuing the welfare of employees and the other infinite resources.

Theme of leadership know how pertains to relational and communicative attributes such as listening, encouragement, conflict management, face to face contact, and conveyance of messages in the least offensive way. Furthermore, strong dispositions of CT and MR were identified as leadership know-how's for enhancing staff sense of value, as well as the ability and ambition of NLs to advocate for things they value and believe in such as quality care, fairness, and respect. Next follows a discussion related to the theme of behavioural characteristics to further elaborate on how CNMs build positive culture.

\subsubsection{Behavioural characteristics}

Nurses in leadership adopt various leadership approaches and styles, and adapt their behaviour depending on the situation. Many literatures that met inclusion criteria of the review described behaviour of NLs and discussed topics in relation to managerial effectiveness, leadership qualities and styles, cultural and professional competence, and ward safety.

Transformational, transactional, and resonant leadership styles have been described most effective leadership approaches by NLs and CNMs for achieving positive outcomes (Black-Arias, 2015; Boldy et al., 2013; Isola et al., 2013; Sellars, 2012). Transformational leaders are said to have "creative insight, persistence and energy, intuition and sensitivity to the needs of others to forge the strategy culture alloy for their organisation" (Avolio \& Bass, 1993, p.112). Transactional leaders "develop exchanges or agreements with their followers, pointing out what will be received if something is done right as well as wrong, and they work within their existing culture, framing their decisions and actions based on operative norms and procedures of their respective organisation" (Avolio \& Bass, 1993, p.112-113). Resonant leaders are seen as 
emotionally intelligent people who are able use various styles of leadership that direct feelings to help a group meet its goals (Boyatzis et al., 2002; Cummings et al., 2014).

Behaviour of nurses in leadership tended to be heavily influenced by economic, political, and social factors within this review of literature. For example in the study by Boldy et al. (2013) on managerial effectiveness, most NLs reported to prefer leadership qualities indicative of transformational leadership that were collaborative in nature such as conflict resolution, negotiation, and diplomacy. Although transactional style of leadership was preferred by African NLs as they reported planning and evaluation, organising, and conducting meetings to be most important. In the later study (Boldy et al., 2018) even though no leadership preferences were made among NLs from Aotearoa, they preferred a combination of both transformational and transactional leadership, reporting attributes such as interpersonal relations, decision making, planning and evaluation, and conflict resolution most important. Same findings were reported among NLs from Singapore, however problem solving was considered more important than resolving conflict in this group. Avolio and Bass (1993) regard practicing both transformational and transactional styles normal because both tactical and strategic thinking as well as culture building is required by leaders to be effective (p.112). Furthermore El Amouri and O'Neill (2014) reported in their study both styles necessary for developing cultural competence in leadership. Reporting both transactional and transformational leadership as important means that NLs regard getting the job done equally as important as building collaborative teams.

Leadership practices of CNMs $(\mathrm{N}=62)$ were measured in a quantitative study by Sellars (2012). Purpose being to determine if transformational leadership behaviour and hospital type (magnet/non-magnet) influenced patient outcomes (rates of patient falls and hospital acquired pressure ulcers). Findings from this study reported no relationship between leadership of CNMs and patient outcomes, which correlates with Wong's (2015) summary of evidence that does not link leadership directly with patient outcomes. However, Wong does provide evidence that creating positive working conditions that optimize strong nursing practice can promote high quality care. 
Quantitative methods were used to measure leadership practices of CNMs ( $N=204)$ to identify CNMs with transformational leadership characteristics (Kallas, 2014). Leadership was measured using the leadership practices inventory (LPI)-self instrument (Kouzes \& Posner, 2017a), that is conceptually based on the transformational leadership model developed by Kouzes and Posner (2017b). A model that proposes five exemplary leadership practices people need to become effective leaders such as; model the way, inspire a shared vision, challenge the process, enable others to act, and encourage the heart. Posner (2016) himself undertook quantitative research to prove the LPI a capable tool for identifying transformational behaviours and for providing feedback to enhance leadership. However, LPI-self is designed as a self-assessment instrument, yet clinical nurse executives ( $\mathrm{N}=36)$ used the $\mathrm{LPI}$-self to profile leadership of their respective CNMs. Like Sellars (2012) study about leadership practices in relation to patient outcomes, leadership practices were reported from NLs self-assessment using LPI-self. Inappropriate use of the LPI-self instrument may have influenced findings of this study.

CNMs $(N=15)$ in a mixed method study reported to change their leadership behaviour from relations, change and task-oriented behaviour depending on the situation or leadership goals (Agnew \& Flin, 2014). Relations-orientated behaviour reported by CNMs included consultation, support, recognition, development, and empowerment. Change-oriented behaviour reported by CNMs included risk taking, encouraging innovative thinking, and leading by example. While task-oriented behaviour that was reported by CNMs included clarification of roles, monitoring of operations and planning. CNMs from this study used relations and change behaviours in order to meet safety targets such as infection rates, patient safety and safety compliance of staff. In demanding situations majority of CNMs changed their leadership behaviour to task focussed behaviours to be more effective in mobilising staff. Change of leadership behaviour was also reported in another quantitative study (Isola et al., 2013). CNMs $(\mathrm{N}=246)$ in this study reported resonant styles of leadership to be more important; visionary, coaching, affiliate, and democratic, than dissonant leadership styles; commanding and isolating. Resonant and dissonant leadership as represented in this study is positioned in primal leadership (Boyatzis et al., 2002). The belief in primal 
leadership is that leadership is an emotional journey where messages of a leader must resonate with their followers' emotional reality in order to give some sense of purpose. That way people move toward a positive direction. Interestingly, although CNM attitudes toward visionary and coaching styles of leadership were most positive, over half of respondents ranked their knowledge and skills pertaining to each leadership style insufficient. This is important because it means that NLs need to understand leadership types so that their own abilities can be strengthened to lead more effectively.

So far reported is literature in relation to behavioural characteristics of NLs specific to competence and styles of leadership known to achieve managerial effectiveness, better patient outcomes and safety outcomes. Literature not yet mentioned is behaviour considered ideal for producing a climate that is safe, professional, and sustainable. The World Health Organisation [WHO] describes a healthy workplace as one where managers and nurses generally collaborate and use continual improvement processes to protect and promote the health, safety and wellbeing of everyone in that environment (Neira, 2010). Dawson et al., (2015) made reference to a caring culture as means of mitigating workplace bullying, for which mutual respect, collaboration, and collegiality were reported effective leadership characteristics that could be utilise by NLs to foster caring culture. Kramer et al., (2010) in their meta-analysis describe visionary and visible as leadership qualities that can create healthy workplace culture. Visionary leaders like transformational leaders aim to inspire others to do what is best for the group or organisation by moving beyond their self-interests, and they utilise behaviours that give followers the knowledge, skills and abilities to achieve organisational goals (Colvin et al., 2014). The meaning of visible is not clarified within Kramer's review, however other supportive behaviours mentioned that may be linked to visible include accessibility, approachability, and safe to talk to. Approachability was also reported by NLs and CNMs in two further studies mentioned (Kiger et al., 2011; El Amouri \& O'Neil, 2014) along with professionalism, cooperative, and flexible. 
Effective and successful leaders are people who others on their own accord choose to follow. Personal traits, leadership know-how, and behavioural characteristics describe how NLs and CNMs act and engage to influence their followers toward leadership visions and leadership orientated goals. Literature selected for this review are important in acknowledging research that has explored perspectives of nurses in leadership, but also highlights numerous gaps in relation to research that has failed to capture the CNM population, Aotearoa context, and subjective methods of inquiry. Further research is needed to address these gaps to develop deeper understanding of how CNMs establish and maintain positive workplace culture.

\subsection{Summary}

Nursing leadership has been studied internationally, although almost all $(\mathrm{N}=16)$ but one study that met inclusion criteria were conducted outside of Aotearoa. The study by Boldy et al $(2013 ; 2018)$ illuminates the need to take into consideration environmental context of NLs to fully understand leadership in its entirety. Not only is research from Aotearoa valuable given we are geographically distant from other parts of the world, but Aotearoa also has its own cultural diversity with its own cultural backgrounds, beliefs, and values that is inspired by a mix of indigenous Māori, as well as Western and other smaller multi-ethnic minorities.

Majority of sample populations used in studies within this review had a mixture of nursing directors, nurse managers, or nurse leaders from various clinical, administrative, or educative roles each with their own set of role responsibilities and accountability. CNMs have their own set of responsibilities that differ from other NLs. They are responsible for staff well-being and performance of frontline nursing staff, and so it is important that they have access to evidence-based literature that is specific to their role and that will support them in their leadership journey.

Quantitative research methods are useful for emphasizing objective measurements to identify patterns, make predictions, test relationships, and generalize results to wider populations. But quantitative methods have also placed limitations on literature by not 
having the ability to delve deep into what individual experiences meant as well as consider historical and cultural contexts that may affect data collection and results. Quantitative methods were prominent in literature identified within the review. Of 17 publications, only a small minority used qualitative study designs $(\mathrm{N}=3)$ or mixed method design ( $\mathrm{N}=2$ ). While establishing generalized facts about leadership practices of NLs and CNMs has been useful, a qualitative approach will allow for deeper exploration of leadership practices and contextual influences that underpin decisions made by research participants.

Of few qualitative studies included within the review, research has explored NL communication patterns toward healthy workplace communication, interventions toward workplace bullying, and ethical leadership. Quantitative studies included in the review has explored leadership qualities, cultural competence, transformational leadership, leadership styles and behaviour, leadership characteristics, and leadership communication. The following chapter will outline the research framework carefully chosen by the researcher to explore perspectives of CNMs leading workplace culture. 


\section{CHAPTER THREE: STUDY DESIGN}

\subsection{Introduction}

Presented in this chapter is a detailed description of study design and processes undertaken to explore perspectives of CNMs leading workplace culture. The rationale for the methodological approach qualitative description will be described along with the philosophical positioning of this study. Methods used will be outlined along with procedures of data collection, data management, and data analysis. Reflexivity, ethical considerations and strategies used to ensure trustworthiness of findings will be described.

\subsection{Research Objectives}

The intention of this research is to understand how CNMs build positive culture in their workplace and to identify leadership attributes and actions that they perceive to be important for generating and maintaining positive workplace culture. With this in mind, the following research objectives will be explored:

- Describe the attributes of positive workplace culture from the perspective of CNMs.

- Understand the actions CNMs take to establish positive workplace culture.

- Describe the challenges CNMs face in creating positive workplace culture.

\subsection{Methodology}

\subsubsection{Philosophical grounding}

The philosophical perspective of this study is naturalistic and sits within a constructivist paradigm of inquiry, where research findings are grounded in the rich experience of participants as they have lived it (Ponterotto, 2010). Research paradigms denote certain beliefs and ideas that give a general perspective about the nature of reality, and methods to examine it (Guba \& Lincoln, 1985). CNM perspectives on building positive workplace culture is a phenomenon that contains complex individual, social and contextual constructs where no single variable can be measured and reported. A naturalistic inquiry allows researchers to capture the true nature of respondents 
personal understanding and interpretation of a phenomenon with little interference as research findings are constructed (Beck \& Polit, 2017).

A positivist paradigm assumes nature of reality as fixed and directly measurable where only one truth or independent variable can be known using methods of objectivity, measurement and control (Guba \& Lincoln, 1985, p.37). People uncomfortable with the possibility of multiple versions of reality offered in naturalistic inquiry are more likely to favour a quantitative paradigm with positivist assumptions. This study proposes to accentuate subjective nature of experiences through qualitative interpretations of how respondents see and understand it.

\subsubsection{Qualitative research}

Qualitative and quantitative methods of research have been analysed to determine which methodology and methods will produce relevant information that pertain to aims and objectives of this study. Large scale quantitative studies were useful for establishing generalised facts about leadership practices of nurse leaders (Balciunas et al., 2019; Boldy et al., 2018; Boldy et al., 2013; Kiger et al., 2011; Isola et al., 2013) that may by popularity be effective, but fail to capture data around its subjects, their contextual influences, and 'real life' considerations that underpin decisions made by its subjects for which qualitative methods offer. Therefore, it is important to explore from a qualitative perspective CNMs perspectives of building positive culture in their workplace and leadership attributes and actions that they perceive to be important for generating positive workplace culture.

A qualitative approach allows for a deep exploration into the understanding of CNM experiences through means of careful collection and analysis of materials that are subjective and narrative (Beck \& Polit, 2017, p.12). Qualitative research has an appreciation for looking at a phenomenon as a whole (holism) to fully understand how the human mind functions and behaves from an individual perspective, as is the case when considering how to answer the research objectives. In contrast, quantitative research uses reductionist methods that are less flexible and concrete realities that are 
developed through strict control of its variables and context, limiting the ability of the researcher to elicit what could be multiple holistic human realities (Erlingsson \& Brysiewicz, 2013).

Flexible inductive and iterative processes of qualitative data collection and analysis will capitalise on significant concepts such as thoughts, behaviour, and actions as they emerge from participant experiences. This is fundamental for understanding CNM experiences of generating and maintaining positive workplace culture, and integrating that information to inform leadership practice, develop a description or theory (Beck \& Polit, 2017; Beckman et al., 2019).

\subsubsection{Descriptive or Interpretive design}

Qualitative inquiry can be interpretive, descriptive or a combination (Beck \& Polit, 2017). Both intend to understand human experience and depict what that experience means to an individual. Essential content for this study will use description. The credibility of descriptive research is questioned for being too simple and less robust than prediction and control designs (Andersen et al., 2009), although is the most frequently employed methodologic approach in practice disciplines because it allows the researcher to stay close to their data "whilst maintaining richness, breadth and depth to gain a near picture of the phenomenon" (Matua \& Van Der Wal, 2015, p.23). Any prior knowledge or preconceptions about the research topic is put aside to grasp the experience in its purest form. It is important to set aside one's beliefs about a topic and attend to the participants experiences as described by the participant in an effort to maintain objectivity (Beck \& Polit, 2017).

Interpretive research goes beyond description and concentrates on unveiling deeper meaning and understanding into participant experiences. Personal knowledge and prior understanding of a research topic is embraced in interpretive research by attending to the richness of the text to facilitate an interpretative understanding as opposed to descriptive understanding (Gear, 2004 as cited in Beck \& Polit, 2017; Lopez \& Willis, 2004). Whilst interpretive methods of research may produce a sophisticated level of 
knowledge, the outcomes for this study are to seek and describe and offer meaning of experiences without drawing specific conclusions or making judgements about what is discovered, similar to being like a vehicle for the voices of those experiencing the phenomenon. Brown and Schmidt (2019) advise descriptive methods a suitable research design for a new researcher that is investigating something little known about, relevant to this study's objectives pertaining to Aotearoa CNMs and what they perceive challenges as well as important role attributes and actions for leading positive workplace culture.

\subsubsection{Qualitative description}

Following on from Boldy et al's (2018) quantitative study about nurse managers desired attributes for managerial effectiveness, this study intends to understand how CNMs build positive culture in their workplace and to identify leadership attributes and actions that they perceive to be important for generating positive workplace culture. Furthermore, identify the challenges of creating positive workplace culture using a qualitative descriptive design. Brink and Wood (2001) refer to exploratory research as an umbrella term of all descriptive qualitative research. This study is 'qualitative description' as the research design is 'exploratory' and 'descriptive' in nature (Beck \& Polit, 2017, p.15).

Qualitative description seeks to provide a comprehensive summary that most people, including researchers and participants would agree as an accurate account of the phenomenon (Sandelowski, 2000a). Main features of qualitative description include flexibility in choice of sampling techniques (homogenous or non-homogenous groups), methods of data collection (interview, focus groups and observation), data analysis techniques (thematic or content analysis) and report of findings (Colorafi \& Evans, 2016). The low inference nature of qualitative description will benefit in terms of keeping accounts of participants concrete to how things were said when addressing research aims and objectives, and benefit participants who have experienced the phenomenon by constructing accounts into how they see the world. 
Earlier nursing studies that used qualitative description were able to clearly depict ordinary life experiences of participants for which this study is intended. Examples include Frankson and Mccallin's (2010) study which explored experiences of nurses in the CNM role of Aotearoa. Interview data described participants felt not only overwhelmed with multiple demands of their role, they lacked role clarity and business management skills. Clendon and Walker's (2017) study explored experiences of nurses in Aotearoa with caregiving responsibilities at home, where interview and focus group data revealed participants felt considerable guilt when at work rather than home, along with physical, emotional, and financial hardship. Overseas, Dewar at al., (2018) explored workplace and organisational barriers of compassionate care from nurses in Iran. Nurses in this study described an unsupportive culture, excessive workloads, inadequate staffing, and lack of value toward compassion as barriers to providing patient care that is compassionate. As illustrated, qualitative description capture's true essence of social phenomena giving the researcher an ability to stay close and true with all data that statistical procedures or means of quantification overlook (Sandelowski, 2000b). Qualitative description is therefore an appropriate research design to analyse and report reality for CNM participants.

\subsection{Methods}

\subsubsection{Study site}

A convenient single site, secondary hospital within the North Island of Aotearoa has been utilised. The site serves a local population of over 225,000 people offering level four and five health services and includes medical, surgical, paediatric, obstetrics, gynecology and mental health. There are approximately 3000 permanent and temporary staff for which nursing is its largest occupational group representing 41 percent. Bed occupancy can accommodate up to 40 patients in the largest clinical area, whilst the smallest can accommodate four patients. There are 24 CNMs employed by the hospital. 


\subsubsection{Access to study site}

Gatekeepers are people within an organization who because of their status could grant or deny the researcher access to the study site and its employees. Most gatekeepers are concerned about the social value of a research project and how study interests could impact on operational functioning, so it was important as the researcher to respect and understand attitudes and context specific influences of gatekeepers and to focus attention on gaining their support (Singh \& Wassenaar, 2016). To give assurance to gatekeepers the researcher articulated any potential risks and benefits of study with reference to what value the research could bring to the organisation, outlined clear recruitment processes, and offered feedback to the organisation of study findings.

Permission to undertake research and gain access to hospital staff was authorized by the District Health Board (DHB) clinical school and ethical review board. Part of the application process required approval from the director of nursing, clinical leader of anaesthesia, radiology and surgical services, and Māori advisors.

\subsubsection{Participant selection, recruitment, and sampling strategy}

Inclusion criteria for this study were CNMs from a hospital setting. The CNM role is positioned between higher board executives and ward unit staff and generally responsible for managing staff, systems, processes and resources for patients, on top of budget setting, budget holding and business planning to ensure effective running of an efficient ward or unit to meet organisational goals (NZNO, 2014). A total of 10 CNMs participated in this study. Participants were not excluded based on age, gender, or ethnicity.

Purposive sampling is a non-probability sampling method used for its practical and convenient attributes such as low-cost, ease of accessibility and language compatibility (Welch, 2014). But largely to acquire a broad range of individuality perspectives from people knowledgeable in the research inquiry to inform research objectives. 
Participants were obtained using a CNM contact list and online contact directory obtained from the study site. Email was the primary recruitment strategy given logistical ease. The email contained an overview of the research question, research significance, research objectives and data collection methods, a statement about the researcher and contact details (Appendix 1).

Respondents expressed interest through return email. The same recruitment email was sent to CNMs who had not responded two weeks afterward to ensure equal opportunity to participate was offered if by chance the first invitation was overlooked. Hand delivered information sheets were given to interested parties to review and discuss with the researcher and trusted people. Signing of consent to participate took place prior to the interview.

No rigid rules apply to sample size in qualitative research, but larger numbers make it easier for researcher's to see and understand subtle features in the data (Morse, 2015). Semi-structured interviews used (see section 3.5) give participants freedom to respond and the researcher ability to probe for additional information, adding greater amount of usable data and therefore less need for higher number of participants if done well. As a guide Braun at el., (2015) recommend for studies using thematic analysis from interview data use 5 to 10 participants for a small project, 6 to 15 participants for a medium project such as masters, and 15 to 30 for a large project such as $\mathrm{PhD}$ (p.229).

\subsection{Data Collection}

Semi-structured face-to-face interviews were used to collect data. Flexible yet controlled methods of semi-structured interviews meant questioning was less prescriptive like structured interviews, and the researcher could move with the flow of what the participant wanted to share about the research topic (Chadwick et al., 2008; Jirojwong \& Welch, 2014). Interviews ranged from 41 to 125 minutes, with an average interview time of 32 minutes. All participants were able to answer all four areas of the interview guide and draw upon personal and professional experiences that addressed questions put forward by the researcher. 
As recommended by Mitchell (2015), a pilot interview took place with a nurse shift coordinator who resembled similar nurse leader characteristics of CNM participants. The interview was audio recorded to be later critiqued and questions/prompts modified as needed to improve interview quality.

A question guide created a framework to avoid deviating from the research topic, but also enhance consistency in the content of data collected (Jirojwong \& Welch, 2014) (Appendix 2). Open-ended questions were set out to elicit data grounded in the experiences of participants and to offer both the participant and researcher room for further exploration. Questions addressed three central clusters of information. Demographic data pertained to age, gender, ethnicity. Professional characteristics yielded data in relation to education, length of nursing and length as a CNM. Questions of leading workplace culture were formulated around study objectives posed, such as leadership qualities, actions taken to establish positivity, and satisfying and challenging aspects of the CNM role. Probing questions encouraged participant's to think more deeply about the experience (Jirojwong \& Welch, 2014). Interviews took place in a single on-site room closed off from external distraction and away from participants usual work environment as a safety measure for the researcher, and a balance in the minimisation of inconvenience for participants, and maintenance of confidentiality.

\subsection{Data Analysis}

Thematic analysis was used for this study to analyse qualitative data with assistance of NVIVO 12 coding software to manage the process of analysing transcripts. Using Braun and Clarke's (2013) guide to thematic analysis, the researcher closely examined interview data to identify common themes, topics, idea's and patterns of meaning to produce a scholarly report of the analysis. Braun and Clarke's process of thematic analysis comprises six phases: familiarizing yourself with the data; generating initial codes; searching for themes; reviewing themes; defining and naming themes; and producing the report (Braun \& Clarke, 2006; 2013). Repeatedly listening to interviews, self-transcription, reading transcriptions, memoing, and note taking were methods used to immerse and engage with data. Interviews were transcribed immediately 
following interview to its true verbal nature and included non-verbal utterances (e.g. coughs, laughter). Self-transcription was chosen given the opportunity to develop early understanding of participant experiences and note for early patterns and potential meanings (Galvin \& Holloway, 2017).

Findings were classified into descriptive ideas that were directly expressed from the text as advised (Braun \& Clarke, 2013; Jones et al., 2016). Coding of empirical data involved labelling words and paragraph's with a summative meaning (Korsgaard \& Skjott, 2019) and being careful not force content to fit into pre-existing coding frames to appear sound (Braun \& Clarke, 2006). As advised, any biases or analytic preconceptions about the research inquiry were 'laid aside' as much as possible for this to occur (Whitehead, 2014). An initial list of 214 codes were drawn using descriptive terms of what that segment of data was about and what it meant in relation to the research topic such as emotions 'felt unprepared', actions 'listening', and character 'adaptable'.

Thematic analysis was used to raise participants perspectives from a descriptive to more abstract level of interpretation and seek more meaning to experiences about the research topic (Braun \& Clarke, 2006). Processes involved further condensing of multiple codes from content analysis into a higher level and smaller number of subthemes and main overarching themes to anchor and strengthen the report of research findings (Corley et al., 2013; Korsgaard \& Skjott, 2019; Jirojwong \& Welch, 2014). Visual representations such as mind-maps and colour post-it notes were useful strategies when making connections and variations between data. Codes that did not fit were housed in a miscellaneous theme created. Refinement and re-refinement of themes ensured data within themes cohered together meaningfully with clear identifiable distinctions between them to capture essence of the story being told (Braun \& Clarke, 2006, p.20). Codes and related data, sub-themes and major themes were discussed with the researcher's supervisor to verify accuracy throughout. A visual depiction of how codes, sub-themes and major theme development are illustrated to demonstrate an audit trail as logical findings were created from participant narratives (Appendix 8 and 9). 
Data analysis discontinued when data saturation was reached and no new information such as codes and themes evolved from data. Data saturation is generally acceptable when new information cannot be attained and further coding and theme development is no longer feasible (Fusch \& Ness, 2015).

\subsection{Ethical Considerations}

When human subjects are involved in a study, those conducting the research are responsible for ensuring participants are not harmed during the process. The Nursing Council of New Zealand govern standards of practice for nurses in Aotearoa for which guidelines such as the code of conduct (NCNZ, 2012) have been established to protect the health and safety of the public. Similarly the Health and Disability Ethics Committee (2012) regulate research involving human beings and ensure researchers meet ethical standards to safeguard participant rights and interests. Consent to conduct research was obtained by Victoria University of Wellington Human Ethics Committee $22^{\text {nd }}$ November 2019, reference number 27985 (Appendix 3). Locality approval was authorised $7^{\text {th }}$ November 2019 to conduct research with CNMs employed by the hospital (Appendix 4). Ethical principles of respect and care, Treaty of Waitangi, minimisation of harm, confidentiality and anonymity were successfully addressed in both applications for permission to conduct research.

\subsubsection{Respect and Care}

To safeguard people from harm or risk, informed consent required obtaining voluntary participation after full disclosure about the study, informing of ethical rights and explaining possible risks and benefits (Beck \& Polit, 2017). A participant information sheet and verbal conversation provided CNMs full disclosure about the nature of research and an opportunity to ask questions up until the interview date. Both the information sheet (Appendix 5) and consent form (Appendix 6) articulated research nature, study purpose and basic ethical rights of confidentiality, anonymity, voluntary consent, withdrawal processes and withholding of information and contact information. Participants were informed they could withdraw from the study at any 
time before or up to two weeks following interview date, and any information provided by them would be returned or destroyed. Signing of informed consent took place on the day of interview.

\subsubsection{Treaty of Waitangi}

Relationship building and cultural sensitivity during this study was guided by Te Tiriti o Waitangi principles; Partnership, Protection and Participation (NCNZ, 2011). CNM perspectives of leading workplace culture were explored regardless of whether participants identified as Māori or other ethnic entity. Authorisation to conduct research was endorsed by the research site Māori health gains and development committee on behalf of eighteen local Iwi on 18 th December 2019 (Appendix 7). Sampling strategy, informed consent and data collection methods were addressed in accordance with Treaty of Waitangi principles for permission to conduct research. In Māori culture whanau meaning family support is pivotal. Participants were invited to bring a support person along to their interview, but all ten declined. There was a mix of diversity amongst participants such as age, gender, and ethnicity. To respect identities of every individual, participants were given opportunity to express any cultural or spiritual requirements to ensure they felt comfortable, and participants were able to offer Karakia (prayer) before commencing interview.

\subsubsection{Minimisation of harm}

CNMs sharing their private views and experiences can evoke memories or strong feelings that are distressing. Under the Health practitioners competence assurance Act 2003 (New Zealand Government, 2019) and nursing code of conduct (NCNZ, 2012) the researcher was obligated to act with integrity and protect participants from exploitation and harm. It was predicted that questioning about barriers to positive workplace culture could potentially provoke an emotional response and stress. Content outlined in the information sheet about the nature of study and ability to with-hold information or pause conversation may have provided participants some sense of comfort, but receptiveness and compassion throughout conversation took precedency as emotional 
patterns and thoughts were shared by participants. Access to counselling and support services by the providers Employer Assisted Programme (EAP) were made available to participants but were not required.

\subsubsection{Confidentiality and Anonymity}

Confidentiality required honouring secrecy of information pertaining to every participant and anonymity involved depersonalising information so that data could not be identified back to where it originated. Anonymity and confidentially were advised as part of informed consent process, and CNMs were not informed about other CNMs who did or did not choose to participate in this study. Identity of participants were known only by the researcher and supervisor.

Unique identifiers were used in place of names and places to maintain confidentiality of participants and research site. Each CNM will be identified as 'CNM' and assigned a number '1-10' based on interview order. De-identification began from transcription and continued throughout stages of data analysis and reporting. Minor details mentioned from participants such as aspects in relation to their site of work, or cultural background were changed due to risk of identification. Raw data pertaining to the research such as audio recording, transcripts and data analysis information was stored electronically on a password protected desk top computer. Paper content was stored in the researchers locked file cabinet. All data will be destroyed after five years as specified by University regulations.

\subsection{Rigour Strategy}

Rigour in qualitative research involves establishing a quality report that convinces audiences that findings of an inquiry are worth paying attention to through validation and authenticity (Galvin \& Holloway, 2017; Guba \& Lincoln, 1985). Debate that surrounds rigour and validity in qualitative research questions whether methodological procedures used conform with criteria of quantifiable research account as rigorous (Sandelowski, 1986). On the contrary, insightfulness and creativity of qualitative 
research intentions are more concerned with people and narratives as opposed to numbers and statistical concepts associated with quantitative methodology.

Principles of trustworthiness were proposed by Guba and Lincoln (1985) as parallel criteria of rigour and validity of quantitative research. Principles of trustworthiness will be established in this study by authenticating Guba and Lincoln's techniques of credibility, dependability, confirmability, and transferability.

\subsubsection{Credibility}

Credibility refers to whether research findings presented can be trusted and the researchers interpretation of the participant's experience is represented adequately (Liamputtong, 2020). Credibility was achieved by constructing true descriptions from data as if participants would recognise it as their own. Participants were given as much time needed to voice their experiences around leadership in relation to workplace culture as a CNM, and equal opportunity of engagement despite difference in duration of interviews. Audio recordings were accurately transcribed and thoroughly checked to ensure interviews were documented verbatim. All 10 participants were offered their interview transcript to undertake member checking processes, of which six participants requested and were sent a copy of their transcript to review, and four participants declined. Transcribed verbatim were frequently reviewed as findings were created to ensure interpretations made were grounded from raw data. By the seventh interview very few new codes, subthemes, or themes were drawn from data. Regardless, data analysis continued for all 10 interview transcripts and audio recorded data to ascertain no new information could be obtained. The researcher worked in consultation with their supervisor to make comparisons and certify accurate interpretations of data.

\subsubsection{Transferability and Dependability}

Transferability refers to the extent study findings can be applied to other times, settings, situations, and people outside the study context (Sandelowski, 2004). And dependability questions whether research can be replicable if same or similar sample 
or context were used (Liamputtong, 2020). This chapter provides a clear description of methodology and methods of data collection and analysis processes used. Thick description of participant demographics, professional characteristics and lived experiences of nurse manager accounts in relation to the research topic are reported in the findings chapter of this thesis. Thick descriptive data will enable the reader interested reach a conclusion about whether a transfer of findings is feasible.

\subsubsection{Confirmability}

Confirmability is maintaining objectivity by eliminating own biases that could influence how data is analysed and interpreted (Liamputtong, 2020). Strategies used to enhance confirmability included regular debriefing with the research supervisor of major themes and subthemes generated through mind maps and post-it notes. This process of confirmability enhanced analytical probing and evaluation of whether descriptions and conclusions were congruent with participants narrative as opposed to the researcher's personal biases, perspectives, and assumptions. Reflexive journaling acknowledged and separated own experiences, opinions, thoughts, and feelings throughout the research process (Matua \& Van Der Wal, 2015). Understanding the researchers own influence on research findings helped to obtain some background understanding of the experience while continuing to allow the participants experience to be prominent in research findings.

\subsubsection{Reflexivity}

Reflexivity is a process of positioning one-self as the researcher into the qualitative research as knowledge is constructed (Guba \& Lincoln, 1985). The topic of this research inquest is value bound where the researcher has their own personal positions and personal perspectives, which for any naturalistic inquirer can make it difficult to maintain complete objectivity (Liamputtong, 2020). Reflexive journaling was a strategy used to critically analyse and conceptualise own thoughts in relation to participants narratives and acknowledge how these might shape findings and eventual outcomes. 
Rallis and Rossman (2017) say that critical subjectivity is a good strategy to use for enhancing transparency and credibility of research findings.

\subsection{Summary}

This chapter outlines the methodological procedures used to guide research processes to understand how clinical nurse managers build positive culture in their workplace and to identify leadership attributes and actions that they perceive to be important for generating positive workplace culture. Furthermore, identify the challenges of creating positive workplace culture in Aotearoa. Justification for qualitative research as a method for data collection and analysis is evident. Qualitative description will capture true in-depth understanding of Aotearoa CNM experiences, but also generate knowledge which can be usefully resourced to devise strategies of effective nursing leadership that are attentive to nursing staff and management needs. The following chapter contains a detailed description of findings using thematic analysis guided by Braun and Clarke's (2006) methods. 


\section{CHAPTER FOUR: FINDINGS}

\subsection{Introduction}

Within this chapter findings of the study will be reported. Demographic and professional information of participants are presented. Three main themes developed following the analysis of interview data (Figure 2). The first theme role preparation provides insight into the readiness of CNMs, describing actions they took to cope with the realities of the job, build good teams, and manage uncertainty. The second theme achieving perspective reveals particular perspective's CNMs consider as they make judgements and the specific skills used to understand situations and make decisions. The final theme intentionality presents leadership strategies CNMs choose to adopt to enhance collaborative behaviour and positive relationships within the team, leading to what they considered to be a positive culture. The summary of findings is drawn upon thesis objectives posed with an overall aim to understand how CNMs build positive culture in their workplace and to identify leadership attributes and actions that they perceive to be important for generating positive workplace culture. Furthermore, to identify the challenges of creating positive workplace culture in Aotearoa.

Figure 2: CNM perspectives of leading positive workplace culture

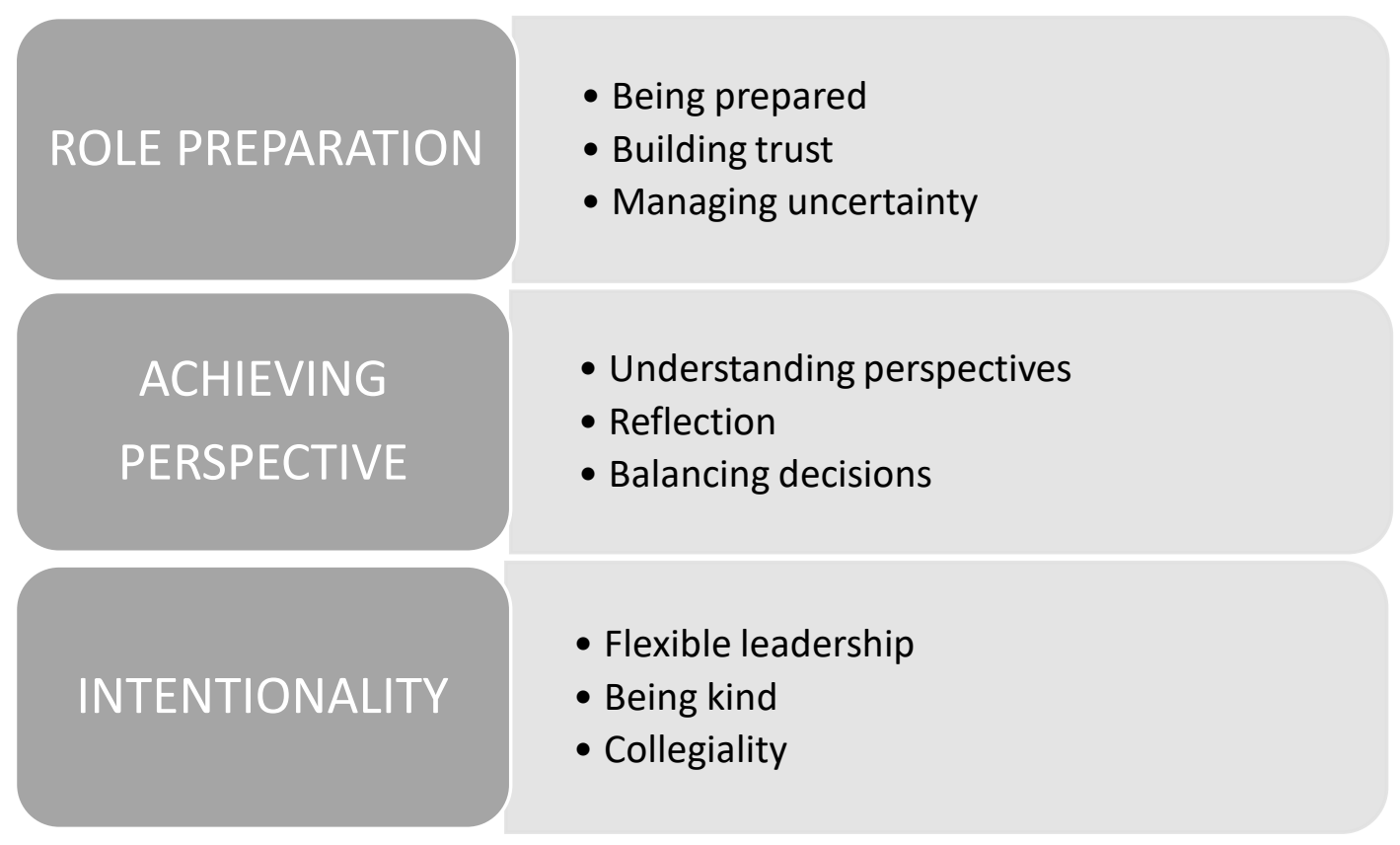




\subsection{Research Participants}

A total of 10 including four male and six females participated in this study. Mean age was 49 , the youngest aged 34 and the eldest aged 63 . All came from a variety of ethnic backgrounds including European decent $(\mathrm{N}=5)$, Māori $(\mathrm{N}=2)$, Cook Island, Indian, and American. Two CNMs led medical wards. Others led haematology and oncology, orthopaedics, emergency care, critical care, surgical, paediatrics, interventional radiology, and short stay, respectively.

Table 1 describes professional characteristics of study participants. Nine CNMs held a post graduate diploma or higher education. Length of time in role as CNM ranged from 1 to 14 years, this being a first-time experience for seven CNMs and third time experience for three. Leadership experience prior to the CNM role included NL, business manager, acting CNM, or clinical supervisor.

Table 2: Professional characteristics

\begin{tabular}{lc} 
Category & Number (\%) of Participants \\
\hline Education & \\
Post graduate certificate & $1(10 \%)$ \\
Diploma & $5(50 \%)$ \\
Masters & $4(40 \%)$ \\
\hline Length of nursing & \\
$10-20$ years & $2(20 \%)$ \\
$21-30$ years & $4(40 \%)$ \\
$31-40$ years & $4(40 \%)$ \\
\hline Length as CNM & \\
$0-5$ years & $5(50 \%)$ \\
$6-10$ years & $3(30 \%)$ \\
$11-15$ years & $2(20 \%)$ \\
\hline CNM experience & \\
First time in role & $7(70 \%)$ \\
Third time in role & $3(30 \%)$ \\
\hline
\end{tabular}

\subsection{Summary of Study Findings}

Whilst each participant discussed their own unique experiences of leading their nursing team, the concept of positive workplace culture was understood by participants as 
something that requires collective input from the entire group involved in planning and the delivery of care. Balancing personal values and role priorities with the needs of employees tended to influence the leadership strategies used by CNMs to create an environment that was healthy and positive. Themes of role preparation, achieving perspective, and intentionality are identified by CNMs as important in building positive workplace culture, each theme will now be discussed.

\subsection{Role Preparation}

Having an idea of things considered important in the context of creating a place of work that was productive and sustainable toward quality outcomes motivated CNMs to strengthen their personal capabilities and consider leadership strategies thought to be effective. Three subthemes emerged from role preparation. Being prepared describes acquired knowledge and practical steps taken to feel prepared and cope with role complexity. The second subtheme building trust is positioned around interpersonal connections to establish confidence between nursing teams and CNMs. And managing uncertainty completes theme of role preparation and describes strategies used by CNMs to constructively manage ambivalence in practice.

\subsubsection{Being prepared}

Being prepared for participants constituted the need for formal and informal education. Acquiring knowledge prepared CNMs to think strategically and manage situations more confidently. Self-confidence shaped how CNMs felt about themselves influencing how they behaved toward staff and colleagues within that environment.

Education such as a master's qualification was considered by CNMs as important for role preparation.

You know you really do need to for all of the senior positions [have]some level of mastorate study. And some of that is about what you really learn out of a masters. What you learn is a different way of learning and knowing. And you learn skills in that learning and knowing that makes you question, it makes 
you look for research, it makes you look at audits, it makes you dig deeper into an issue. And what that does is it creates a way of thinking that allows you to then move into those management spaces. (CNM 3)

Organisational level workshops were described useful for learning about leadership strategies, but participants would have liked to receive more information specific to their role and responsibilities such as recruitment; "I'd never recruited anyone and you just get thrown in" (CNM 4); performance management; "I didn't know how to performance manage people and when I did have to performance manage somebody I got conflicting information" (CNM 5); business and financial aspects; "I find the financial reporting challenging as well because my backgrounds nursing and then having to keep an eye out on all the financials as well because it is one of my KPI's I have to keep an eye on it and I find that challenging" (CNM 10); and information technology systems "probably the pay system getting to know what systems to use and what processes are in place and how you use them". (CNM 9)

Participants with a master's level qualification in business management administration and health service management emphasised the importance of understanding the difference between leadership and management, and ability to apply both concepts appropriately to be effective as a CNM.

Ordinary nursing master's that is a fantastic thing, unless you have got some business papers in that actually it does not really set you up well for that role. (CNM 3)

There is a difference between leadership and management. . . someone could be a good manager and not a good leader and some can be a good leader and not a good manager. . . just because they are good and competent on the floor does not necessarily mean they are going to be a good manager. (CNM 2)

\footnotetext{
${ }^{1}$ Key Performance indicator (KPI) is a measurement value health organisation's use to track progress toward strategic goals.
} 
In addition to education there were practical skills CNMs considered important for being prepared such as organisational skills; "I am very much into an organised ward" (CNM 10), and ability to triage tasks; "If someone comes to me with something and if I have got ten things to do that day, that might be my eleventh thing". (CNM 2)

CNMs prepare themselves by upskilling through higher education and utilising skill sets perceived useful for everyday processes and responsibilities. Being prepared in the view of CNMs helps to shape positive workplace culture by building confidence, establishing positive rapport, and gaining trust from their team. The next subtheme to be discussed is building trust and the communication strategies used by participants to build trusting relationships.

\subsubsection{Building trust}

Having experienced the positive influence trust has on collaborative behaviour and performance in the workplace, CNMs favour working relationships built on trust. CNMs build trusting relationships by encouraging autonomous practice; "I'll give them a few solutions but then let them go away and you know try and sort it out themselves" (CNM 5). And they avoid micromanaging staff.

I do not want them [nurses] thinking that I am looking over their back. I want to trust that they are going to do the job. If they [nurses] are constantly looking over their back, they are not going to be concentrating and that is not a way to work. (CNM 2)

When there is distrust or unhappiness CNMs observe a change in the nursing teams' level of engagement; "they often sneak out the back door rather than passing my office, they do not read their emails, they don't get involved in any discussions about any change or any complaints that we need to talk about, they're silent". (CNM 4)

CNMs build trust by being honest and transparent with staff. Participants spoke about trust being an ability to deal with things that are hard, for example "have tough conversations" (CNM 2). One participant explained communicating transparently upon 
meeting new employees to provide clear understanding of workplace expectations and how they can contribute toward the team culture.

One of the important things that I do with my staff when they start is talk about care values to the point that there is nothing else to talk about. What it does is I know that they understand what my expectations are, what the organisation and team expectations are, and this is how I expect my staff to behave when they are here. (CNM 7)

CNMs described encouragement, honesty and transparency as key techniques used to build trust and influence staffs effort and level of engagement. As discussed, being prepared included both educational preparation and an attitude that wants to foster trust. Role preparation was also positioned in an ability to understand and react to uncertainty and will now be discussed.

\subsubsection{Managing uncertainty}

Managing uncertainty is about the readiness of CNMs and the strategies they used to manage ambiguity or complicated situations. Just as being prepared is important for exhibiting role confidence to the team, CNMs effectively like to bring order, calmness, and create certainty and hope to the team. From the perspective of CNMs, managing uncertainty in view of workplace culture often related to people management, introducing change and resource availability.

People management was described the most difficult and time-consuming part of the CNM role by all participants, but equally a rewarding aspect particularly when supporting and building confidence in individuals; "she was coming to work with a smile on her face all the time and she was doing shift leadership and I just remember watching her, she was flourishing, she loved it, you could see she was enjoying it". (CNM 2)

Negative aspects of people management related to disciplining, terminating contracts, and evaluating practice when expectations of the organisation were not being met. 
I had a nurse that was underperforming, and I was getting complaints from both staff and patients and patient's families. So, I just went straight ahead and started meeting with her to give her the feedback and to provide her with an opportunity to improve herself, and it basically all turned turtle on me, and we ended up in a very bad place with it. (CNM 4)

Introducing change created apprehension for participants. In particular they worried about getting by in from the team as they felt that nurses were reluctant to change; "nurses are some of the worst people in the world for change they don't want to see change" (CNM 2). In the implementation of change CNMs had both positive and negative experiences.

... they liked the idea and said they were all keen to give it a go. I explained to them in order for it to work it needed full support of staff to do it and if there was any resistance then the staff that were positive for it had to talk to the ones that were resistant to justify why they wanted it to be done that way. Positive outcome it is going really well. (CNM 1)

A couple of times that I have tried to make changes I have had a handful of nurses who have resented the change and put a lot of energy into sabotaging it. But when you look at the change model you are always going to get that, and you just have to work with that. (CNM 4)

CNMs spoke about the difficulties to provide a stable structure for the nursing team to be able to provide high quality care when resources such as nursing $\mathrm{FTE}^{2}$ and finances are limited. Hard choices have needed to be made concerning allocation of resources to meet organisational priorities. CNMs were concerned about constantly working with a deficit of registered nurses and a poor skill mix. They saw the impact of such deficits on their team's health and mental wellbeing.

\footnotetext{
${ }^{2}$ Full time equivalent (FTE) is a unit that indicates the number of hours worked by a single employee in a week. For example, an FTE of 1.0 is equivalent to a full-time worker, while 0.5 is half of full-time working hours.
} 
We are working at a deficit all the time. You know you [the organisation] expect us to be at 113 percent but you are not going to support the nursing staff. The nurses are in tears on an afternoon shift you know you expect them to do all these extra hours. (CNM 5)

You have got to make sure you have got a really good senior base to look after those graduate nurses but also look after those high acuity patients. So, it is very much about making sure that you have got the right skill mix. (CNM 1)

CNMs struggle with the recruitment lag of three months and say they need FTE allowance increased to reach a safe staffing level for their clinical areas. Participants were concerned in their ability to motivate the nursing team when constantly understaffed.

We have been trying to get up to a safer staffing level. And probably 70 percent of your time is actually looking for staff to do extra. . . because our staffing mix has not been right, I have been more clinical than I have in my role which is probably been a negative. (CNM 5)

Despite issues regarding tight budgets CNMs are practical and accept the organisation is like a business where everyone needs to work together in an effort to provide quality service, but also balance operational expenditure.

Being realist and knowing that there is not an endless pool of money, that actually there is limitations as to what we can buy or how much we can spend. It is a business. And if this were your private practice or your own business you would possibly be even tighter with your finances because it is about saving money, it is about making money and we cannot afford to just to spend money. (CNM 1)

Role preparation for CNMs incorporates building on knowledge and technical skills to function how they know best for their team, and they aim to foster trust as a strategy to maintain staff engagement and a positive culture. Role preparation also pertains to 
CNMs managing situations with confidence to create assurance for the team even in difficult circumstances. Managing safety of nurses and patients with resources had and handling different responses from people through periods of organisational or workplace change were examples of how CNMs created positive workplace culture. The second major theme identified and next described is achieving perspective.

\subsection{Achieving Perspective}

This theme is about participants in this study using perspective-taking as a way to better perceive and understand other people's viewpoints and situations in order to build positive workplace culture. By gaining perspective CNMs spoke about their ability to consider how people may be thinking or feeling, allowing them an opportunity to move between their own perspectives and those of others.

Three subthemes were identified from CNM descriptions of how perspective-taking is used to better enhance workplace culture. Understanding perspectives is the first subtheme and relates to how CNMs gauge what their team may be thinking or feeling both personally and professionally and how they look at viewpoints beyond their immediate frontline staff to enhance collegiality. Reflection describes how CNMs think about and evaluate every aspect of an experience to better understand what took place, and how they responded. Balancing decisions is the final subtheme and describes mental processes that take place as CNMs make their decisions.

\subsubsection{Understanding perspectives}

CNMs immerse themselves into the clinical environment with their team to understand what is like to be in different roles and contexts. To become immersed in what nurses actually do is a process of perspective-taking. This allowed CNMs to be physically and mentally surrounded in what their team experience and helps them understand how the ward is functioning, and what may need to be implemented or changed.

I need to go and immerse myself in that pre assessment area, I need to be one of the nurses on the floor, I need to see patients, I need to run my own 
clinic and I need to know exactly what is going on. . So, day to day nine to five for arguments sake Monday to Friday I was in there immersed with the nurses seeing what I could do, what I could change ... I learnt a huge amount from doing that and I would like to think I am a better leader and manager as a result of it. (CNM 2)

Perspective-taking through clinical immersion was described as a method of relationship building, getting to know staff and their perspectives at an interpersonal level and at the same time an opportunity for CNMs to assess individual practice.

I also try and spend time with them [staff] on the floor when they are working. The two solutions for that, they get some help from me, we get to know each other, but I also know how their work is going, how their work is progressing, have they advanced from that level last month to this month, and it gives me the strength of having that stronger relationship with them. (CNM 7)

Participants who did not speak about clinical immersion, described being thoughtfully sensitive to needs of their team by conscientiously reflecting on and empathising how their team members may be feeling in certain situations.

You have to remember what it was like yourself when you were a nurse on the floor. . I sit there a lot of the time and I put myself back in their place and think my God they are out there they have got five patients and you know it is hard. (CNM 6)

I take bits from everything and try and to look at things through different lenses and try and understand it from the different perspectives in what they are looking at and what their priorities would be. (CNM 10)

CNMs described listening perceptively as an important tool in gaining the views of others; "just listening, what are they trying to say, what is the underlying factor. . listen, listen, listen' (CNM 7). Being able to listen perceptively goes deeper than just hearing words. It involves reading between the lines of what a person is actually trying to say, 
considers what a person is not saying and compares what they really might be thinking to how they are behaving. Perceptive listening helps CNMs to consider multiple views and communicate in a way their team thinks they are being heard and understood.

It is about being able to take that step back, be an influencer, listen to the whole story, find the whole story. Do not just go by hearsay and one view. There will always be two views and it is very important as a leader not to be swept into one view. (CNM 3)

Despite having different views CNMs are gaining perspective when they attempt to understand and be sensitive to other disciplinary views with the aim of shaping collaborative and collegial relationships within their team.

I work closely with doctors I work closely with admin. They are all different individuals with different agendas but in common reality we have all got a common aim, a common focus, a common vision. It is hard to work with people who do not have insight about that. (CNM 7)

As described, CNMs try to foster close working relationships and collegiality by situating themselves in contexts similar to that of their team to gauge how members may be thinking or feeling. Listening and observing are common approaches CNMs use to gain insight into how others may see the world. Building upon the theme of understanding perspectives is reflection, a process CNMs use to increase selfawareness and behave more thoughtfully.

\subsubsection{Reflection}

Reflection is a learning process used generally to help people understand situations, themselves, and other people, and compelled CNMs to think about what knowledge might mean at a personal and professional level. Participants described having an internal dialog about events, and from this they achieved insight and established ways of moving forward. CNMs build positive workplace culture using reflection as a way to learn from experiences and consider where improvements can be made. 
CNMs used two forms of reflective processes to understand people and manage situations effectively. The first was 'reflection-in-action' which involved CNMs thinking about their options at the same time a situation was occurring to gain new perspective but also draw upon skills they had to find solutions in practice.

Any problem that comes to me the philosophy goes back to do we have that partnership, are we participating, am I protecting your needs ... am I sensitive to your demands and needs and your culture. If I can bring in those philosophies and remind myself that this is what we are trying to achieve I think I will not go wrong. (CNM 7)

In contrast 'reflection-on-action' was used as CNMs described retrospectively thinking about an experience sometime after an event had occurred. This reflective process gave CNMs more time to think about an appropriate course of action, giving them time to consider options.

Really important is for the leader to step back and say hey this is really pushing my buttons. I need to go and reflect why that is happening. Why is this pushing my buttons, what is this about here. And then you go right, if that is what is pushing my buttons in this scenario, now I need to investigate did that really happen and what does that mean, and what are the outcomes from that. (CNM 3)

CNMs use processes of reflection to make sense of their own perspectives, their teams' perspectives, their surroundings, and why they feel a certain way about an experience. Reflection-in-action and reflection-on-action enabled CNMs to find their own meaning and establish ways of moving forward. The final subtheme as it relates to achieving perspectives is balancing decisions which describes how intuition and reasoning are two processes that influenced actions and decision making of CNMs.

\subsubsection{Balancing decisions}

CNMs are naturally positioned as a bridge between senior management and frontline nursing staff. Fostering a shared culture that is positive involves CNMs considering the 
perspectives of their leader, their staff, and patients. Intuition and reasoning were two decision-making processes described by participants. Intuition is the act of doing what CNMs think and feel to be right despite not always having support from peers.

One of my nurses lost a parent a while ago and I knew she was struggling, and my leader told me that I was only allowed to give her one-week bereavement sick leave. I felt that was too restrictive. I could see that if she came back to work after one week, she was not going to be healthy in the workplace. So, I just worked with her on that, and she had a bit more sick leave, she took a bit of annual leave and she had a little gradual return to work. And so, what we got is a nurse that was fully engaged coming back and healthy and ready. (CNM 4)

CNMs accept that decisions made by them will not always please everyone; "I think there are some people that I am not ever going to please" (CNM 5), "there are decisions sometimes that they may not see fit for them" (CNM 7). Knowing this CNMs also understand they have a job to do and have been put into their role to make decisions; "As a manager you are put into the role for a specific reason, you've got experience and you've got a whole set of skills and sometimes a decision just needs to be made" (CNM 2). And while CNMs all want to imbed participative leadership into their practice by inviting their team into decision development, more complicated decisions require more structured thinking where CNMs independently use their own intuition and reasoning to establish and create a balance that benefits the workplace.

Reasoned decision-making on the other hand is grounded in the here and now as decisions made by CNMs are built from facts. In these instances, CNMs described using a more directive approach toward staff so that they could achieve their own leadershiporientated goals.

I think it is really important to be decisive on certain issues because what you can easily get is a fracture in the group because some people have gone one way and some people going the other way. Whereas if you need to be the 
bad guy who says that is the rules, that's just it...I think decisiveness is really important. (CNM 8)

CNMs make reasoned decisions when everything else such as their own opinions and those of their staff are put aside to focus on what patient's need and what their perspectives are to find the best solution.

Whatever we are doing let us put the patient in the middle and think about a solution that works for them first. . .I think then the understanding is that you and I are not more important, the patient is more important so let us work out a solution for that. (CNM 7)

Perspective taking is used by CNMs to build positive workplace culture by knowing what their immediate and extended team is thinking or feeling to better understand their frame of reference and establish decisions that will influence positive relationships and patient outcomes. They practice perspective taking by listening perceptively, immersing themselves in clinical activities, and having an awareness of other role perspectives and priorities to imagine if not experience being in another person's circumstance. And they use reflection to mindfully examine what an experience means in order to act. The final theme discussed is intentionality which describes specific acts of leadership CNMs used to foster positive workplace culture.

\subsection{Intentionality}

CNMs deliberately choose leadership strategies that foster open, clear communication to purposefully create positivity in their workplace and enhance collaborative relationships within their team. Three subthemes within this theme include flexible leadership, being kind, and collegiality. Flexible leadership encapsulates CNMs intentional and authentic approach in leading nursing teams. Being kind is positioned around strategies used to establish a culture of kindness to enhance the quality of social transactions and relationships among team members. And final theme collegiality describes how CNMs create collaborative relationships and develop their staff to enhance team functioning. 


\subsubsection{Flexible leadership}

Coaching is a preferred leadership style adopted by participants. They liked the idea of not being solely responsible for all decisions and delegation of tasks and therefore used coaching to offer individual team members an opportunity to participate in decisionmaking processes.

When you are coaching someone, you are helping them to figure out a problem. So, I very rarely will just openly tell people what to do I will almost always say what do you think we should do because usually they have an idea, they just want to run it past you. (CNM 8)

CNMs describe the need to be adaptable to situations that require different types of communication. In particular a commanding style 'do as I ask' was used in an urgent situation where one participant needed their directions followed to achieve an end purpose.

There was no more discussion about can we do this can we do that. . we are moving out every single patient I want the consultant to come and see all his discharges before four o clock, move the patient to transit lounge... there was a deadline, the instructions were clear. (CNM 7)

Flexible leadership is also about role modelling behaviour and setting a good example of expectations, so staff have no excuse to act different. CNMs build positive workplace culture by exhibiting behaviours that model professionalism, positivity, and constructive techniques of communication.

If I come to work late with my hair all over my face with nail polish on and long nails and looking scruffy you know that is setting the scene. I think it is really important as a leader to set the scene, to look professional, behave professional. I let myself show my happiness to staff. (CNM 4)

CNMs adopt flexible styles of leadership because different situations require different responses to be effective. Coaching was the preferred style of leadership for participants, but challenging circumstances are an example of when management styles 
considered were those that gave the leader complete control. CNMs have strong interest in or concern for the needs of their nursing team and they like to role model expectations of behaviour. In addition to flexible leadership, being kind was identified a second subtheme of intentionality and describes how kindness is considered significant for encouraging positive workplace culture.

\subsubsection{Being kind}

Theme of being kind describes CNMs exercising gestures they thought would help team members to feel good about themselves and build healthy relationships that foster positive workplace culture. Being kind from the perception of CNMs is them communicating to other people, in particular nursing staff, a sense of comfort and belonging to that culture. And they convey this message through forms of perspectivetaking (see 4.5 Achieving perspective) and communication.

One participant perceived "kindness culture" (CNM 3) as a depiction of positive workplace culture. Another participant identifies kindness as appreciating and looking for the good in others despite dissimilarities; "respecting differences of people you know no one is the same" (CNM 6). Other gestures of being kind included forms of communication; "being mindful of what you say and how you say it and where you say it" (CNM 9); and acts of thoughtfulness "every week I do allocations for the weekend and I always write have a wonderful Sunday or happy Saturday or if it is a holiday, I just write awesome team I'll put it in a big bubble. (CNM 5)

In return CNMs were hopeful their acts of kindness would help them to be perceived by their nursing team as approachable and willing to listen "I need to know that when my door is open that they feel comfortable to walk in and not be hesitant about coming in and go oh my gosh I'm going to be growled at". (CNM 1)

Judging whether team culture is positive is stated to be obvious to participants when nursing staff are observed in the most difficult circumstances or when there is conflict in point of views or personal values. 
You could look at their face on the most stressful day and if you feel they are talking to their colleagues, they are trying to help others, they are trying to talk to the patient... that instantly tells me that there is some good healthy work culture. (CNM 7)

You just get a general sense as you walk out there. Is there a heaviness to the ward in regard to people not being chatty friendly, talkative, bubbly, all those sorts of things. You kind of pick it up that maybe somethings not right. (CNM 1)

Kindness is particularly valued for its impact on quality of patient care. "My greatest moments are not about the big resuscitations, they're about when I see one of my nurses reaching out and holding somebody's hand and just being in the moment with that patient". (CNM 3)

In summary of being kind, CNMs perceive kindness important for building positive workplace culture for encouraging people to be themselves in that environment, and to feel safe and comfortable while in that space. The last subtheme of intentionality is collegiality and describes strategies toward creating collaborative behaviour and development of nurses to enhance team functioning.

\subsubsection{Collegiality}

Collegiality was perceived important for positive workplace culture because for participants it meant that values within that environment are shared, and there is a supportive, respectful, and fair culture that encourages healthy socialisation and positive work ethic. Other descriptors of collegiality stated "cohesiveness" (CNM 1, 6), "teamwork" and "working side by side" (CNM 8), "speaking up" (CNM 1, 2), "work together as a team" (CNM 1, 10), "being supportive" and "well-functioning team" (CNM 10), "team mates", "same team" and "everyone's responsibility" (CNM 2)', "cohesive collegial teams" (CNM 3), "multidisciplinary team" and "collegial connectedness" (CNM 6), and "collective well-being" (CNM 4). 
Participants stated they deliberately do things to demonstrate to members of their team that they are of value and an important asset to the team. CNMs use incentives as a sign of gratitude and acknowledgment of staff efforts; "I do a fruity Friday [a basket of fruit every Friday of the week]. . . and that's kind of my way of saying look thank you for what you've done this week, you know l appreciate all of the work that you do" (CNM 9). These incentives can also be statements of recognition; “...we are not busy today, sort yourselves out put your names in a hat and one of you can leave here at quarter past two, half past two. Because that's all I can offer them [nurses]" (CNM 6).

Working together with staff as an equal despite hierarchy in the cooperate ladder was considered important for encouraging sense of value among staff and for building courage in staff's ability to advocate for what they thought was best for them, their workplace, and patients.

I think when nurses are challenging you there is no hierarchy there, and they are just going, hey look here is another nurse, we are on the same team. I have got a different idea and I am going to express that. I think that is a good thing. (CNM 2)

Staff opinions were considered important by participants for not only solving problems, but a way of generating leadership and accountability from their ideas. CNMs aim to build a team of leaders to save themselves work, but also to give the nursing team reason to become more engaged, feel trusted, and take ownership.

We just need to sometimes try to find how we get the best out of that person, what is it that makes them tick. It is my goal as charge nurse to try and find out what is it that makes them want to be the best they can. What makes them want to be working at the top of their scope. (CNM 2)

Nurses are encouraged to be autonomous and seek out own learning opportunities. But some CNMs purposefully identify what individual learning needs are and set up the space and structure needed to provide educational opportunities. Assigning staff to 
new experiences is intended to grow individual skill sets and build confidence within the group.

I will make sure I get the expert people out and doing other things and leave the least experienced people in the room for the whole day so that they amongst themselves can grow that confidence. Oh, we've got to do an ultrasound, um I don't know how to do it, well the three of you will figure out how to do it. And so, what that does in a team environment is allow for people to blossom and actually find out what they're capable of. (CNM 8)

To conclude, theme of intentionality is CNMs using leadership strategies that build cohesiveness among the team and creates positive working relationships at the benefit of workplace culture. Incentives and avoiding superiority were strategies CNMs used to show value toward members of their team. Generating leadership within the team and seeking out learning opportunities for staff was described to professionally develop individuals as well as keep them engaged.

\subsection{Chapter Summary}

This chapter has addressed the research objectives posed. That being to understand how CNMs build positive culture in their workplace and to identify leadership attributes and actions that they perceive to be important for generating positive workplace culture. Furthermore, identify the challenges of creating positive workplace culture. CNM's upskilled themselves to effectively manage people and the administrative responsibilities of the organisation. They meticulously made thoughtful decisions and are inclined to consider their horizontal and lateral team's perspectives with patient needs forefront in the process. Styles of leadership preferred are those that create sense of partnership and collaboration among the group, and kindness was perceived an important value. Positive workplace culture is perceived by CNMs as collegiality, and they have intentions of building collegial relationships through generating leadership within the team and seeking opportunities that values and develops staff to keep them engaged. In the following chapter, these themes will be discussed in the context of current literature and will include recommendations for the application of findings. 


\section{CHAPTER FIVE: DISCUSSION}

\subsection{Introduction}

In chapter four, the three themes of role preparation, achieving perspective, and intentionality were significant findings of this study. This research was conducted to understand how CNMs build positive culture in their workplace and to identify leadership attributes and actions that they perceive to be important for generating positive workplace culture. Furthermore, it aimed to identify the challenges of creating positive workplace culture in Aotearoa. The overarching finding is that CNMs deliberately engaged in strategies to build positive culture and the more prepared they were for their roles, the better equipped they were to do so. Role preparation relates to building knowledge and technical skills through various forms of education and practical experience to cope with realities of the CNM role. Achieving perspective is the strategy used by CNMs to understand other people's viewpoints, enabling them to make more holistic and effective decisions. Intentionality is also a purposeful action taken by CNMs to build collaboration and make team members feel valued and respected.

The purpose of this chapter is to describe the significance of these findings in view of current literature and to explore the potential clinical and educational implications these findings have for nurse leaders. Clinical and educational implications will be outlined in the recommendations section. Study strengths and limitations will also be acknowledged, and suggestions made for further research.

\subsection{Role Preparation}

As presented in the findings chapter CNMs felt inadequately prepared for their role. The following section will explore preparation of CNMs in the context of published literature. In particular this section sets out to highlight the significance management education and technical skill development are toward role preparation in the transition to CNM role. 


\subsubsection{Education development}

This study found no consistent approach to educating CNMs for ensuring their competence. No educational provisions are in place to ensure their ongoing development; but such provisions are essential for meeting the expanding and everchanging responsibilities that underpin the CNM role. While earlier literature forecasted an increase in nurse manager role responsibilities (Baumgardner et al., 1994a; Flarey, 1991) and the need for continuing education (Bauntgardner et al., 1994b; Tygart \& Vaughan-Wrobel, 1993), it is evident that current literature has not re-evaluated CNM role responsibilities or the content necessary for their educational preparation within a contemporary healthcare context. In clinical practice, frontline nurses have wellstructured career pathways that ensure ongoing competence and professional development expectations that are required by the NCNZ (2021). There are some requirements that are outlined by the NCNZ depending on which level of competence they sit (competent, proficient, or expert), but no national competency requirements for CNMs. CNM development is very much self-directed, and the Aotearoa nursing profession do not formally expect them to achieve specific management competencies. Minimum qualification sought to become a CNM is post graduate diploma and this is reflected in 90 percent of the population that has been explored.

In-house workshops on leadership were found to be useful for CNMs in this study, but information with a management focus is what they desired most in preparation. But even then, participants described exhausting leadership workshops offered by the organisation and were left with no education or professional development progress plan. The literature provides evidence that management training and experiential learning based programmes increase nurse manager competence and knowledge (Bauntgardner et al., 1994b). Two decades ago, head nurses and supervisors ( $N=63$ ) reported management topics to be most beneficial learning in preparation for their roles (Adams, 1991), and furthermore, senior managers (CEO's and nurse administrators $\mathrm{N}=297$ ) in another study by Tygart and Vaughan-Wrobel (1993) reported management knowledge and skills to increase their job satisfaction because it meant they could participate more fully in decisions (i.e. conflict management, time 
management, quality assistance, and standards and regulations). The literature is implying that nurses in management positions would be better prepared to assume their role if they acquired knowledge in relation to being a manager, not just a leader. This finding was also reflected among the study population explored.

CNMs with business/management qualifications at master's level were more confident in discussing positive culture and leadership strategies they used in comparison to CNMs with nursing as their primary degree. No literature was identified to compare business/management with nursing-based qualifications on management effectiveness in nursing. Although a review of literature by Cotterill-Walker (2012) found postgraduate nursing education at masters level associated with positive nursing outcomes such as confidence and self-esteem, growth and communication, increase in knowledge and analytical thinking, and improved decision making. Even though education at master's level was not shown to be directly linked to patient outcomes in this review of literature, education is shown to be important for providing nurses in leadership with the tools they needed to positively influence their followers who provided direct care to patient's (Laschinger \& Wong, 2013). In practice then when supporting clinical leaders, it is important that career planning and educational structure is put in place to help them achieve their goals. Information obtained through a performance appraisal is fundamental for providing foundation for training and development that keeps CNMs and frontline staff motivated and engaged.

Performance appraisal systems are effective for identifying and facilitating professional development opportunities. However, findings from this study identified that performance appraisals are not occurring on a regular basis for both CNMs and frontline healthcare staff. Not only do performance appraisals encourage nurses to take on new roles within the organisation, they can improve the quality of healthcare practice if performance is adequately and properly rewarded by organisational leaders (Choudhary \& Puranik, 2014; Metcalf, 2001). From a clinical leader perspective, performance appraisals provide an opportunity to minimise or remove performance deficiencies that are most important to maintain a quality nursing team (Metcalf, 2001). 
Inconsistency in a performance appraisal system, like the current approach, impacts CNMs and their managers ability to set shared expectations about performance, delays any modification of behaviour toward more effective habits, and furthermore interrupts career planning development that is most needed to prepare nurses and clinical leaders for new roles and responsibilities. Performance appraisals were considered an important tool for building moral and positive workplace culture by CNMs in this study. Technical skill development, which follows, also played a contributing role in the preparation of CNMs in this study.

\subsubsection{Technical skill development}

It was clear that many participants did not feel they had sufficient technical skills needed to perform management aspects of their role. Particularly with regard to business and financial processes, technological systems and software, and management of people. CNMs ( $N=12)$ in Agnew and Flin's (2014) study similarly reported that they were appointed with insufficient management skills. These researchers recommending business management skills be part of preparation for the CNM role. Cramer and Warshawsky (2019) also reported similar findings in their research using cross-sectional methods, where nurse managers $(\mathrm{N}=647)$ considered themselves to be least confident in organisational system competencies relating to finance, strategic management, and performance improvement; all are critical for leading transformation of healthcare organisation. On the other hand, nurse manager strengths in Cramer and Warshawsky's study included confidence in human resource management and technology. Outcomes that are inconsistent with findings from my study as CNMs described technology and managing people as challenging aspects of their role. Nonetheless it highlights that CNMs commonly lack management and business competencies.

Most participants had not anticipated a nurse management career pathway until they were placed into role of CNM. Evidence suggests that not anticipating a career in nursing administration and management is common, and so successful candidates find themselves taking management positions without being sufficiently prepared (Cathcart \& Greenspan, 2012; Chase, 2012). Part of the issue is institutions are not providing 
organisational climates that develop direct care nurses who in future may find an open door to management at their level in the organisation (Espinoza et al., 2009). As mentioned, performance appraisals can provide nurses who are interested in management an opportunity to share their aspirations so that clinical leaders are aware and can support them in what they need to prepare. Although when an employer does not value the same commitment of developing nurses into leaders and managers, preparing for management as a direct care nurse could prove more difficult, particularly for funding reimbursement. This highlights the importance of developing same values that are shared between CNMs and their employees.

A change in approach to the development of nurse managers may mean that those who hire CNMs consider looking beyond generic qualifications on nursing resumes. Determining if applicants have or are working toward business and management competence might make certain the right fit for the role. Journalist Kathleen Sanford (2011) who has experience in staff nursing, management, chief nurse executive, and administration, advocates management education for nurse leaders be augmented and tailored to cover topics specifically developed for individual managers or group of leaders, and be customised to learning needs of the leader. Management education has the potential to build business and management competencies for example planning and budgeting, organising and staffing, controlling and problem solving (Kotter, 1996). Competencies that participants in this study described being least confident.

Despite having management/business qualifications, CNMs still described transitioning into role of $\mathrm{CNM}$ a challenging time for them. Part of the problem was lack of one-toone support and "not knowing what they didn't know" when new and difficult situations arose. Participants described learning most of what they needed to know on the job, and they utilised what skills they had into their practice. According to the literature, learning by doing is effective for skill development. Using mixed method research, Lombardo et al. (1988) found that $70 \%$ of learning comes from challenging experiences. Furthermore $20 \%$ of learning comes from developmental relationships, and $10 \%$ comes from coursework and training. These findings are situated in the 1980's an era much 
different from today's context, nevertheless if this theory is to be considered in relation to CNMs, it means experiential learning is what predominantly drives the learning process and education only acts as a facilitator in the process. Therefore, a nurse who is highly qualified (clinical or business/management) may not mean that they are more competent than their colleague with a post graduate certificate and 20 years' experience. In support of this idea, Kuraoka (2019) used quantitative research methods to evaluate the relationship between experiential learning and nursing management competency. Findings of this research reported that concrete experiences, that is being involved in new experiences, a factor most related to nursing competency. Furthermore, experiencing the challenge of dealing with difficult tasks and struggling with new problems most important for competency development. Kouzes and Posner (2017) wrote a book about how leaders mobilise others to want to get extraordinary things done in organisations, quote leadership as an "observable pattern of practices and behaviours, and a definable set of skills and abilities. Any skill can be learned, strengthened, honed, and enhanced, given the motivation and desire, along with practice, feedback, role models, and coaching" (p.302). From this body of evidence, experiential learning is most important in preparation for role given the appropriate support. This happened to be the case among participants in this study, although the problem was, they felt unsupported during transition to CNM. They described it "a lonely time" for them, feeling like they were "thrown in" to role and expected to "learn to fly" on their own.

If healthcare institutions depend on clinical leaders to fully support their goals, CNMs need to be supported, provided feedback, and mentored into positions of management so that they can become a better leader and manager, because this is where CNMs described feeling most unprepared.

\subsection{Achieving Perspective}

The emergence of this research finding was based on descriptions of how participants endeavour to balance attention of both self-interest and interests of their team. 
Implications of this theme that will be discussed are intelligence (social and emotional) and role modelling, beginning with the concept of empathy.

\subsubsection{Empathy}

Perspective taking is positioned in empathy which effectively means adopting the psychological view of people by "understanding, being aware of, being sensitive to, and vicariously experiencing the feelings, thoughts, and experience of another" (MerriamWebster Online Dictionary, 2020). Empathy forms the basis of how people form connectedness to one another, and as a caring profession is the foundation of nursing care. Thus, nurses and leaders in health need to be able to imagine themselves in situations of other people to fully understand what people are experiencing, because this is what develops the innate desire to want to respond with facilitative acts (TodaroFranceschi, 2019). Patterson (2018) describes empathy as three states of mind, each with their own interpretation of perspective taking. These are affective, compassionate, and cognitive understanding. Affective understanding involves feeling another person's emotional state and reacting in a way that is appropriate to the situation. Compassionate understanding involves feeling the feelings of another and communicating appropriate behaviour (verbal and non-verbal) of genuine concern. This discussion will focus on cognitive understanding, a process of thought about how others may be thinking and feeling and in particular how CNMs used cognitive understanding to determine what they could do to help in situations of perspective taking.

Generally agreed within the literature is that perspective taking is a cognitive or intellectual process that results in an affective (reactive) response of empathy (Axtell \& Parker, 2001; Patterson, 2018). For empathy to occur, the individual experiencing it, which in this case is nursing staff of CNMs, must know that it is happening and the empathiser (CNM) must have some understanding of what their staff are feeling (Hoffman, 1975). The assumption then is that regardless of one's developmental level of empathy, empathetic experience will vary depending on one's cognitive appraisal of the situation (Axtell \& Parker, 2001). What this means is as CNMs are attempting to understand the thoughts of their nursing team, more inclined are they to lead 
empathetically with capacity to understand their feelings and needs, communicate with them effectively, and build successful relationships that lead to positive culture.

When CNMs make decisions, they are condensing several factors into one that balances the needs and wellbeing of everyone within that culture, and individuals different goals, perspectives, and motivations. Thinking about what is best for others as well as themselves aligns with Batson's (2009) theory of cognitive empathy. In this theory perspective taking is separated into internal perspective taking processes of imaging how the 'other person' or group of people would feel, and imaging how 'one-self' would feel. There is an argument that positions an individual's capacity to be self-aware and relate to others by gaining perspective as a higher level of cognitive functioning (Axtell \& Parker, 2001). Both empathy and perspective taking have been linked to social intelligence and emotional intelligence (Civelek et al., 2018; Goleman, 1995). How they link to leadership practice of CNMs, and workplace culture follows.

\subsubsection{Social Intelligence and Emotional Intelligence}

Social Intelligence (SI) and emotional Intelligence (EI) are different constructs of intelligence with some overlaps. Empathy (also acknowledged in literature as cognitive empathy) is one of four constructs that make up SI, coupled with social skills, situational awareness, and situational response. In Rahim's (2014) study exploring relationships between $\mathrm{SI}$ and creative performance among business students, $\mathrm{SI}$ is defined as;

"the ability to be aware of relevant social situational contexts; to deal with the contexts or challenges effectively; to understand others concerns, feelings and emotional states; and to speak in a clear and convincing manner knowing what to say, when to say it and how to say it and to build and maintain positive relationships with others" (p.46).

Cognitive empathy and reacting with positive social skills influence better management in more stressful situations, such as conflict resolution (D'Souza \& D'Souza, 2013; Flynn \& Grubaugh, 2018), problem solving and negotiation (Barry et al., 2005). Understanding how others feel is only part of empathy in $\mathrm{SI}$, as the right social skills are needed to be 
effective an empathising. Situational awareness and situational response are two further constructs of SI that together are said to give leaders the ability to successfully collect and use information to make effective decisions (Civelek et al., 2018). SI was not measured among participants for the purpose of this study and so it cannot be assumed that participants in this study are a representation of SI. Although by perspective taking and responding appropriately in a way that is perceived by others as being sensitive to what their needs are; they are intelligently role modelling positive social skills that will prompt their team to mirror same skills that build positive workplace culture.

Like SI, El is perceived as a form of perspective taking. Mayer and Salovey (1990) who first constructed El define it as "an ability to monitor one's own and other's feelings and emotions, to discriminate among them, and to use this information to guide one's thinking and actions" (p.189). Later Goleman (1995) popularised Mayer and Salovey's theory with five dispositions of El. Empathy being one of those dispositions along with self-awareness, self-regulation, motivation, and social skills. The study of El in nursing research has increased because of its perceived importance in increasing aptitude to cope with various situation's (Bar-On et al., 2003), and has been linked to multiple outcomes such as performance and organisational citizenship (Côté \& Miners, 2006), and nursing leadership (Codier et al., 2011; Echevarria et al., 2017). In a quantitative study examining the relationship between Western Australian nurse managers $(N=96)$ self-assessed empathy, and leadership behaviours and work satisfaction as rated by their subordinates $(N=563)$, Skinner and Spurgeon's (2005) found that when staff perceived their manager to possess a range of empathetic traits, namely empathetic concern, perspective taking, and empathetic matching, they were more likely to feel satisfied in their work and inspired to achieve beyond normal workplace expectations.

Therefore, when CNMs practice empathy they have greater capacity to identify, understand, and communicate in a way that is perceived by their staff as being sensitive to what their needs are. As a result of feeling understood, staff feel as if they want to positively contribute to the workplace which in turn builds positive workplace culture. 
The last key point of perspective taking is participants reference to keeping their own personal and professional values forefront to their leadership behaviour.

\subsubsection{Role modelling values}

Authenticity and having a solid foundation of clearly articulated values was important for participants in this research. Values acted like an internal compass which guided thinking and actions of CNMs. They liked to role model what their personal and professional values were with an expectation that this would then shape how people behaved within that culture. Kouzes and Posner (2017) argue that effective leadership involves first being clear about what our own guiding principles are before expecting others to follow same lead. The authors stress the importance of understanding personal values as well as the values of employees to build productive and genuine working relationships.

"When leaders do not understand their own personal leadership philosophy, their communication and actions can be confusing. Furthermore, if their leadership philosophy is not clear, their team will not know what values and beliefs should guide their actions when encountering daily challenges. This confusion will lead to low levels of team commitment, as people are not able to either identify with or support the leader's values" (p.50).

Popular leadership theories that dominate in nursing leadership are values-based theories. These include transformational leadership (Black-Arias, 2015; Boldy et al., 2013; El Amouri \& O’Neill, 2014; Kallas, 2014; Sellars, 2012), authentic leadership (Kramer et al., 2010), and ethical leadership (Atashzadeh-Shoorideh \& BarkhordariSharifabad, 2018). Values-based leadership has been linked to empowerment and job satisfaction, increased wellbeing of staff and less burnout, trust and enabling staff to voice concerns, interprofessional working and collaboration, and positive patient outcomes (Bennett et al., 2021). Having a clear understanding of values help to inform the strategic direction and the intentional actions of CNMs. 


\subsection{Intentionality}

Participants constructed mental ideas of how they wanted their workplace to function, and they deliberately drew upon leadership techniques that they believed would be effective in creating and sustaining healthy working relationships. Purposeful actions CNMs used to enhance workplace culture determined the underlying meaning to this theme. There are two aspects of CNMs intentionality to discuss, flexible leadership and accountability.

\subsubsection{Flexible leadership}

Different situations called for different types of leadership behaviour for participants in this study. This finding correlates with other studies exploring the association leadership style (behaviour) has with safety outcomes of staff and patients (Agnew \& Flin, 2014), departmental success and employee satisfaction (Isola et al., 2013). O'Neil (2011) says that there is no single formula that can be applied to every person in positions of leadership, and that managers must be able to change their behaviour in order to adapt to the constantly changing healthcare environment. What is important is that nurses who move into management roles do so with fluidity (Yoder-Wise, 2019), meaning with grace and ease. Learning and developing skills should then be a continuous process for managers whereby each will develop his or her own individual style but will continue to improve his or her abilities in order to make better decisions that benefit the organisational and societal context.

There are so many leadership styles, theories, and approaches (Ahmed et al., 2016) that it can become confusing to distinguish one from the other. This could explain why over half of CNMs in this research did not have a specific leadership approach that they could identify with. However, when participants were asked to specify leadership qualities considered successful in leading positive workplace culture, effortlessly they articulated various leadership skills (e.g. listening, being friendly, honest, transparent, role modelling, being available, empathetic, having clear expectations, decisiveness, confidentiality, clear communication, being a facilitator, being practical, being able to engage, having enjoyment, being diplomatic, able to prioritise, being fair, 
understanding, non-judgemental, an investigator, an influencer, good with people, and good follower). An indication that most CNMs are more concerned with 'things they do' to promote positive relationships between themselves and staff rather than adopting actual leadership philosophies.

In a mixed method study, CNMs ( $\mathrm{N}=15)$ reported using different styles of leadership (Agnew \& Flin, 2014). Task focussed behaviours (clarifying roles, monitoring operations, short term planning) were used in demanding situations, and relations behaviours (consulting, supporting, recognising, developing, empowering) and change behaviours (envisioning change, taking risks for change, encouraging innovative thinking, external monitoring, leading by example) to improve safety outcomes. Furthermore, in Wong's (2015) summary of evidence, positive outcomes of task-orientated behaviour, as mentioned, were found related to family satisfaction with care, meanwhile transactional behaviour which focusses on tasks and rewards was found to increase patient satisfaction. From this mixed result, Wong identified that leaders who communicate clear standards and performance expectations in addition to promoting positive team working relationships, also increase patient satisfaction.

Although in context of highly stressful environments where patient care can be extremely demanding and life threatening such as the emergency department, intensive care, or critical care, based on Wong's conclusion, it could be that task orientated behaviour is used more often than relations behaviour. Resulting in tasks being prioritised over the emotional needs of staff contributing to the current reports of fatigue, moral distress, and lower rates of engagement (Butler et al., 2014). As a solution Atashzadeh-Shoorideh et al., (2019) recommend nurse leaders use a combination of transformational (relational) and transactional (task-orientated and rewards) leadership for improving job satisfaction and quality of nursing services. One way of combining the two could include the use of coaching which was described by participants as a common leadership technique they used to build positive workplace culture. 
Coaching is a newer concept in nursing, but not in leadership and management. It is designed to build leadership abilities that enhance job performance and professional development (Abel \& Nair, 2015) by facilitating individuals to think about how they might work and behave differently (Wakefield, 2006). In an article about the role of coaching in leadership development, Yarborough (2018) maintains that coaching can help leaders learn how to reflect on their experience, extract insights, and use those insights to inform their leadership practice. CNMs in this study liked the idea of generating leadership within their team and building a team that wanted to see change. And they used coaching as their way of creating this vision, through supportive behaviour, guidance in finding answers, assisting staff through performance issues, collaborating with individuals to problem solve, encouraging autonomous practice, using appropriate communication, and facilitating decisions. They described coaching as a process of encouraging individuals within their team to come up with solutions for themselves as opposed to providing the answers.

In contrast, whilst coaching may seem a relatively straight forward approach, managers are finding it hard to find the time to coach given the multiple demands of a manager (Goleman, 2000). Particularly when interfering with bottom line performance targets and management reporting for CNMs. Ladyshewsky (2010) advises first strengthening the relationship with staff through trust building, shared values, El, and performance management processes for coaching to be successful on outcomes. As CNMs continue to build leadership in their team and encourage autonomy, they are essentially fostering a culture of accountability as staff learn to take responsibility for their own thinking and practice.

\subsubsection{Accountability}

The principle of accountability is ethically positioned where individuals within a group answer for their behaviour and decisions and accept responsibility for their actions. Krautscheid (2014) provides a more comprehensive definition of nursing accountability which denotes that by nurses accepting responsibility for their actions, they develop strong personal commitment to achieve professional expectations, develop desire to 
learn, and are ready to accept ownership for their work as they uphold nursing standards and performance. Where CNMs fit in this representation of accountability is their position in power. They have the ability to normalise appropriate behaviour in their workplace by rewarding ethical behaviour, but also identifying and managing and when necessary disciplining unethical conduct (Njoroge et al., 2014). Furthermore they can foster climates that encourage education, manageable targets and expectations, and provide adequate resources (Garcia-Capilla et al., 2020) that will enable nurses to safely function in climates that will not distract them from making good decisions. By deliberately choosing leadership strategies that role models expectations, enhance autonomy and self-leadership, and reward positive behaviour, CNMs in this study are building positive culture by generating accountability within their team.

Demonstrating value for ethics and accountability as a manager can create climates where self-reporting and speaking up is encouraged. CNMs need to know if, where, and when problems exist so that they can essentially deal with concerns as they emerge to maintain positive culture and ultimately patient safety. Yet managers need people in the know to speak out. For this to happen frontline nurses need to feel valued and confident in themselves before they may be willing to share with others how they feel (O'Hagan \& Persaud, 2009). More emphasis on ethical leadership may proceed this motion. Atashzadeh-Shoorideh and Barkhordari-Sharifabad (2018) in their study about outcomes of ethical leadership describe it as:

"creating and supporting an environment that ensures individuals practice ethical behaviour. Determining, analysing, and accommodating between fundamental values of nursing and nursing behaviour, and showing ethical commitment to respecting the nurses and behaving toward them on the basis of justice and empathy" (p.1052).

Positive outcomes linked to ethical climates include decrease in frequency and intensity of moral distress (Bell \& Breslin, 2008), effects toward reduced turnover rates (Isoaho et al., 2015; Yemi-Sofumade, 2012), organisational commitment (Huang \& Tsai, 2008), increased performance and job satisfaction (Huang \& Tsai, 2008; Isoaho et al., 2015), 
organisational citizenship behaviours (Huang et al., 2012), wellbeing and psychological empowerment (Rantika \& Yustina, 2017). The body of knowledge is suggesting that if CNMs demonstrate ethical expectations, empower ethical behaviour, and hold their nursing team accountable for their own performance, more or less are they empowering their team with courage needed to be heard.

What we do not want to see are consequences of cultures of silence where people are reluctant to speak out. CNMs are accountable to their staff and have a moral and ethical obligation to act in good faith, yet there continues to be issues of workplace bullying and incivility among the nursing profession (An \& Kang, 2016; Dawson et al., 2015; Etienne, 2014; Fang et al., 2016). Quite simply if managers are not aware of the problems that exist within their department, what we are seeing are toxic workplace cultures from the effects of people who are frightened to share their ideas and concerns in fear of being rejected, blamed, or intimidated. These behaviours negatively affect workplace culture and can hinder safe patient care.

\subsection{Recommendations}

The premise for this thesis was that the leadership of CNMs plays a contributing factor toward workplace culture, important for nurse satisfaction and quality of patient care. To prepare and develop nurses into leadership positions, it is important that organisation leadership teams actively equipped them with the right management tools to confidently lead people toward successful outcomes for the organisation and patients.

Three main recommendations have emerged from this research study:

1. It is recommended that all CNMs in Aotearoa receive specific educational preparation for their roles.

2. Structured orientation and mentorship packages should be developed for CNMs in Aotearoa. 
3. It is recommended that performance appraisals are conducted habitually with CNMs and that CNMs are supported in best practice when undertaking appraisals with their nursing teams.

Each recommendation will now be discussed in greater detail.

Prescriptive educational prerequisites could be considered when hiring nurses for the CNM role. It became clear in this study the difference in confidence participants with business/management knowledge had compared to participants with nursing as their primary degree. A recommendation from this research is that CNMs undertake post graduate education that covers management and business functions such as managing resources, rostering, budgeting, and managing people. This should be done at the beginning, if not before transition so that nurses moving into clinical management are provided with confidence to be proficient in these responsibilities. The organisation could collaborate with local tertiary institutions to devise customised education pathways fit for all levels of nursing management from beginner to experienced. Because of the various levels of experience and education of CNMs in this study, varying education needs exist among CNM individuals. For example, CNMs from larger hospitals may require management skills different from those needed by CNMs with fewer employees in smaller hospitals. Programmes could be tailored to suit individual learning needs to assume longevity of learning and professional development. Organisations can begin by providing education programmes similar to that of Baumgardner et al., (1994) with theoretical, hands-on, and individualised training that covers organisation specific processes that CNMs in this study would have like more knowledge about.

Formal structured orientation programmes and mentoring relationships should be established for new CNMs. And mentors need to be provided with sufficient training and one-on-one time from their own schedules to cater for facilitative learning of CNMs as they transition. There ought to be consistency in CNM development, and nurses need to feel supported during this process. Effective mentoring can facilitate this process of learning and support. 
Senior management need to ensure they are undertaking regular performance appraisals with CNMs, and furthermore they need to support CNMs in best practice when conducting performance appraisals with their nursing teams. The appraisal meeting is an opportunity for nurses to express their needs and concerns and discuss their career aspirations. Information obtained through performance appraisals will provide a foundation for training and development that is needed to keep nurses motivated and engaged in their workplace. Furthermore, participating in performance appraisals will provide direct care nurses the opportunity to share and prepare themselves for future management roles.

\subsection{Strengths and Limitations}

The choice of qualitative description has allowed the researcher to provide a comprehensive summary from CNMs perspectives their view of leading positive workplace culture, a topic that has not yet been explored within Aotearoa. This research describes first-hand leadership attributes and actions that CNMs in Aotearoa employ to foster positive workplace culture and the common challenges that occur when creating positive workplace culture. Furthermore, recommendations for practice that come directly from leaders who directly manage frontline healthcare teams have been devised. This addresses the gap in knowledge about how CNMs build and maintain positive workplace culture in Aotearoa.

This study used participants from a variety of clinical departments, each with unique patient conditions, acuities, specialised medical and nursing staff, and equipment making the management of cultural difference inevitable. Although responsibility and accountability of managers in this research are alike, they are managing teams that are coping with individualized pressures in response to their particular clinical areas and level of care. The advantage of having CNMs from a range of diverse clinical areas enhances the transferability of findings to other hospitals in Aotearoa.

Some limitations should be noted. First the researcher is assuming that participants within this study are fostering a positive workplace culture, and that the leadership 
intention of CNMs do lead to happy and motivated teams. What cannot be known from this research is if CNMs actions directly impact on positive workplace culture or if nurses feel that CNMs do foster such a culture. However, the intention of this research was to understand from a CNM perspective how they went about building positive workplace culture. Understanding other points of view and perspectives can be explored in future research.

Second, as participation in this research was voluntary, this may have increased the risk for self-selection bias as CNMs decided entirely for themselves whether or not they wanted to participant based on their interest in the research topic. Purposive sampling was criterion of gaining ethics approval and so recruitment based on self-interest to the topic was unavoidable. However, option to participate was offered to all CNMs within the research site to include the total population. This needs to be taken into consideration throughout evaluation of findings.

Third, inclusion criteria for this study were CNMs from a hospital setting. There are some limitations to this as it means that research findings from this research cannot be applied to another CNM group, such as those within the community, rest home, or tertiary hospital setting. For transferability to occur, readers must consider some similarity in the population of interest and understand the contexts in which these research results were influenced.

\subsection{Future Research}

The findings of this research identified from the perspective of CNMs leadership attributes and actions that they perceived to be important for generating positive workplace culture. Furthermore, the challenges of creating positive workplace culture in Aotearoa. This research is limited to $10 \mathrm{CNMs}$ within a secondary hospital setting. A Delphi study across Aotearoa should be undertaken to determine other expert CNM opinions on leading positive workplace culture, challenges they face, and any further leadership strategies they consider to be effective and not considered by participants within this study. CNMs should come from a variety of contexts for example tertiary 
level hospitals, mental health (community and inpatient), community practices (district nursing and general practice), or rest home facilities. Further research in these areas will establish common attributes of CNMs that drive culture in a variety of contexts within our current healthcare climate.

As this study is assuming CNM participants are leading workplace culture, further research could undertake a qualitative study with respective staff of CNMs to understand CNMs teams' perspectives on leadership in relation to workplace culture.

\subsection{Conclusion}

This research sought to understand how CNMs build positive culture in their workplace and to identify leadership attributes and actions that they perceive to be important for generating positive workplace culture. Furthermore, it aimed to identify the challenges of creating positive workplace culture in Aotearoa. Ten clinical nurse managers from Aotearoa participated in semi structured face-to-face interviews. Knowledge was generated using thematic analysis. This research adds significant value to the current body of knowledge important attributes that CNMs feel are necessary in their role for leading positive workplace culture working in a secondary hospital within Aotearoa.

It is the content of postgraduate education CNMs have along with their personal experiences that provides them with knowledge and skills to positively influence their followers and workplace culture. Perspective taking enables CNMs to foster understanding that is sensitive to the needs of others, and shared values are made known by role modelling expectations. CNMs use various leadership behaviour, whilst coaching is an effective approach used to generate accountability and leadership within the teams functioning.

Strengths and limitations have been outlined. Recommendations for improvement are aimed at refining aspects of education, mentorship, and performance appraisals with the intention of enhancing positive workplace culture. 
It is important that CNMs, nurses in leadership, and senior management read this research so that they understand processes taken to establish positive workplace culture in busy healthcare environments in Aotearoa. CNMs are pivotal for shaping level of enjoyment, working relationships, and working processes that influence quality of care. This research provides strategies to best support CNMs in their role so that they can provide the environmental structure frontline healthcare teams need to provide desired outcomes. 


\section{APPENDICIES}

Appendix 1 - Recruitment Email

\section{Attention CLINICAL NURSE MANAGERS}

\section{I need your experience in leading}

\section{workplace culture}

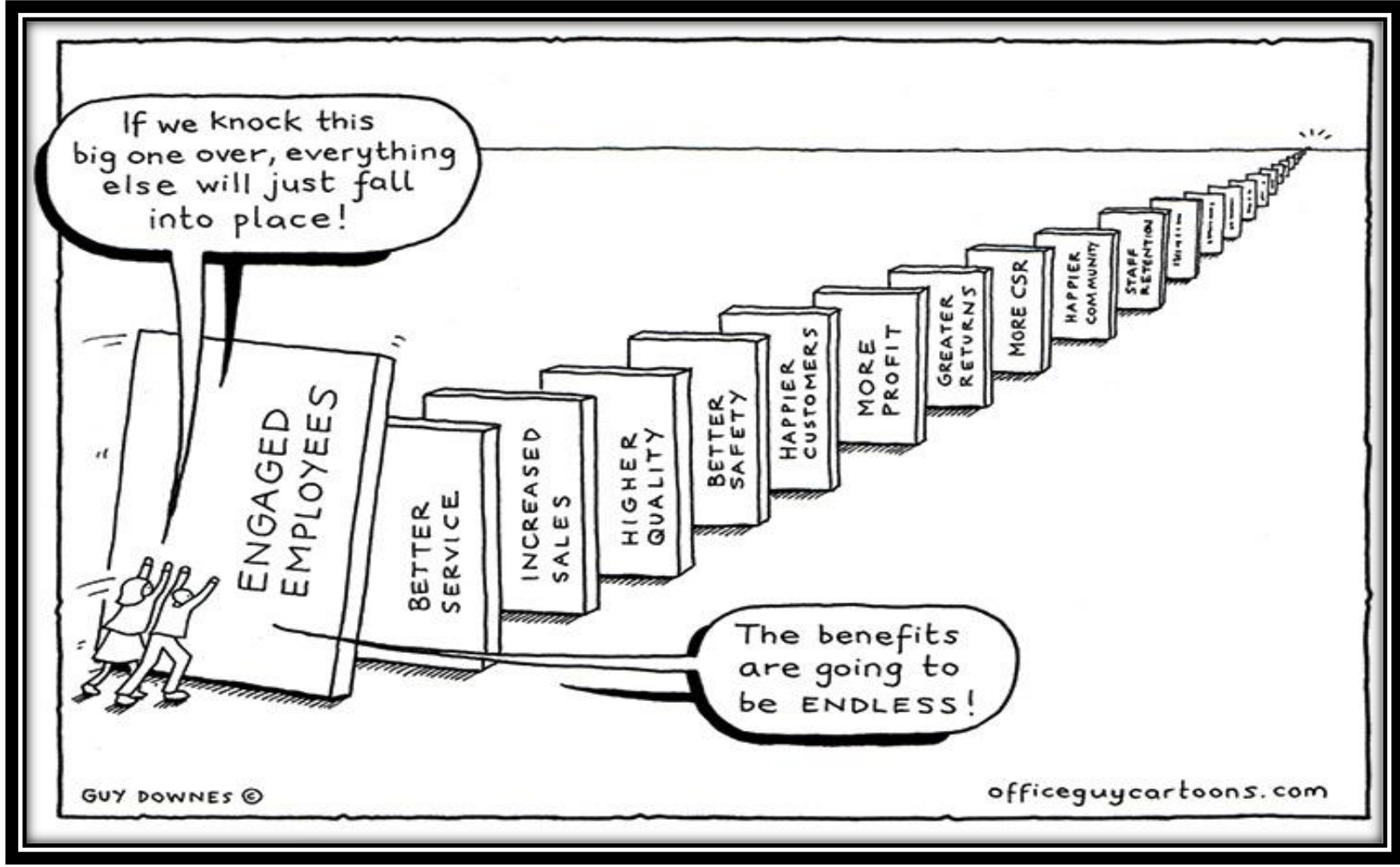

My name is Krystle Graham. I am a registered nurse working toward my master's research project on workplace culture in nursing. I am inviting Clinical Nurse Mangers from Tauranga Hospital to share their views of leading workplace culture.

Your perspectives are key to my research so I would love to hear from you!

If you are interested in taking part or would like more information, please email me @ or phone/text/chat 


\section{Why you?}

Nursing in New Zealand and across the globe are faced with similar challenges as the context of healthcare continues to change and evolve. Clinical nurse managers are positive change agents in creating effective working environments that can influence healthcare delivery and organisational outcomes. You are the driving force of leading positive workplace culture yet there is lack of research on what is practically done to generate positive workplace culture or indeed what challenges are faced in doing so from the lens of clinical nurse managers. Your perspectives can establish any barriers as well as enablers of generating positive workplace culture from a leadership perspective. In turn findings can be usefully resourced to devise leadership strategies attentive to nursing staff needs.

And so, your experience and your perspectives are valuable for informing what we do not know.

\section{Why is this research significant?}

- No research yet asks clinical nurse managers their perspectives of creating positive workplace culture. This research will address this gap

- Clinical nurse managers are the pivotal link between higher board executives and day-today needs of their staff, yet little research has explored their experiences and if any their challenges in leading positive culture

- More research would benefit capturing verbal data (Qualitative research) that can produce a clearer picture that reflects true experiences of clinical nurse managers in their natural environment

- There is need to take into consideration environmental context of nurse managers to fully understand nursing leadership in its entirety

- Nursing leadership has been researched internationally, however majority done overseas as opposed to NZ

- Not only is NZ research valuable being geographically distant from other parts of the world, but culture is inspired by a mix of indigenous Maori unique to NZ

\section{What are the research objectives?}

1. Describe the attributes of positive workplace culture from clinical nurse managers perspective

2. Understand the actions clinical nurse managers take to establish positive workplace culture

3. Describe the challenges nurse managers face in creating positive workplace culture

It is your view that will be key to success of this research and means of having your experience heard!!

I will work hard around your busy schedule to ensure this research does not impact your professional or personal lifestyle.

I am more than happy to discuss any questions you may have about the study and your involvement as a participant. Otherwise please contact me if you are interested or not interested. I look forward to your response.

Krystle Graham 


\section{Appendix 2 - Semi Structured Interview Guide}

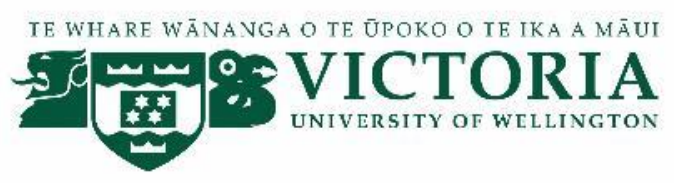

Graduate School of Nursing, Midwifery and Health

\section{SEMI-STRUCTURED INTERVIEW QUESTIONS - Participant copy}

\section{Demographics:}

1. Is English your preferred language to part take in this interview?

2. What is your age?

3. What is your gender?

4. Can you tell me which ethnic group or groups you belong to?

5. What is your highest level of nursing education?

\section{Professional characteristics:}

1. How long have you been nursing?

2. When did you start your current role as clinical nurse manager?

3. What clinical area do you manage?

4. How many nursing staff are you responsible for?

5. Have you worked as a clinical nurse manager prior to this role?

6. Did you receive any management training for your role?

\section{Questions about leading workplace culture:}

1. What does positive workplace culture look like to you?

2. What leadership qualities do you feel are essential in leading positive workplace culture?

3. How do you create a positive workplace culture in your ward or unit?

4. Do you have a preferred leadership approach you find most effective for leading positive culture? And how do you determine that approach is successful?

5. Can you describe if any the challenges of leading positive workplace culture?

6. What aspects of your role do you find most satisfying? 


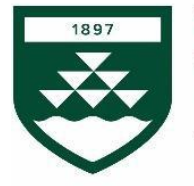

VICTORIA UNIVERSITY OF WELLINGTON

TE HERENGA WAKA

\begin{tabular}{|c|c|}
\hline TO & Krystle-Lee Graham \\
\hline FROM & $\begin{array}{l}\text { Associate Professor Judith Loveridge, Convenor, Human Ethics } \\
\text { Committee }\end{array}$ \\
\hline DATE & 22 November 2019 \\
\hline PAGES & 1 \\
\hline \multirow[t]{2}{*}{ SUBJECT } & Ethics Approval Number: 27985 \\
\hline & $\begin{array}{l}\text { Title: Leadership toward positive workplace culture in } \\
\text { Aotearoa New Zealand: Clinical nurse manager perspectives }\end{array}$ \\
\hline
\end{tabular}

Thank you for your application for ethical approval, which has now been considered by the Human Ethics Committee.

Your application has been approved from the above date and this approval is valid for three years. If your data collection is not completed by this date you should apply to the Human Ethics Committee for an extension to this approval. 


\section{Appendix 4 - Locality Consent to Conduct Research}

Krystle-Lee Graham

7 Nov 2019

Dear Krystle-Lee

Study Ref: 2019-3

RE: Attributes of positive workplace culture: Clinical nurse manager perspectives

I am pleased to advise that this research application has been authorised to be conducted within the District Health Board ( DHB).

It is your responsibility to ensure that your research is conducted in accordance with the DHB research policy. The Research policy is available under the Controlled Documents section on OnePlace, and can also be accessed via the DHB Research OnePlace page

As a condition of this authorisation, you are required to:

(i) inform the Research Office of the start and stop dates of your project.

(ii) contact the Research Office if there are any changes to your study protocol; and

(iii) provide a copy of the final study outcomes or report once your research has been completed.

Please contact the Research Office by email at research@ dhb.govt.nz.

Please do not hesitate to contact the Research Office for further information about your application. We wish you all the best for yourstudy.

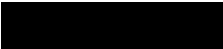

Clinical School Coordinator

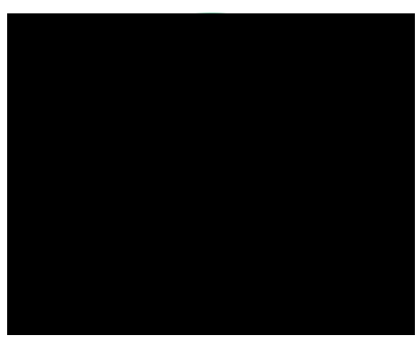




\section{Appendix 5 - Participant Information Sheet}

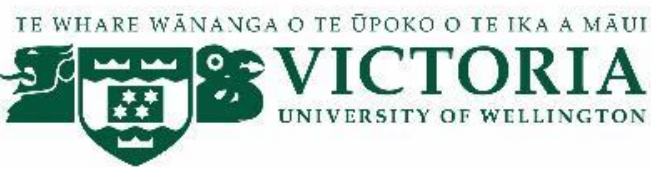

\section{Leading positive workplace culture: Clinical Nurse Manager perspectives - PARTICIPANT INFORMATION SHEET}

You are invited to take part in this research. Please read this information before deciding whether or not to take part. If you decide to participate, thank you. If you decide not to participate, thank you for considering this request.

\section{Who am I?}

My name is Krystle Graham and I am a master's student in the graduate School of Nursing, Midwifery and Health at Victoria University of Wellington. This research project is work towards my thesis.

\section{What is the aim of the project?}

This project aims to explore Clinical Nurse Managers perspectives of leading workplace culture. This research has been approved by the Victoria University of Wellington Human Ethics Committee (application reference number 27985), Bay of Plenty District Health Board and endorsed by Toi Ora Maori health gains and development of behalf of 18 Iwi.

\section{How can you help?}

You have been invited to participate as a clinical nurse manager. If you agree to take part, I will interview you in what I define as a 'safe space' that best suits you. I will ask you questions about leading workplace culture. The interview is expected to take 30 to 60 minutes. I will audio record the interview with your permission and transcribe (write it up) later. You can choose to not answer any question or stop the interview at any time, without giving a reason. You can withdraw from the study by contacting me any time before or up to two weeks following interview. If you withdraw, the information you provided will be destroyed or returned to you.

\section{What will happen to the information you give?}

This research is confidential. This means that the researchers named below will be aware of your identity, but research data will be combined which means your identity will not be revealed in any reports, presentations, or public documentation. 
Only my supervisor and I will read notes and transcript of the interview. Transcripts, summaries, and any recordings relating to you and your experience will be pseudonymised to ensure confidentiality. Data will be kept securely and destroyed 5 years from date of thesis completion.

\section{What will the project produce?}

Information from my research will be used for my master's thesis, academic presentations and/or academic publication and/or presented to conferences.

\section{If you accept this invitation, what are your rights as a research participant?}

You do not have to accept this invitation. If you do decide to participate, you have the right to:

- $\quad$ choose not to answer any question;

- $\quad$ ask for the recorder to be turned off at any time during the interview;

- $\quad$ withdraw from the study before and up to 2 weeks following interview;

- $\quad$ ask any questions about the study at any time;

- $\quad$ receive a copy of your interview transcript;

- be able to read any reports involving yourself of this research by emailing the researcher to request a copy.

\section{If you have any questions or problems, who can you contact?}

If you have any questions, either now or in the future, please feel free to contact me or my supervisor.

\begin{tabular}{|l|l|}
\hline Principle Researcher & Contact Information \\
\hline Krystle Graham & Email: \\
Registered Nurse & \\
BN, PG Dip Nurs science & \\
\hline Supervisor & \\
\hline Helen Rook & Phone: \\
Lecturer & Email: \\
Graduate School of Nursing, & \\
Midwifery and Health. Victoria & \\
University of Wellington. & \\
\hline
\end{tabular}

\section{Human Ethics Committee information}

If you have any concerns about the ethical conduct of the research, you may contact the Victoria University HEC Convenor: Dr Judith Loveridge. Email hec@vuw.ac.nz or telephone 


\section{Appendix 6 - Participant Consent Form}

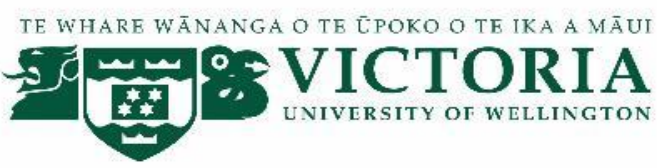

Graduate School of Nursing, Midwifery and Health

\section{Leading positive workplace culture: Clinical Nurse Manager perspectives - CONSENT TO INTERVIEW}

\begin{tabular}{|l|l|}
\hline Principle Researcher & Contact Information \\
\hline Krystle Graham & Phone: \\
Registered Nurse & Email: \\
BN, PG Dip Nurs science & \\
\hline Supervisor & Phone: \\
\hline Helen Rook & Email: \\
Lecturer & \\
Graduate School of Nursing, & \\
Midwifery and Health. Victoria & \\
University of Wellington. & \\
\hline
\end{tabular}

- I have read the Information Sheet for clinical nurse managers taking part in the study designed to explore leadership experiences of workplace culture. My questions have been answered to my satisfaction. I understand that I can ask further questions at any time YES/NO

- I agree to take part in audio recorded interview.

YES/NO

I understand that:

- I may withdraw from the study by contacting the researcher at any time before up to two weeks post interview date and any information that I have provided will be returned to me or destroyed.

YES/NO

- This consent and information I provide for the study will be destroyed five years from date of thesis completion.

YES/NO

- Any information I provide (e.g. interview recordings, notes, research data) will be kept confidential to the researcher and research supervisor.

YES/NO 
- I understand that results from my interview will be used for a master's thesis and/or presented at conferences.

- I understand that organisational consent has been provided and the organisation will not be named in any of the reports.

YES/NO

- My name will not be used in reports and utmost care will be taken not to disclose any information that would identify me.

YES/NO

- I would like a copy of the transcript of my interview

YES/NO

- I would like to receive a copy of the final report and have added my email address below

YES/NO

Declaration by participant: I hereby consent to take part in this study

Participant's name:

Signature of participant:

Date:

Contact phone number:

Email:

Declaration by researcher: I have given the participant a written information sheet and a verbal explanation of the study. I have answered questions the participant has about the study and believe the participant understands the study and has given informed consent to participate.

Researcher's name:

Signature of researcher:

Date: 


\section{Appendix 7 - Maori Health Advisory Committee Approval}

10 December 2019

\section{Krystle-Lee Graham}

Study Title Name: Leadership toward positive workplace culture in Aotearoa New Zealand: Clinical nurse manager perspectives

Tēnā koe

Your application has been endorsed by Manukua Executive Director Development on behalf of the 18 iwi of Māori Health Gainsand Health Board.

All health research conducted in New Zealand and within is of relevance to Māori.

As a Treaty partner and a priority population Māori involvement in health research is critical because Māori are disproportionately represented in the majority of health and wellbeing statistics Māori Health Gains and Development recommends you utilise the Guidelines for Researchers on Health Research Involving Māori (2010) to assist you in planning and conducting your research project in aculturally sensitive, safe, and responsive way.

Please provide a summary of your research findings and recommendations at the completion of your work to Māori Health Gains and Development by submitting your summary via our OnePlace page. The summary should include your analysis of the data by ethnicity, age, deprivation with a focus on any Maori Health themes that may be relevant. You may be invited to present your findings in person to Kaumatua (Māori Elders Council).

Nāku noa, nā

\section{Pou Haumanu - Clinical Director | Mãori Health Gains and Development On Behalf Of}




\section{Appendix 8 - Example of NVIVO 12 Thematic Codes and Raw Data}

\begin{tabular}{|c|c|c|c|c|}
\hline Q Search Projert & & $\checkmark$ & 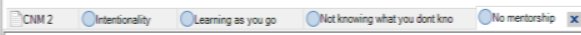 & $\mathbf{x}$ \\
\hline Name & F Réterences & ـ & & \\
\hline Disengaged taff & 4 & 10 & 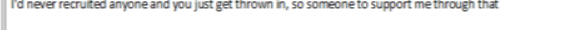 & \\
\hline Resignation's & 4 & 5 & recruitment process would have beenreallygood. & \\
\hline 0 Dissatisfied talf & 4 & 10 & & \\
\hline High sick calls and ACC leave & 3 & 5 & & \\
\hline Being the reminder pesson & 3 & 5 & Reference $4-1.28 \%$ coverage & \\
\hline O) Competing pessonalities & 2 & 2 & 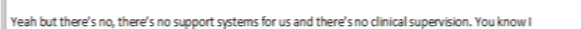 & \\
\hline O Menaging a large tram & 2 & 2 & & \\
\hline Monaging a fatigued team & 2 & 2 & think these roles ther should be built in, it thhould be once a morth compulsory dinical supervision & \\
\hline Eaming respect & 2 & 3 & Winthenenter & \\
\hline Buiding a cass of dismissel & 2 & 7 & in theseroles. & \\
\hline OPreventing farvourtism & 1 & 1 & & \\
\hline O Engaging with al staff & 1 & 2 & 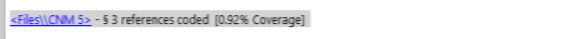 & \\
\hline Staff not asking for help & 1 & 4 & & \\
\hline Oäntaining staff engaggement & 1 & 4 & Reference $1-0.41 \%$ coverage & \\
\hline O) Challenging behaviour & 1 & 1 & The preceptor that i had, it was a two-week orientation and they were 2 nurses that & \\
\hline 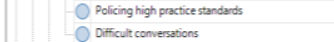 & $\frac{1}{1}$ & $\frac{2}{1}$ & were acting ACNN5 while they were looking for the CNV. The CNN had left 4 months & \\
\hline 日 Scope of CNem & 9 & 54 & 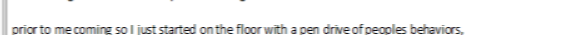 & \\
\hline Role complexity & 6 & 18 & & \\
\hline Balsncing high wortioad & 6 & 21 & and there was no orientation book. I didn't know really know what I was doing other & \\
\hline 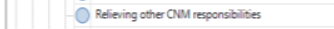 & 2 & 4 & than myjob genericic jobdistrnit description. & \\
\hline Being positioned betheen senice lesders and staff & 2 & 5 & & \\
\hline OAuthoritive resticitions & 1 & 3 & & \\
\hline O) The uncertaintes & 1 & 1 & Reference $2-0.248$ covierage & \\
\hline O Vaying role prionites & 1 & 2 & And the staff werevery fractured and it was quite dificult just, didin't know any of the & \\
\hline EO Roleprepartion & 9 & 52 & 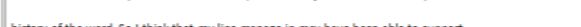 & \\
\hline OLearning a s you go & 5 & 12 & history of the ward. Sol I think that my line manage in mar have been able to support & \\
\hline O long workhours & 4 & 5 & mea irtilebit better in regards torelationships, & \\
\hline O Notknowing what you dont know & $\begin{array}{l}4 \\
3\end{array}$ & 7 & & \\
\hline $\begin{array}{l}\text { Acquining dysfinctional culture } \\
\text { D Nomentioship }\end{array}$ & $\frac{3}{3}$ & $\frac{9}{9}$ & Reference $3-0.26 \%$ Coverage & \\
\hline Knowing where and who to seech help from & 2 & 4 & 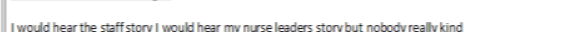 & \\
\hline
\end{tabular}

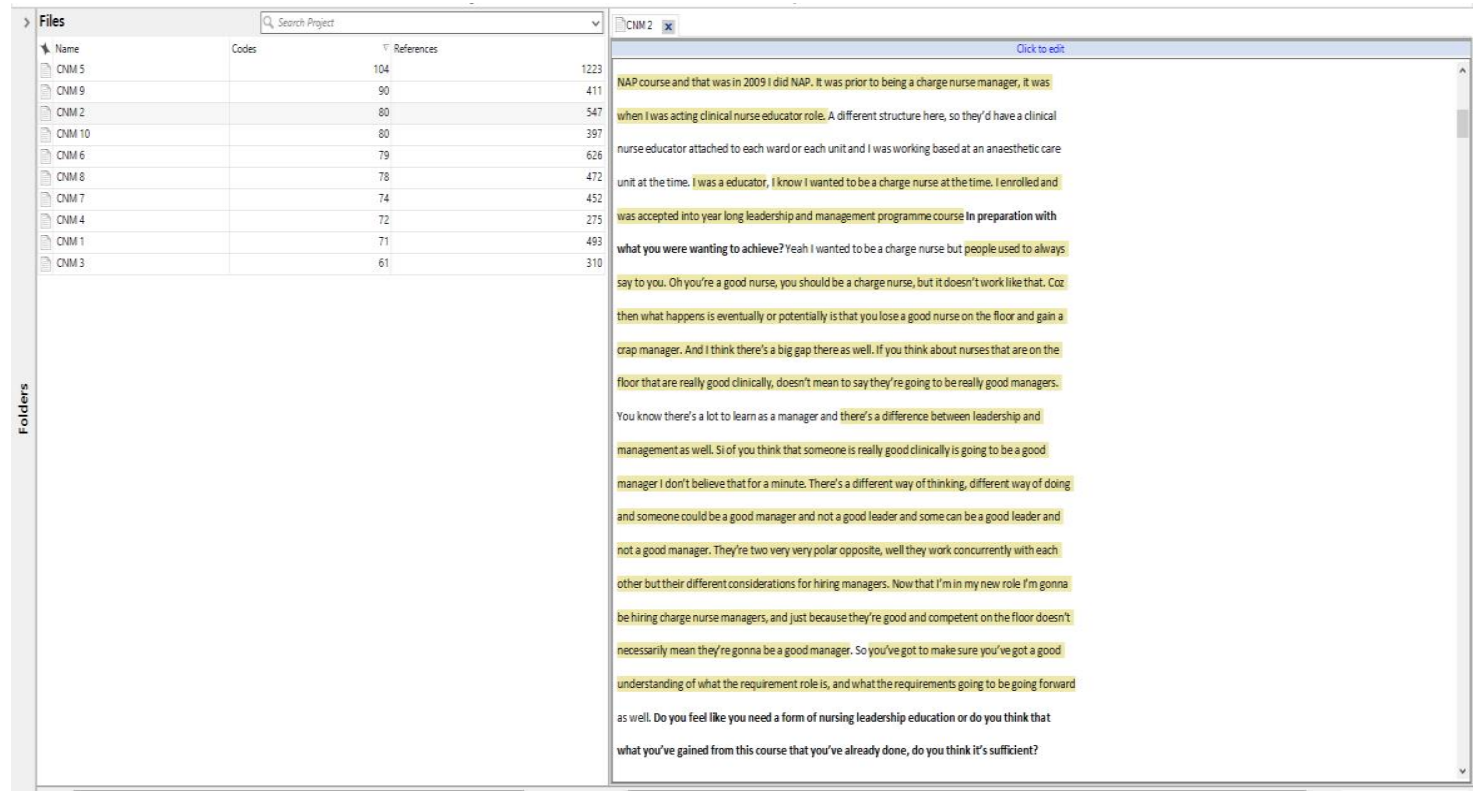


Appendix 9-Mind Maps and Themes Table

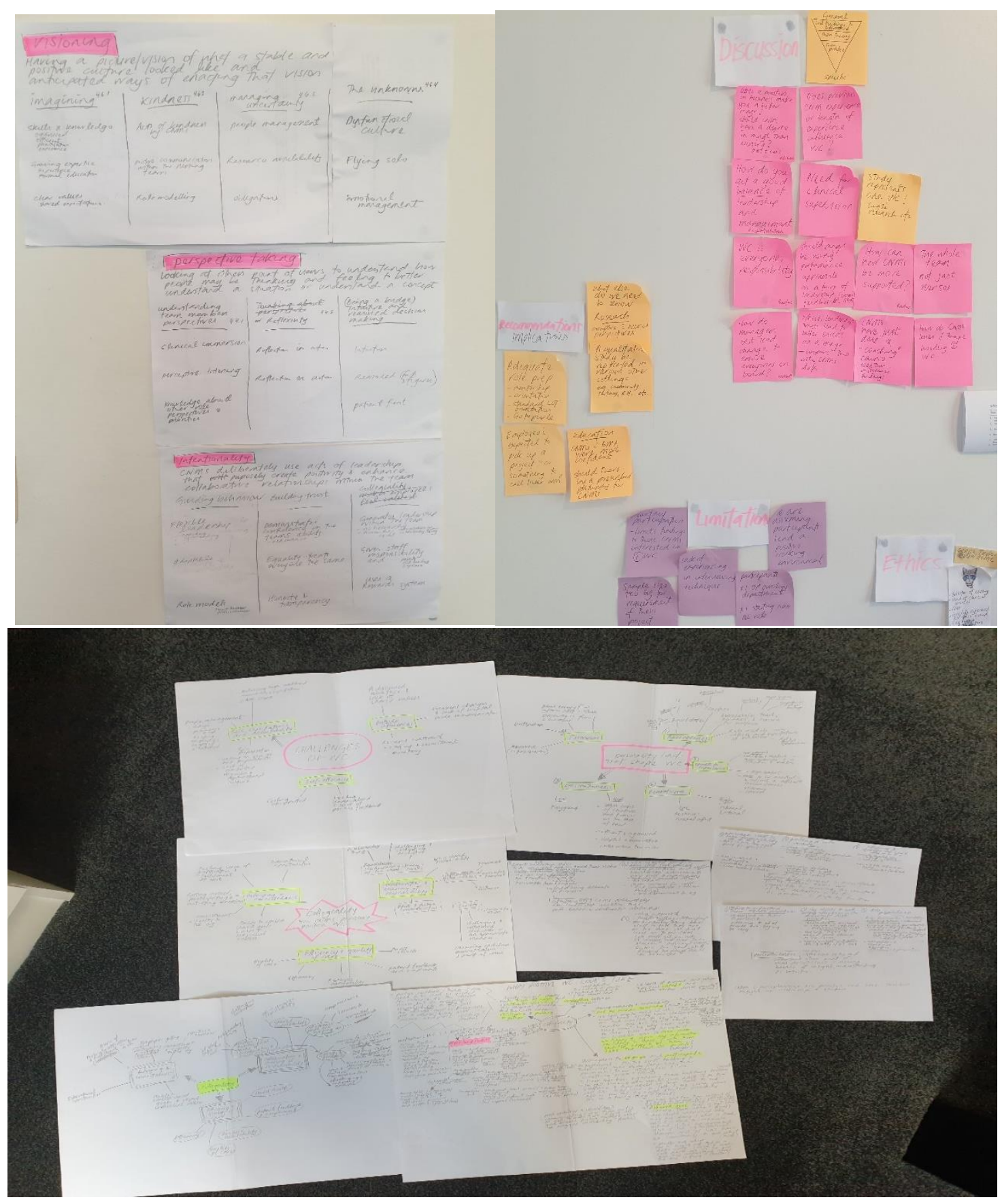




\section{REFERENCES}

Abel, A. L., \& Nair, S. V. (2015). The rise of coaching in organizations. In C. D. Gullette, E. R. Hoole, \& D. D. Riddle (Eds.), The Center for Creative Leadership handbook of coaching in organizations (pp. 5-28). Jossey-Bass.

Adams, D. (1991). Management needs of head nurses and supervisors: Designing a continuing education course. The Journal of Continuing Education in Nursing, 22(1), 16-20.

Agnew, C., \& Flin, R. (2014). Senior charge nurses leadership behaviours in relation to hospital ward safety: A mixed method study. International Journal of Nursing Studies, 51(5), $768-780$.

Ahmed, Z., Khan, I., \& Nawaz, A. (2016, January 1). Leadership theories and styles: A literature review. Journal of Resources Development and Management.

https://www.researchgate.net/publication/293885908_Leadership_Theories_and_Style S_A_Literature_Review

Aiken, L. H., Aungsuroch, Y., Cho, E., Clarke, S., Finlayson, M., Kanai-Pak, M., Poghosyan, L., Sloan, D. M., \& You, L. (2011). Importance of work environments on hospital outcomes in nine countries. International Journal for Quality in Health Care, 23(4), 357-364.

Aiken, L. H., Clarke, S. P., Finlayson, M., \& Poghosyan, L. (2010). Nurse burnout and quality of care: Cross-national investigation in six countries. Research in Nursing \& Health, 33(4), 288-298.

Akerjordet, K., \& Severinsson, E. (2008). Emotionally intelligent nurse leadership: A literature review study. Journal of Nursing Management, 16(5), 565-577.

American Association of Critical Care Nurse. (2019, June 10). Healthy work environments.

https://www.aacn.org/nursing-excellence/healthy-work-

environments?tab=Patient\%20Care 
American Association of Critical Care Nurses. (2020). Meaningful recognition.

https://www.aacn.org/nursing-excellence/healthy-work-environments/meaningfulrecognition

An, Y., \& Kang, J. (2016). Relationship between organizational culture and workplace bullying among Korean nurses. Asian Nursing Research, 10(3), 234-239.

Andersen, R. S., Neergaard, M. A., Olesen, F., \& Sondergaard, J. (2009). Qualitative description-the poor cousin of health research? BMC Medical Research Methodology, 9, $52-52$.

Ashton, T., Finlayson, M., Hughes, F., Leung, W., North, N., \& Rasmussen, E. (2013). Nurse turnover in New Zealand: Costs and relationships with staffing practises and patient outcomes. Journal of Nursing Management, 21(3), 419-428.

Atashzadeh-Shoorideh, F., \& Barkhordari-Sharifabad, M. (2018). Ethical leadership outcomes in nursing: A qualitative study. Nursing Ethics, 25(8), 1051-1063. Scopus.

Atashzadeh-Shoorideh, F., Falcó-Pegueroles, A., Lotfi, Z., \& Pishgooie, A. H. (2019). Correlation between nursing managers leadership styles and nurses job stress and anticipated turnover. Journal of Nursing Management, 27(3), 527-534. Scopus.

Avolio, B., \& Bass, B. (1993). Transformational leadership and organisational culture. Public Administration Quarterly, 17(1), 112-121.

Avolio, B., \& Bass, B. (2004). Multifactor leadership questionnaire. Mind Garden. https://www.mindgarden.com/documents/MLQGermanPsychometric.pdf

Axtell, C. M., \& Parker, S. K. (2001). Seeing another viewpoint: Antecedents and outcomes of employee perspective taking. The Academy of Management Journal, 44(6), 1085-1100.

Balciunas, S., Galdikiene, N., Green, P., Helminen, M., Suominen, T., \& Trus, M. (2019). Connection between organizational culture and climate and empowerment: The perspective of nurse managers. Nursing \& Health Sciences, 21(1), 54-62. 
Bar-On, R. (2004). The bar-on emotional quotient inventory (EQ-i): Rationale, description and summary of psychometric properties. In G. Geher (Ed.), Measuring emotional intelligence: Common ground and controversy (pp. 115-145). Nova Science Publishers.

Bar-On, R., Bechara, A., Denburg, N. L., \& Tranel, D. (2003). Exploring the neurological substrate of emotional and social intelligence. Brain: A Journal of Neurology, 126(8), 1790-1800.

Barry, M., Lewicki, R. J., \& Saunders, D. M. (2005). Negotiation. McGraw-Hill/Irwin.

Bass, B. M., \& Riggio, R. E. (2006). Transformational leadership (2nd ed.). Lawrence Erlbaum Associates.

Batson, D. C. (2009). Two forms of perspective taking: Imagining how another feels and imagining how you would feel. In Handbook of imagination and mental simulation. Psychology Press.

Baumgardner, C. A., Henninger, D. E., Jones, L. W., \& Sullivan, P. D. (1994a). Management development: Preparing nurse managers for the future. The Journal of Nursing Administration, 24(6), 32-38.

Bauntgardner, C. A., Henninger, D. E., Jones, L. W., \& Sullivan, P. D. (1994b). Management development: Preparing nurse managers for the future part 2, program evaluation. JONA: The Journal of Nursing Administration, 24(7-8), 24-31.

Beck, C. T., \& Polit, D. F. (2017). Nursing research: Generating and assessing evidence for nursing practice (10th ed.). Lippincott Williams \& Wilkins.

Beckman, T. J., Ratelle, J. T., \& Sawatsky, A. P. (2019). Qualitative research methods in medical education. Anesthesiology, 131(1), 14-22.

Bell, J., \& Breslin, J. M. (2008). Healthcare provider moral distress as a leadership challenge. The Journal of Nursing Administration, 10(4), 94-97.

Bennett, C. L., Blanchard, D., James, A., \& Slanley, D. (2021). Nursing and values-based leadership: A literature review. Journal of Nursing Management, jonm.13273. 
Black-Arias, M. (2015). The relationship between perceived leadership characteristics and nurse leaders' self-reported competency [Ph.D., Northcentral University]. http://search.proquest.com/nahs/docview/1803939457/abstract/EE1E03A9B15A4166P $\mathrm{Q} / 3$

Boldy, B., Carryer, J., Gower, S., Hughes, K., \& Jones, M. (2018). Attributes of an effective nurse manager in New Zealand: An analysis of nurse manager perceptions. Nursing Praxis in New Zealand, 34(2), 27-37.

Boldy, D., Della, P., Gower, S., Jones, M., \& Michael, R. (2013). Attributes for effective nurse management within the health services of Western Australia, Singapore and Tanzania. Australian Health Review, 37(2), 268-274.

Bonner, A., Hayes, B., \& Pryor, J. (2010). Factors contributing to nurse job satisfaction in the acute hospital setting: A review of recent literature. Journal of Nursing Management, 18(7), 804-814.

Boyatzis, R., Goleman, D., \& McKee, A. (2002). Primal leadership: Realizing the power of emotional Intelligence. Harvard Business School Press.

Braun, V., Clark, V., \& Hayfield, N. (2015). Thematic analysis. In J. A. Smith (Ed.), Qualitative Psychology: A practical guide to research methods (pp. 222-248). SAGE Publications. Braun, V., \& Clarke, V. (2006). Using thematic analysis in psychology. Qualitative Research in Psychology, 3(2), 77-101.

Braun, V., \& Clarke, V. (2013). Successful Qualitative Research: A Practical Guide for Beginners. SAGE.

Bressler, S., Cicchillo, V. J., Derr, D. M., \& Young, J. L. (2011). Compassion satisfaction, burnout, and secondary traumatic stress in heart and vascular nurses. Critical Care Nursing Quarterly, 34(3), 227-234.

Brink, P. J., \& Wood, M. J. (2001). Basic steps in planning nursing research: From question to proposal (5th ed.). Jones \& Bartlett. 
Brown, J. M., \& Schmidt, N. A. (2019). Evidence-based practice for nurses: Appraisal and application of research (4th ed.). Jones \& Bartlett.

Brown, M. E., Harrison, D. A., \& Trevino, L. K. (2005). Ethical leadership: A social learning perspective for construct development and testing. Organizational Behaviour and Human Decision Processes, 97(2), 117-134.

Butler, C., Clark, K., Griffin, M., Leslie, G., Lyons, P., Mason, V., \& Walke, E. (2014). Moral distress, and work engagement in surgical intensive care unit trauma nurses. Dimensions of Critical Care Nursing, 33(4), 215-225.

Cameron, K. S., \& Quinn, R. (1999). Diagnosing and changing organizational culture: Based on the competing values framework. Personnel Psychology, 59(3), 755-757.

Cardiff, S., Manley, K., Sanders, K., \& Webster, J. (2011). Effective workplace culture: The attributes, enabling factors and consequences of a new concept. International Practice Development Journal, 1(2).

CASP. (2018, June 8). CASP Critical appraisal skills programme. https://casp-uk.net/

Cathcart, E. B., \& Greenspan, M. (2012). A new window into nurse manager development. Journal of Nursing Administration, 42(12), 557-561.

Catling-Paull, C., Duffield, C., King, M., O'Brien-Pallas, L., \& Roche, M. (2009). Staff satisfaction and retention and the role of the nursing unit manager. Collegian, 16(1), 11-17.

Chadwick, B., Gill, P., Treasure, E., \& Stewart, K. (2008). Methods of data collection in qualitative research: Interviews and focus groups. British Dental Journal, 204, 291-295. Chase, L. K. (2012). Are you confidently competent? Nursing Management, 43(5), 50-53. Cherian, U. S. (2016). Impact of meaningful recognition on nurses' work environment in ICU: A comparative exploration of nurse leaders' and staff nurses' perception [D.N.P., The University of North Carolina at Chapel Hill]. http://search.proquest.com/nahs/docview/1828128699/abstract/D815214EF2344CDOP $\mathrm{Q} / 1$ 
Choudhary, G. B., \& Puranik, S. (2014). A study on employee performance appraisal in health care. Asian Journal of Management Sciences, 2(3), 59-64.

Civelek, I., Liang, F., \& Rahim, M. (2018). A process model of social intelligence and problemsolving style for conflict management. International Journal of Conflict Management, 29(4), 487-499.

Clendon, J. (2010). Nursing in Aotearoa New Zealand: A definition. New Zealand Nurses Organisation.

Clendon, J. (2011). 2020 and beyond: A vision for nursing. New Zealand Nurses Organisation. Clendon, J., \& Walker, L. (2017). Nurses as family caregivers-barriers and enablers facing nurses caring for children, parents or both. Journal of Nursing Management, 25(2), 93101.

Codier, E., Kamikawa, C., \& Kooker, B. M. (2011). The impact of emotional intelligence development on nurse managers. Nursing Administration Quarterly, 35(3), 270-276.

Colorafi, K. J., \& Evans, B. (2016). Qualitative descriptive methods in health science research. Health Environments Research \& Design Journal, 9(4), 16-25.

Colvin, K., Cornelius, C. J., \& Taylor, C. M. (2014). Visionary leadership and its relationship to organizational effectiveness. Leadership \& Organization Development Journal, 35(6), $566-583$.

Corley, K. G., Giola, G. A., \& Hamilton, A. L. (2013). Seeking qualitative rigor in inductive research: Notes on the gioia methodology. Organizational Research Methods, 16(1), $15-31$.

Côté, S., \& Miners, C. T. (2006). Emotional intelligence, cognitive intelligence, and job performance. Administrative Science Quarterly, 51(1), 1-28. https://doi.org/10.2189/asqu.51.1.1 
Cotterill-Walker, S. M. (2012). Where is the evidence that master's level nursing education makes a difference to patient care? A literature review. Nurse Education Today, 32(1), $57-64$.

Coughlan, M., \& Cronin, P. (2017). Doing a literature review in nursing, healthcare and social care (2nd ed.). Sage.

Coughlan, M., Cronin, P., \& Smith, V. (2015). Understanding nursing and healthcare research. Sage.

Cramer, E., \& Warshawsky, N. (2019). Describing nurse manager role preparation and competency. The Journal of Nursing Administration, 49(5), 249-255.

Crimp, H. (2017). Insights into effective interventions for the prevention and management of workplace bullying in the New Zealand public service. Victoria University of Wellington. Crowne, K. A., Goldman, B., Krouse, A. M., Patterson, B., Proenca, J., \& Young, T. M. (2017). Leading nurses: Emotional intelligence and leadership development effectiveness. Leadership in Health Services, 30(3), 217-232.

Cummings, G., Davey, M., Lee, H., Macgregor, T., Paul, L., Stafford, E., \& Wong, C. (2008). Factors contributing to nursing leadership: A systematic review. Journal of Health Services Research \& Policy, 13(4), 240-248.

Cummings, G. G., Davey, M., Lee, H., Lo, E., MacGregor, T., Muise, M., Stafford, E., \& Wong, C. A. (2010). Leadership styles and outcome patterns for the nursing workforce and work environment: A systematic review. International Journal of Nursing Studies, 47(3), 363385.

Cummings, G. G., Ducharme, L., \& Wong, C. A. (2013). The relationship between nursing leadership and patient outcomes: A systematic review update. Journal of Nursing Management, 21(5), 709-724. 
Cummings, G. G., Grau, A. L., Laschinger, H. K., \& Wong, C. A. (2014). Resonant leadership and workplace empowerment: The value of positive organizational cultures in reducing workplace incivility. Nursing Economic\$, 32(1), 5-44.

Cummings, G. G., \& Wong, C. A. (2007). The relationship between nursing leadership and patient outcomes: A systematic review. Journal of Nursing Management, 15(5), 508521.

Davies, H., \& Mannion, R. (2018). Understanding organisational culture for healthcare quality improvement. British Medical Journal, 363.

Dawson, C. M., Johnson, S., \& Skarbek, A. J. (2015). A phenomenological study of nurse manager interventions related to workplace bullying. The Journal of Nursing Administration, 45(10), 492-497.

De Witte, H., Lens, W., Van den Broeck, A., \& Vansteenkiste, M. (2008). Explaining the relationships between job characteristics, burnout, and engagement: The role of basic psychological need satisfaction. Work \& Stress, 22(3), 277-294.

Dempsey, C., \& Reilly, B. A. (2016). Nurse engagement: What are the contributing factors for success? Online Journal of Issues in Nursing, 21(1), 8-8.

D'Souza, E. S., \& D'Souza, M. S. (2013). Valuing communication for effective nurse leadership in nursing practice. International Journal of Nursing Care, 1(2), 63-67.

Dyrbye, L. N., Shanafelt, T. D., \& West, C. P. (2018). Physician burnout: Contributors, consequences and solutions. Journal of Internal Medicine, 283(6), 516-529.

Echevarria, L. M., Krouse, A., \& Patterson, B. J. (2017). Predictors of transformational leadership of nurse managers. Journal of Nursing Management, 25(3), 167-175.

El Amouri, S., \& O’Neill, S. (2014). Leadership style and culturally competent care: Nurse leaders' views of their practice in the multicultural care settings of the United Arab Emirates. Contemporary Nurse : A Journal for the Australian Nursing Profession, 48(2), 135-149. 
Emerson, L. (2005). Writing guidelines for business students (3rd ed.). Thomson/Dunmore Press.

Erlingsson, C., \& Brysiewicz, P. (2013). Orientation among multiple truths: An introduction to qualitative research. African Journal of Emergency Medicine, 3(2), 92-99. https://doi.org/10.1016/j.afjem.2012.04.005

Espinoza, D. C., Lopez-Saldana, A., \& Stonestreet, J. S. (2009). The pivotal role of the nurse manager in healthy workplaces: Implications for training and development. Critical Care Nursing Quarterly, 32(4), 327-334.

Etienne, E. (2014). Exploring workplace bullying in nursing. Workplace Health \& Safety; Thousand Oaks, 62(1), 6-11.

Eun Ji, S., Kyoung-Ja, K., \& Moon Sook, Y. (2018). Exploring the influence of nursing work environment and patient safety culture on missed nursing care in Korea. Asian Nursing Research, 12(2), 121-126.

Facione, N., Facione, P., \& Sanchez, C. (1994). Critical thinking disposition as a measure of competent clinical judgement: The development of the california critical thinking disposition inventory. Journal of Nursing Education, 33, 345-350.

Fang, L., Fang, S., \& Huang, S. (2016). Workplace bullying among nurses in South Taiwan. Journal of Clinical Nursing, 25(17-18), 2450-2456.

Flarey, D. L. (1991). Redesigning management roles. The Journal of Nursing Administration, 21(2), 40-45.

Flynn, L., \& Grubaugh, M. L. (2018). Relationships among nurse manager leadership skills, conflict management, and unit teamwork. The Journal of Nursing Administration, 48(7/8), 383-388.

Frey, R., Gott, M., Robinson, J., \& Wong, C. (2018). Burnout, compassion fatigue and psychological capital: Findings from a survey of nurses delivering palliative care. Applied Nursing Research, 43, 1-9. 
Fusch, P. I., \& Ness, L. R. (2015). Are we there yet? Data saturation in qualitative research. The Qualitative Report; Fort Lauderdale, 20(9), 1408-1416.

Galvin, K., \& Holloway, I. (2017). Qualitative research in nursing and healthcare (4th ed.). Wiley \& Sons.

Garcia-Capilla, D. J., Rubio-Navarro, A., Rutty, J., \& Torralba-Madrid, M. J. (2020). Accountability issues in an English emergency department: A nursing perspective. International Emergency Nursing, 51, 100881.

Giallonardo, L., \& Wong, C. A. (2013). Authentic leadership and nurse-assessed adverse patient outcomes. Journal of Nursing Management, 21(5), 740-752.

Goleman, D. (1995). Emotional intelligence. Bantam Books.

Goleman, D. (2000). Leadership that gets results. Harvard Business Review, 78(2), 78-100.

Gu, D., Liang, C., Ma, Y., Xie, Y., \& Zhao, S. (2020). How transformational leadership and clan culture influence nursing staff's willingness to stay. Journal of Nursing Management, 28(7), 1515-1524. https://doi.org/10.1111/jonm.13092

Guba, E. G., \& Lincoln, Y. S. (1985). Naturalistic inquiry. Sage Publications.

Hahtela, N., Helminen, M., McCormack, B., Paavilainen, E., Slater, P., \& Suominen, T. (2015). Nurses' perceptions of workplace culture in primary health care in Finland. International Nursing Review, 62(4), 470-478.

Hartnell, C. A., Kinicki, A., \& Ou, A. Y. (2011). Organizational culture and organizational effectiveness: A meta-analytic investigation of the competing values framework's theoretical suppositions. Journal of Applied Psychology, 96(4), 677-694.

Hartung, S. Q., \& Miller, M. (2013). Communication and the healthy work environment: Nurse managers' perceptions. Journal of Nursing Administration, 43(5), 266-273. Scopus.

Health and Disability Ethics Committee. (2012, December 12). Ethical standards for health and disability research. https://ethics.health.govt.nz/ethical-standards-health-and-disabilityresearch 
Hoffman, M. L. (1975). Developmental synthesis of affect and cognition and its implications for altruistic motivation. Developmental Psychology, 11(5), 607-622.

Huang, C., \& Tsai, M. (2008). The relationship among ethical climate types, facets of job satisfaction, and the three components of organizational commitment: A study of nurses in Taiwan. Journal of Business Ethics, 80(3), 565-581.

Huang, C., Tsai, M., \& You, C. (2012). A multidimensional analysis of ethical climate, job satisfaction, organizational commitment, and organizational citizenship behaviors. Nursing Ethics, 19(4), 513-529.

Hunt, R., \& Pavlish, C. (2012). An exploratory study about meaningful work in acute care nursing. Nursing Forum, 47(2), 113-122.

Isoaho, H., Leino-Kilpi, H., Meretoja, R., \& Numminen, O. (2015). Ethical climate and nurse competence-Newly graduated nurses' perceptions. Nursing Ethics, 22(8), 845-859. Isola, A., Laukkala, H., Paasivaara, L., Suhonen, M., \& Vesterinen, S. (2013). Nurse managers' perceptions related to their leadership styles, knowledge, and skills in these areas-a viewpoint: Case of health centre wards in Finland. ISRN Nursing, 2013, 951456-951458. Jambrović, I., Mrkonjić, R., Rašić, I., Ristić, J., \& Rukavina, M. (2019). Analysis of the organisational culture in two Croatian hospitals. British Journal of Nursing, 28(10), 647651.

Jenks, C. (2005). Culture (2nd ed..). Routledge.

Jirojwong, S., \& Welch, A. (2014). Data collection: Qualitative research. In S. Jirojwong, M. Johnson, \& A. Welch (Eds.), Research methods in nursing and midwidery: Pathways to evidence-based practice (2nd ed., pp. 120-139). Oxford.

Jones, J., Snelgrove, S., Turunen, H., \& Vaismoradi, M. (2016). Theme development in qualitative content analysis and thematic analysis. Journal of Nursing Education and Practice, 6(5), 100-110. 
Kallas, K. D. (2014). Profile of an excellent nurse manager: Identifying and developing health care team leaders. Nursing Administration Quarterly; Frederick, 38(3), 261.

Kiger, A. J., Schwarzkopf, R., \& Sherman, R. O. (2011). Charge nurses perspectives on frontline leadership in acute care environments. ISRN Nursing, 2011, 164052-164058.

Korsgaard, S., \& Skjott, L. M. (2019). Coding qualitative data: A synthesis guiding the novice. Qualitative Research Journal, 19(3), 259-270.

Kotter, J. P. (1996). Leading change. Harvard Business School Press.

Kouzes, J. M., \& Posner, B. Z. (2017a). LPI: Leadership Practices Inventory. https://www.leadershipchallenge.com/LeadershipChallenge/media/SiteFiles/resources/ sample-reports/tlc-lpi-self-report-v5.pdf

Kouzes, J. M., \& Posner, B. Z. (2017b). The leadership challenge. How to make extraordinary things hapen in organisations (6th ed.). John Wiley \& Sons.

Kramer, M., Maguire, P., \& Schmalenberg, C. (2010). Nine structures and leadership practices essential for a magnetic (healthy) work environment. Nursing Administration Quarterly, 34(1), 4-17. Scopus.

Krautscheid, L. C. (2014). Defining professional nursing accountability: A literature review. Journal of Professional Nursing, 30(1), 43-47.

Kuraoka, Y. (2019). The Relationship Between Experiential Learning and Nursing Management Competency. The Journal of Nursing Administration, 49(2), 99-104.

La Grow, S., Rodgers, V., Towers, A., \& Woods, M. (2015). Researching moral distress among New Zealand nurses: A national survey. Nursing Ethics; London, 22(1), 117-130.

Ladyshewsky, R. K. (2010). The manager as coach as a driver of organizational development. Leadership \& Organization Development Journal, 31(4), 292-306.

Lamont, L. (2015). Leadership and staff engagement: An essential link. Nursing Leadership, 28(3), 8-9. 
Laschinger, H. K., \& Wong, C. A. (2013). Authentic leadership, performance, and job satisfaction: The mediating role of empowerment. Journal of Advanced Nursing, 69(4), 947-959.

Liamputtong, P. (2020). Rigour and ethics in qualitative reseacrh. In Qualitative research methods (5th ed.). Oxford University Press.

Lombardo, M. M., McCall, M. W., \& Morrison, A. M. (1988). The Lessons of Experience. Macmillan Incorporated.

Matua, G. A., \& Van Der Wal, D. M. (2015). Differentiating between descriptive and interpretive phenomenological research approaches. Nurse Researcher, 22(6), 22-27.

Mayer, J. D., \& Salovey, P. (1990). Emotional intelligence. Imagination, Cognition and Personality, 9(3), 185-211.

Mccallin, M., \& Frankson, C. (2010). The role of the charge nurse manager: A descriptive exploratory study. Journal of Nursing Management, 18(3), 319-325.

Merriam-Webster online dictionary. (2020). Empathy. https://www.merriamwebster.com/dictionary/empathy?src=search-dict-box

Metcalf, C. (2001). The importance of performance appraisal and staff development: A graduating nurse's perspective. International Journal of Nursing Practice, 7(1), 54-56.

Ministry of Health. (2016). New Zealand health strategy: Future direction. Wellington: Ministry of Health.

Mitchell, G. (2015). Use of interviews in nursing research. Nursing Standard, 29(43), 44-48.

Morse, J. M. (2015). Analytic strategies and sample size. Qualitative Health Research, 25(10), 1317-1318.

Moxham, L., Tillott, S., \& Walsh, K. (2013). Encouraging engagement at work to improve retention. Nursing Management, 19(10), 27-31. 
Musil, C. M., Nosek, L. J., \& Zori, S. (2010). Critical thinking of nurse managers related to staff RNs' perceptions of the practice environment. Journal of Nursing Scholarship, 42(3), 305-313.

Neira, M. (2010). Healthy Workplaces: A model for action. For employers, workers, policymakers and practitioners. World Health Organization.

New Zealand Government. (2019). Health practitioners competence assurance act 2003. http://www.legislation.govt.nz/act/public/2003/0048/latest/DLM203312.html New Zealand Nurses Organisation. (2014, September 9). NZNO nursing leadership section, NZNO tapuhi mana whakatipu. https://www.nzno.org.nz/groups/colleges_sections/sections/nzno_nurse_managers_ne w_zealand

New Zealand Nurses Organisation. (2018). NZNO Strategy for Nursing 2018-2023. https://www.nurses.org.nz/leadership_development_and_sustainability Njoroge, P. K., Renn, R. W., Steinbauer, R., \& Taylor, R. R. (2014). Ethical leadership and followers' moral judgment: The role of followers' perceived accountability and selfleadership. Journal of Business Ethics, 120(3), 381-392.

Nursing Council of New Zealand. (2011). Guidelines for cultural safety, the Treaty of Waitangi and Maori health in nursing education and practice. Nursing Council of New Zealand. Nursing Council of New Zealand. (2012). Tikanga whanonga code of conduct: New code of conduct for nurses.

https://www.nursingcouncil.org.nz/Public/Nursing/Code_of_Conduct/NCNZ/nursingsection/Code_of_Conduct.aspx?hkey=7fe9d496-9c08-4004-8397-d98bd774ef1b

Nursing Council of New Zealand. (2019). Standards and guidelines for nurses.

http://www.nursingcouncil.org.nz/Publications/Standards-and-guidelines-for-nurses Nursing Council of New Zealand. (2021, September 3). Approved professional development and recognition programmes (PDRPS). 
https://www.nursingcouncil.org.nz/Public/Nursing/PDRPs/NCNZ/nursingsection/PDRPs.aspx

O'Hagan, J., \& Persaud, D. (2009). Creating a culture of accountability in health care. The Health Care Manager, 28(2), 124-133.

O'Neil, A. (2011). Manager to leader: Skills and insights for a successful transition. CCH Australia.

O'Neil, D. (2006, August 8). What is culture. https://www2.palomar.edu/anthro/culture/culture_1.htm

Pagon, M., \& Skela Savič, B. (2008). Relationship between nurses and physicians in terms of organizational culture: Who is responsible for subordination of nurses? Croatian Medical Journal, 49(3), 334-343. https://doi.org/10.3325/cmj.2008.3.334

Patterson, J. (2018). Empathy: A concept analysis. International Journal for Human Caring, 22(4), 217-223.

Ponterotto, J. G. (2010). Qualitative research in multicultural psychology: Philosophical underpinnings, popular approaches, and ethical considerations. Cultural Diversity and Ethnic Minority Psychology, 16(4), 581-589.

Posner, B. (2016). Investigating the reliability and validity of the leadership practices inventory. Administrative Sciences, 6(4), 1-23. https://doi.org/10.3390/admsci6040017 Rahim, M. A. (2014). A structural equations model of leaders' social intelligence and creative performance. Creativity and Innovation Management, 23(1), 44-56.

Rallis, S. F., \& Rossman, G. B. (2017). Learning in the field: An introduction to qualitative research (4th ed.). Sage, Thousand Oaks.

Rantika, S., \& Yustina, A. (2017). Effects of ethical leadership on employee well-being: The mediating role of psycological empowerment. Journal of Indonesian Economy and Business, 32(2), 121-137. 
Rook, M. H. (2017). Living nursing values: A collective case study [PhD]. Victoria University of Wellington.

Sandelowski M. (1986). The problem of rigor in qualitative research. Advances in Nursing Science, 8(3), 27-37.

Sandelowski, M. (2000a). Focus on research methods: Whatever happened to qualitative description? Research in Nursing \& Health, 23(4), 334-340.

Sandelowski, M. (2000b). Whatever happened to qualitative description? Research in Nursing \& Health, 23(4), 334-340.

Sandelowski, M. (2004). Using qualitative research. Qualitative Health Research, 14(10), $1366-$ 1386.

Sanford, K. (2011). The case for nursing leadership development: Leadership development for nurses can have a positive impact on an organization's bottom line, particularly in light of future financial challenges. Healthcare Financial Management, 65(3), 100-106.

Sellars, B. B. (2012). Nurse manager transformational leadership practices and patient outcomes among magnet and non-magnet hospitals [Ph.D., University of San Diego]. http://search.proquest.com/nahs/docview/1040888086/abstract/D815214EF2344CDOP Q/95

Singh, S., \& Wassenaar, D. (2016). Contextualising the role of the gatekeeper in social science research. South African Journal of Bioethics and Law, 9(1), 42.

Todaro-Franceschi, V. (2019). Compassion fatigue and burnout in nursing: Enhancing professional quality of life. Springer Publishing Company.

Tygart, M. W., \& Vaughan-Wrobel, B. C. (1993). Management Education needs of nurse administrators in long-term care. Journal of Gerontological Nursing, 19(3), 33-38.

Tylor, E. (1871). Primitive culture: Researches into the development of mythology, philosophy, religion, art, and custom. John Murray. 
Valizadeh, L., Zamanzadeh, V., Dewar, B., Rahmani, A., \& Ghafourifard, M. (2018). Nurses perceptions of organisational barriers to delivering compassionate care: A qualitative study. Nursing Ethics, 25(5), 580-590. https://doi-

org.helicon.vuw.ac.nz/10.1177\%2F0969733016660881

Wakefield, M. (2006). New views on leadership coaching. The Journal for Quality and Participation, 29(2), 9-12.

Welch, A. (2014). Sampling in qualitative research. In S. Jirojwong, M. Johnson, \& A. Welch (Eds.), Research methods in nursing and midwifery (2nd ed., pp. 87-97). Oxford.

Whitehead, L. (2014). Qualitative data analysis. In Research methods in nursing and midwifery: Pathways to evidence-based practice (2nd ed., pp. 140-161). Oxford.

Wong, C. A. (2015). Connecting nursing leadership and patient outcomes: State of the science. Journal of Nursing Management, 23(3), 275-278.

Wood, R. L. (2018). Nurses first: So that patients can receive first rate care. Journal of Public Mental Health, 17(1), 45-48.

World Health Organisation. (2016). The global strategic directions for strengthening nursing and midwifery 2016-2020. World Health Organization.

https://www.who.int/hrh/nursing_midwifery/global-strategic-midwifery20162020.pdf?ua=1

Yarborough, J. P. (2018). The Role of Coaching in Leadership Development. New Directions for Student Leadership, 2018(158), 49-61.

Yemi-Sofumade, H. B. (2012). The relationship between ethical and authentic nurse leadership and the turnover intentions of staff nurses [Ph.D., Capella University]. In ProQuest Dissertations and Theses.

http://search.proquest.com/docview/1019234370/abstract/369AA54C97424781PQ/1

Yoder-Wise, P. S. (2019). Leading and managing in nursing (7th ed.). Elsevier. 